$1-1-1945$

\title{
The growth and composition of the tops of peach trees in sand culture in relation to nutrient-element balance
}

\author{
D. S. Brown
}

Follow this and additional works at: https://researchrepository.wvu.edu/ wv_agricultural_and_forestry_experiment_station_bulletins

\section{Digital Commons Citation}

Brown, D. S., "The growth and composition of the tops of peach trees in sand culture in relation to nutrient-element balance" (1945). West Virginia Agricultural and Forestry Experiment Station Bulletins. 322.

https://researchrepository.wvu.edu/wv_agricultural_and_forestry_experiment_station_bulletins/325 @ WVU. It has been accepted for inclusion in West Virginia Agricultural and Forestry Experiment Station Bulletins by an authorized administrator of The Research Repository @WVU. For more information, please contact ian.harmon@mail.wvu.edu. 
West Virginia University Libraries

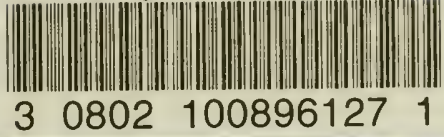





\title{
The Growth and Composition of the
} tops of Peach Trees in Sand Culture in Relation to Nutrient-element Balance

\author{
BY \\ D S. BROWN
}

Agricultural Experiment Station

College of Agriculture, Forestry, and Home Economics

West Virginia University

C. R. Orton, Director

Morgantown 
Introduction. ..........................................

I. Growth of the trees

Materials and methods.................................. 4

Appearance of the trees in the deficiency series........... 8 8

Measurements of growth.............................. 14

II. Composition of the trees

Methods.............................................. 26

The amount of the elements in the tops.................. 28

The relations between the elements........................ 44

III. The relation between growth and composition.............. 50

The diagnosis of deflclencles......................... 58

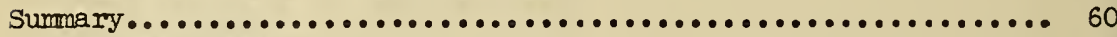

L1terature cited.......................................... 63

hppendix tables........................................ 65

NOTE

The following dissertation was presented in partial fulfillment of the requirements for the degree of Doctor of Philosophy in the Graduate School of Ohio State University.

\section{ACKNOWLEDGMENT}

The assistance of the following is gratefully acknowledged: Professor F. S. Howlett, Department of Horticulture and Forestry, Ohio State University; Professors R. S. Marsh and R. H. Sudds, Department of Horticulture, West Virginia University; and Mr. James Stone, a former student. The courtesies of the Departments of Horticulture, of Agricultural Blochemistry, and of Agronomy and Genetics at West Virginia Un1versity and of the Department of Horticulture at the University of Illinois are also acknowledged. 


\section{THE GROWTH AND COMPOSITION OF THE TOPS OF PEACH TREES IN SAND CULTURE IN RELATION TO NUTRIENTT-ELERMENTI BALANCE}

\section{by D. S. Brown}

\section{INTRODUCTION}

The concept of a balance in nutrient-element relationships has evolved as the result of the frequently demonstrated interdependence of the elements in their effects on plant growth. Its significance in relation to fruit trees, although indicated, at least indirectly, by a number of investigations ( evaluated. The objective of this investigation has been, therefore, to attain a better understanding of balance and, more specifically, to evaluate its significance with respect to the elements nitrogen, phosphorus, potassium, and calcium in relation to the growth and composition of young peach trees.

Unfortunately, perhaps, balance has been subject to a variety of interpretations, ranging from those which are quite definite in conveying the idea of a fixed proportionality to those which are indeterminate in their implication of some varlable sort of equilibrium between the elements. As a consequence, the term frequently has been amblguous. The difficulty, however, seems to have resulted not so much from the variability in the implications of the term as from its frequent use without enough definition or qualification to indicate the nature of the relationships which it was intended to describe.

In this investigation, belance is considered essentially as a modification of the principle of limiting factors applied to nutrient-element relationships. In applying this principle It is obvious that the degree of effectiveness of the nutrientelement supply is limited ultimately by the other environmental factors and by the genetic nature of the plant. Consequently, for a given plant in a given environment there is a maximum amount of growth which will result when none of the elements is limiting. That combination of elements in which none of them is limiting constitutes the nutrient-element supply with the highest intensity of balance. Such a supply is defined as that one with which results the maximum amount of growth possible within the limits of other environmental factors and of the genetic nature of the plant. Nutrient- 
element balance, therefore, is always to be qualified, by implication at least, by the limiting effect of the genetic nature of the plant and by environmental factors other than the nutrient-element supply.

Theoretically, at least, the nutrient-element supply with the highest intensity of balance should be composed of one and only one combination of the elements, each of which is available in its proper amount. Therefore, if the supply of any given element were deviated to a level either above or below its proper amount, that element would then become limiting, and a reduction in growth should result. However, within the limits of such an altered supply of the element there also should be a maximum amount of srowth which is possible, but which is less than that resulting when the supply of the element is at its proper level under conditions of the highest intensity of balance. For those conditions in which an element is limiting, a balanced nutrient-element supply of a comparatively lower intensity may be defined, therefore, as that one with which results the maximum amount of growth possible within the limits of the supply of that element.

The application of the principle of limiting factors to the concept of balance thus provides for a number of balancer nutrient-element supplies of comparatively different intensities, each of which may be defined and qualified by the factors limiting growth. Such a provision is desirable because the maximum growth which results for a given plant in a given environment when none of the nutrient elements is limiting may not be of the type or quality actually desired; for example, such growth might not be as conducive to fruitfulness as the lesser grouth which would result with a nutri. ent-element supply of a lower intensity of balance.

\section{GROWTH OF THE TRTES}

\section{Materials and Methods}

The experiment was conducted in a greenhouse of the Department of Horticulture at Nest Virginia University. Oneyear-old budded Elberta peach trees were planted on April 5 and 6,1940 . They were headed back at 18 inches above the bud union and all laterals were removed. The roots were 
washed free of dirt and pmuned just enough to permit them to fit easily into the 4-gallon galvanized garbage pails in which the trees were planted. A total of 114 trees were used, although only 108 were included finally in the experiment proper. The other six were planted so that reserves would be available if any of the trees did not start properly. The trees were remarkably uniform in appearance.

The pails, which were coated on the inside with a petroleum asphalt, were fitted with a glass tube in the bottom for drainage. The roots of the trees were covered to a point approximately an inch below the bud union with a fine quartz sand which was obtained from a glass factory in Morgantown, West Virginia. After the trees were planted the sand was flushed thoroughly with water. Rain water which was diverted from the roof of the greenhouse into a large, asphalt-lined, concrete bin was used throughout the experiment.

The pails were arranged on supports on a concrete bench in the greenhouse. The supports were so constructed that a quart Mason jar could be placed underneath the pails below the drainage outlet. At the beginning of the season the trees were arranged in tiers of four across the bench, 28 tiers in all, but later half of them were moved to another bench in the same house. At that time, they were arranged in tiers of two across each bench so as to give maximum room for each tree.

There were 54 different treatments which represent all the possible combinations of three concentrations each of nitrogen, phosphorus, and potassium and two of calcium. There were two trees per treatment. The concentrations in parts per million in the culture solutions are given in Table 1.

Stock solutions of $\mathrm{Ca}\left(\mathrm{NO}_{3}\right)_{2}, \mathrm{CaCl}_{2}, \mathrm{Mg}\left(\mathrm{NO}_{3}\right)_{2}, \mathrm{MgSO}_{4}$, $\mathrm{MBHPO}_{4}, \mathrm{KH}_{2} \mathrm{PO}_{4}, \mathrm{KCl}$, and $\mathrm{K}_{2} \mathrm{SO}_{4}$, and Ca-acetate were used in the preparation of the culture solutions. Manganese and boron were supplied from a stock solution of $\mathrm{MnSO}_{4}$ and $\mathrm{H}_{3} \mathrm{BO}_{3}$. Ferric citrate was used as a source of iron.

No attempt was made to control the total concentration of the solutions. Obviously those with the highest concentrations of the elements had higher osmotic pressures than the more dilute solutions. Iikewise, the initial pH of the 
Table 1. The Concentrations of $\mathrm{N}, \mathrm{P}, \mathrm{K}$, and $\mathrm{Ca}$ as ppm in the Culture Solutions Supplied to the Trees

\begin{tabular}{cccc}
\hline Element & High (H) & $\begin{array}{c}\text { Concentration } \\
\text { Medium (M) }\end{array}$ & Low (L) \\
\hline $\mathrm{N}$ & $1000^{*}$ & 100 & 10 \\
$\left(\right.$ as $\left.\mathrm{NO}_{3}\right)$ & $(4430)$ & $(443)$ & $(44)$ \\
$\mathrm{P}$ & 200 & 20 & 2 \\
$(\mathrm{as} \mathrm{PO})$ & $(612)$ & $(61)$ & $(6)$ \\
$\mathrm{K}$ & 800 & 80 & 8 \\
$\mathrm{Ca}$ & 1000 & 100 & - \\
\hline
\end{tabular}

*The Magnesium concentration accompanying high N was $965 \mathrm{ppm}$, but only $185 \mathrm{ppm}$ with medium and low $\mathrm{N}$.

solutions, which varied from about 4.5 to 5.5 , was not controlled. Once the solutions had pessed through the sand, their pH approached 7.0 .

For convenience the concentrations in Table 1 are designated as high (H), medium $(M)$, and low $(\mathrm{I})$. The low concentrations were planned as deficlency levels; the medium concentrations were selected as being ample for good growth, as indicated by the work of Cullinan et al. (6). No def1ciency level of $\mathrm{Ca}$ was used. The high concentrations were chosen with the possibility in mind that they might prove to be greatly excessive.

It was not possible by the use of calclum nitrate to maintain the medium $\mathrm{Ca}$ level and at the same time supply all of the nitrate required in the $\mathrm{h} 1 \mathrm{gh}-\mathrm{N}$-medium-Ca series. Therefore, to supplement the $N$ supplied as calclum nitrate, magnesium nitrate was used. It was selected instead of sodium nitrate because it was believed that any effects of Mg might be evaluated more readily than those of $\mathrm{Na}$ and because, in the analysis of the trees at the conclusion of the experiment, the determination of $\mathrm{Mg}$ would be somewhat simpler than that of $\mathrm{Na}$. The use of magnesium nitrate resulted also in a high concentration of $\mathrm{Mg}$. In the high-N-high-Ca series it was not necessary to use as much magnesium nitrate to 
maintain the $N$ concentration because more calcium nitrate could be used; however, the Mg level was made equal to that in the high-N-medium-Ca serles by the use of magnesium sulfate. It was thought that this level of $\mathrm{Mg}$ might prove to be undesirably high, expecially when $\mathrm{Ca}$ was medium, so the Mg concentration of the medium and low $N$ series was reduced to a uniformly lower concentration throughout those two series (Tablo 1 ).

About the midale of August the supply of ferric citrate on hand was depleted; ferric sulfate, which was available, was substituted. About two weeks later certain trees began to show signs of excessive wilting. However, most of those affected wilted only during the day and recovered at night. It was learned later that peach trees in sand culture are not tolerant to ferric sulfate (5), although apple trees apparently will withstand a considerable concentration of the salt. The few trees whlch were most severely affected were partly defollated at the time they were harvested, which was about ten days after the first wilting was observed. Since differences in growth were definitely established before the wilting occurred, the growth relations of the trees under the different treatments were not altered. The wilting also had no apparent effect on the results of the chemical analyses. It is belleved that the trees were harvested before any major alterations in their composition had occurred.

One quart of water was applied daily to each tree unt 11 April 13, on which date a similar application of the solution containing the lowest concentrations of all four elements was begun. New shoots developed rapidly within the next two weeks. All but three of the strongest were removed from each tree, an effort being made to leave shoots which were spaced at intervals along the trunk. With but one or two exceptions, ell those selected continued to develop.

On April 27 the differential treatments were assigned to the trees at random with the restriction that no two recelving the same treatment were adjacent. At first, each tree recelved one quart of solution daily, poured on the surface of the sand. The leachings were collected, made to volume with water, and reused once. Beglnning May 31 , the quart which was prepared from the preceding leachate was applied at 8 a.m.; this was followed at 4 p.m. by the application of another which was freshly prepared. Beginning in July, the largest trees were using considerable water as evidenced by the fact that the solution applied in the after- 
noon did not leach through; these were given a quart of water about 2 p.m. whenever the day was bright and warm. The sand in all the pails was flushed with water once a week.

The diameters of the trunks were measured at a point just above the bud union at planting time, two measurements being taken at right angles to each other. They were measured again just before harvest. The increase in diameter was calculated, and the values for the two measurements on each trunk were averaged. The length of the shoots to the nearest five millimeters was measured a few days before the trees were harvested.

Harrest was begun on September 7 and cormpleted on September 13. The tops of 27 trees were sampled on each of the first four days. The leaves were stripped from the shoots in the morning, after which the tops were cut off at the bud union and separated into shoots and trunks. The wood was split into small sections. The samples were put into cheese-cloth sacks and placed in a forced-draft oven at a temperature of $100-105^{\circ} \mathrm{C}$. Leaf samples were left in the oven for 20 to 30 minutes, the wood samples 30 to 35 minutes. The number of samples prepared at any one time was adjusted so that a new lot could be placed in the oven when the preceding lot was removed. After the samples were taken from the oven they were hung in a drying room used by the Department of Agronomy and Genetics for drying large numbers of samples. The temperature of this room was variable between 50 and $60^{\circ} \mathrm{C}$.

After all of the tops were harvested, the roots were removed from the sand, washed, and weighed. The fine roots, approximately 2 to $3 \mathrm{~mm}$ and under in diameter, were separated from the larger roots, which included the stock below the bud union; both lots were treated in the same manner as the tops.

All of the samples were remored from the drying room after about two weeks, then weighed.

\section{Appearance of the Trees in the Deficiency Series}

The trees as a whole grew well and reacted quickly to the different treatments, the duplicates being remarkably similar. As the season progressed, the slower growth and 
the development of characteristic symptoms by the trees in the deficiency series became especially noticeable.

The low-N series: Nitrogen deficiency symptoms were apparent among the trees of the low- $N$ series by the middle of May; the leaves were lighter green than those on trees recelving more $N$. The linear growth of the shoots was slow; only a few laterals to the main shoots developed. Maximum growth for most of the trees of this series was reached by the middle of July. Figure 1 shows a typical low-N tree at harvest time.

By the first of June there was a noticeable difference in condition of the follage between the trees of the low-N series receiving high $\mathrm{Ca}$ and those receiving medium $\mathrm{Ca}$. Both groups showed the light yellowish-green follage characteristic of $\mathrm{N}$ deficiency, but the symptoms were more pronounced on those trees recelving high $\mathrm{Ca}$. In addition, the margins of the leaves in this group were mottled with yellow; eventually the margins and the tips of these leaves became brown and paper thin. Many of the leaves dropped and some of the laterals of the low-N-high-Ca trees were nearly defollated except for a few leaves near the terminals. A few shoots began to die back from the tips. None of the injury was shown by the leaves or shoots of the trees receiving low-N-medium-Ca (compare Fig. 1 and 2).

Because it was impossible to supply all of the $\mathrm{Ca}$ in the low-N-high-Ca series as calcium nitrate and so also maintain the low-N supply, the $\mathrm{Ca}$ in the $\mathrm{N}$-deficient solutions was supplied as calcium chloride. Therefore it was thought that the injury might be the result of high chloride concentrations $(10,11,12)$. With that in view, one half of the trees in this series was supplied, beginning on June 17, with solutions in which calcium acetate was used for the additional $\mathrm{Ca}$ needed to raise the level from medium to h1gh. The \#2 trees in the low-N-high-Ca serles as listed in the Appendix Tables 1 to 8 received the acetate. In about two weeks there were definite indications that the progress of the injury had been stopped or at least checked considerably on the trees to which the acetate had been applied. However, those trees produced only very little or no new growth, whereas the chloride trees made some additional growth later in the season, even though they were partly defoliated. The differences between the trees were also indicated in the analyses of the tissues (Appendix Tables 3 to 8 ). The trees receiving the acetate were con- 

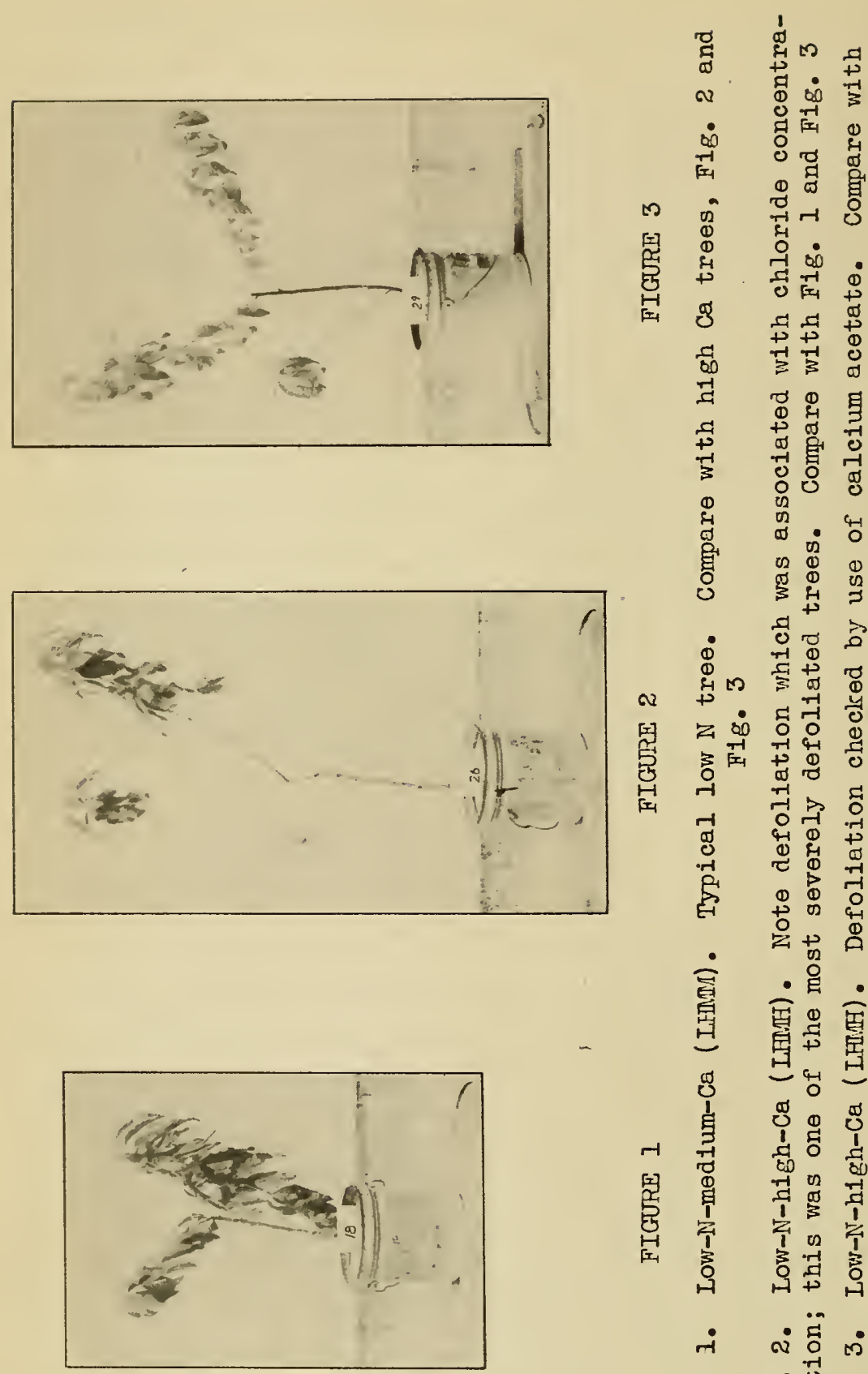

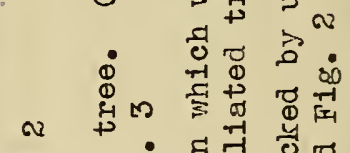

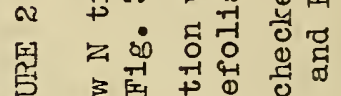

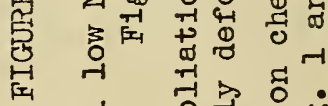

형

厯

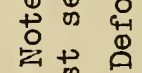

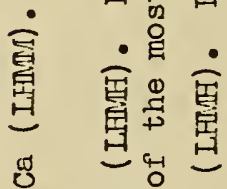

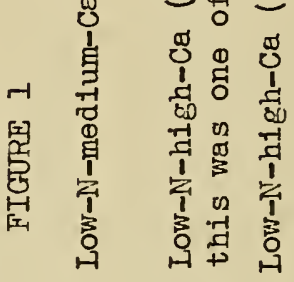

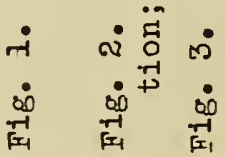



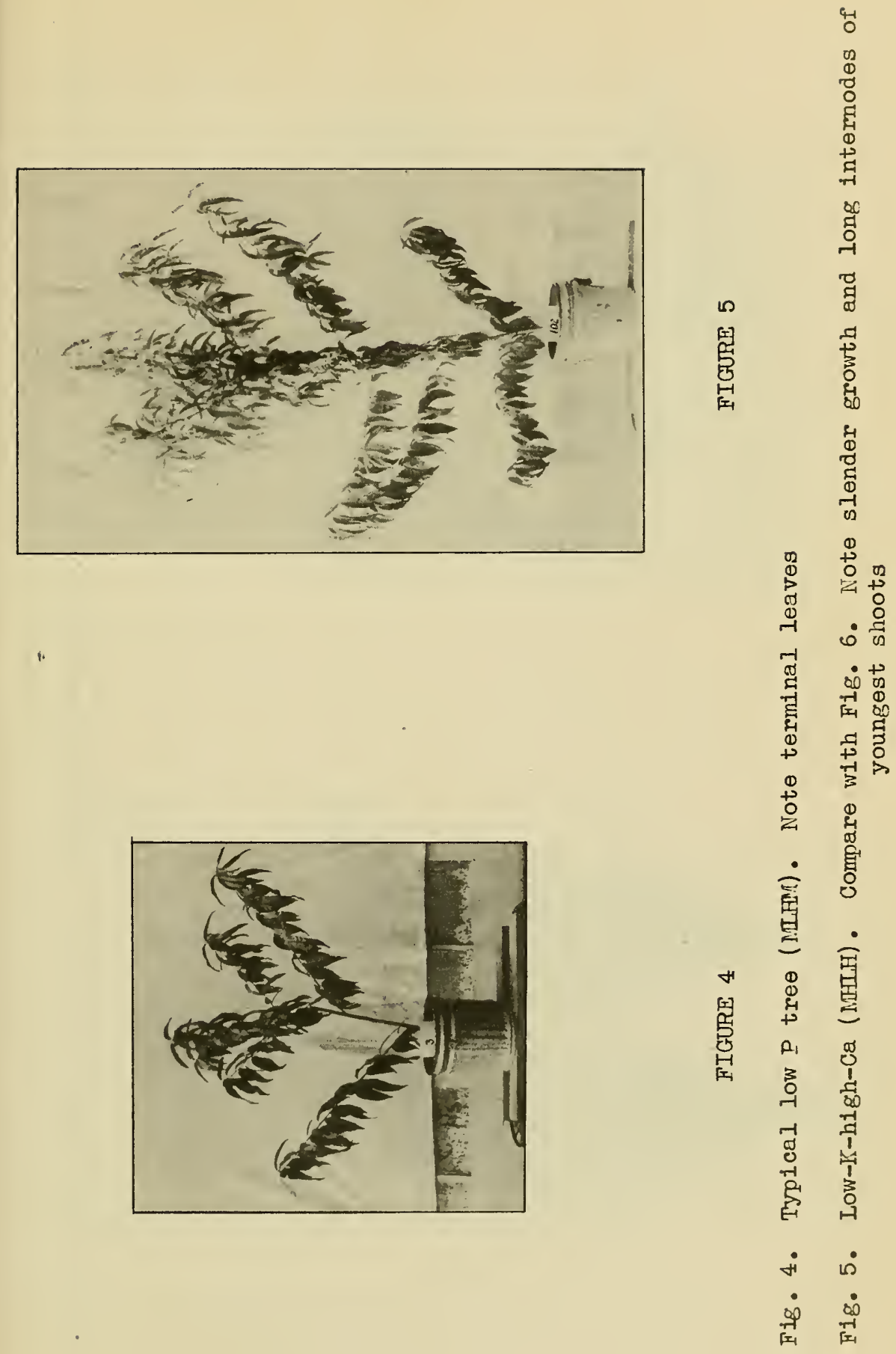

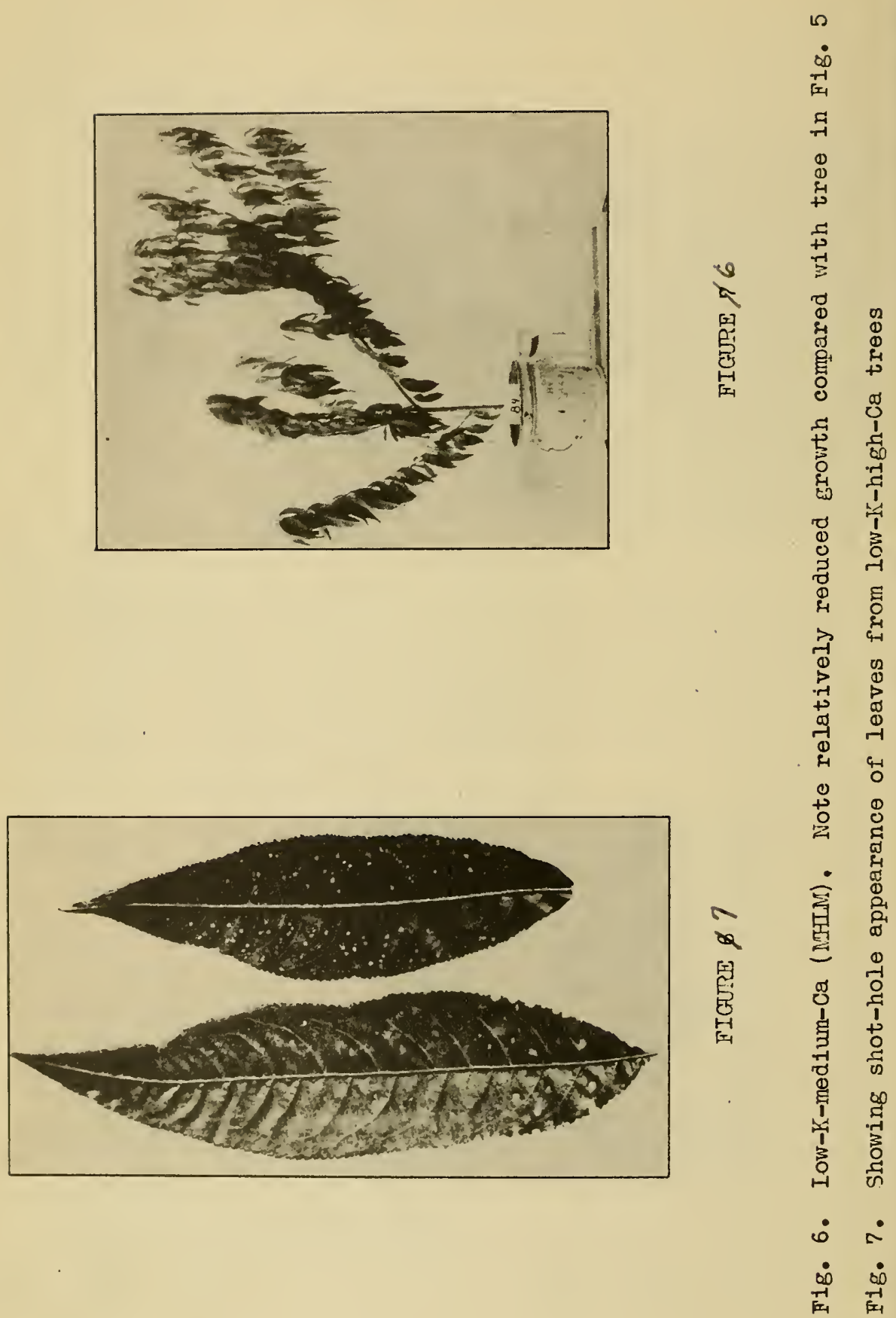

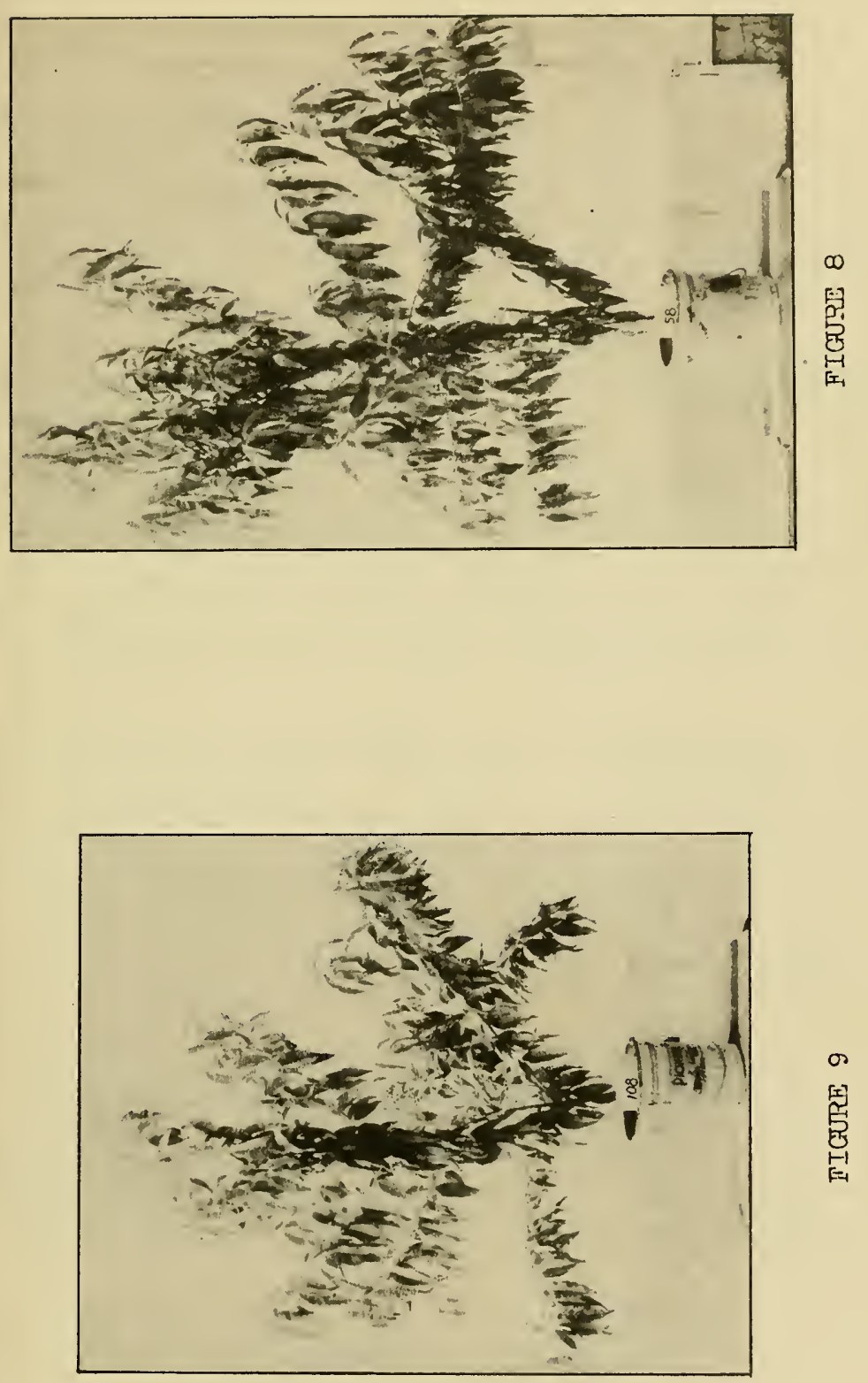

a

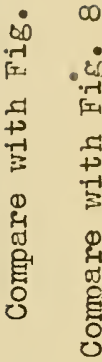

密

ह日 द

개

品

穷 穷

.

क 2

$\$$ \&

+ H

ભู

+

E

究 究

क्ष

్ㅐㅇ 壳

ம

$\stackrel{\infty}{+1} \stackrel{0}{-1}$ 
slderably lower in $N$ and $P$, but not consistently lower in $\mathrm{K}, \mathrm{Ca}$, or $\mathrm{Mg}$. (See Figs. 2 and 3 for comparison of low-Nhigh Ca trees with and without calcium acotate as they appeared at harrest time.)

It should be noted that the trees recelving high Ca in the medium-N series were supplied with almost as much calclum chloride as those which were injured in the low-N series However, the medium $N$ trees showed no signs of the injury. Apparently, the injurious effect of the chloride was offset by medium $\mathrm{N}$.

The low-P series: Symptoms of phosphorus deficiency developed more slowly than those of $\mathrm{N}$ deficlency. Distinct symptoms of $P$ deficlency were not evident on the trees of the low-P serles until mid-July. The leaves of these trees were a dull, somewhat purplish green. The terminal leaves were leathery in texture; their shape was long and narrow; they were flat and unwrinkled, extending stiffly at right angles to the axis of the shoot (Flg. 4). The shoots, which were stifr and woody, were short and only slightly branched. Maximum growth was attained in most of the low-P trees by mid-July.

The low- $K$ series: By the middle of July, the youngest leaves of the low-K trees were smaller than comparable leaves on trees receiving more $\mathrm{K}$. A few of the terminal leaves were slightly rolled. The newer shoot growth was long and slender (F1g. 5). The foliage of the low-K-high-Ca trees became marked in the intervelnal areas by small necrotic lesions which dropped out and gave a shot-hole appearance to the leaves (F1g. 7). The necrosis did not appear when low $K$ was accompanied by medium Ca, low $\mathrm{P}$, or low $\mathrm{N}$. The low-K-mediumCa trees made less growth than those receiving low-K-hlgh$\mathrm{Ca}$ (F1gs. 5 and 6); the reduced growth of the low-K-mediumCa trees was especially noticeable in the high-N series. Maximum growth on those trees was reached by mid-June, whereas other low-K trees continued growth until harrest. When the $P$ supply as well as $K$ was deficient, the trees showed only symptoms of $\mathrm{P}$ deficiency.

\section{Measurements of Growth}

Data for the length and the dry weight of shoots are presented in the text in Table 2 , which is a summary of the data for the measurements as presented for individual trees 
In Appendix Table 1.* The sumary was made by averaging the data for each of the primary treatments, $N, P, K$, and $C a$, and for their interactions, NP, NK, PK, $\mathrm{NCa}, \mathrm{PCa}, \mathrm{KCa}, \mathrm{NPCa}, \mathrm{NKCa}$, and PKCa. To obtain the averages, the data for the 108 trees in the experiment were arranged in groups, each of which included the figures for those trees receiving a particular level of one element, or the particular levels of more than one element in the case of the interactions. The data for each group were averaged to obtain the summary data for those trees receiving the treatment common to that group. Thus, to obtain the averages for high, medium, and low $N$ the trees were divided into three groups of 36 trees, one for each of the levels of $\mathrm{N}$; averages for each of the three levels of $P$ and $K$ were obtained from similar groups of 36 trees. For Ca there were two groups of 54 trees each, one for each of the two levels of that element.

The number of trees included in each average for the interactions depended upon the number of elements considered in the interaction and the levels at which each was supplied. Thus, for the NP interaction involving two elements each with three levels of supply, there were 9 groups of 12 trees each, representing those groups of trees receiving high-N-high-P, high-N-medium-P, high-N-low-P, medium-N-high-P, etc. Similarly, the averages for the NK and the $P K$ interactions were obtained from groups of 12 trees each, with a total of 9 groups for each interaction. For the $\mathrm{NCa}, \mathrm{PCa}$, and $\mathrm{KCa}$ interactions, two elements also were involved, with $\mathrm{Ca}$ at two levels of supply and the others at three, so that there were 6 groups of 18 trees from which the averages were obtained. For each of the interactions $\mathrm{NPCa}, \mathrm{NKCa}$, and $\mathrm{PKCa}$, there were 18 groups of 6 trees each for which averages were obtained.

Table 2 is in effect a series of subtables each of which is designated by the letter or letters of a primary treatment or interaction. The averages for the primary treatments indicate the general effects of each element individually. Their interactions indicate the manner in which the individual effects vere modified by the effects of the other elements. If, for example, it is desired to determine the effects of $N$,

*Data for measurements of trunk diameters, dry weight of trunks and roots, and dry weight per unit length of shoots also are presented in Appendix Tables 1 and 2. Only the data for the length and dry weight of shoots are used in the discussion, since they are, for the most part, representative of the other measurements of growth. 
Table 2a. Total Length and Dry We1ght of Shoots. Averages for Primary Treatments and their Interactions

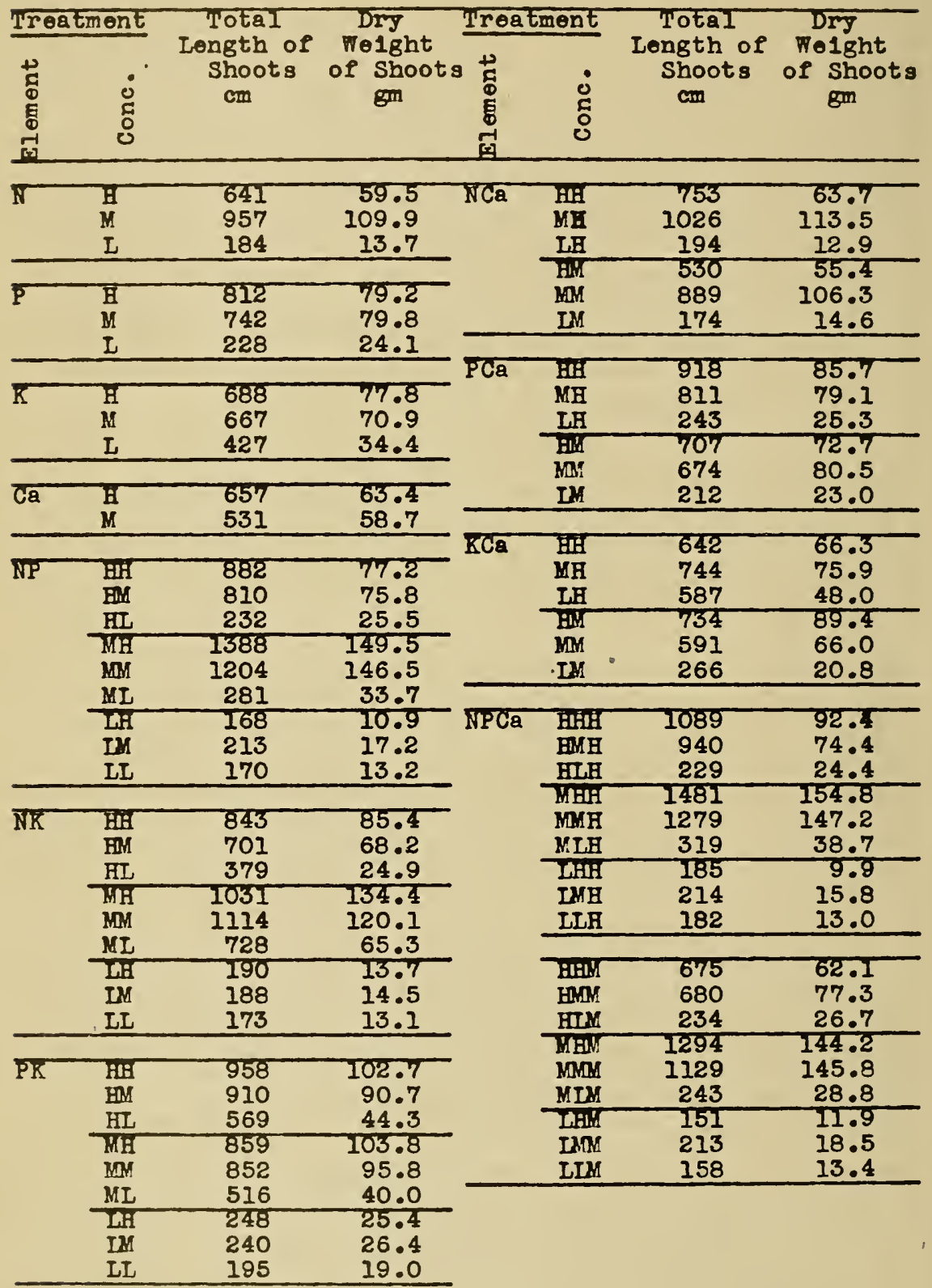


Tablo 2b. Total Length and Dry Welght of Shoots. Averages for Primary Treatments and their Interactions

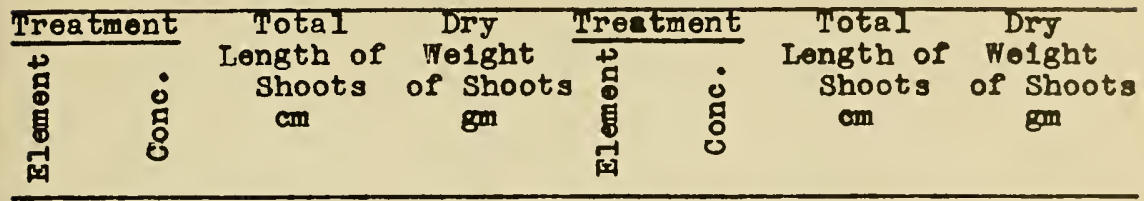

\begin{tabular}{|c|c|c|c|c|c|c|c|}
\hline NKCa & $\begin{array}{l}\text { BHH } \\
\text { HMH } \\
\text { HLH }\end{array}$ & $\begin{array}{l}813 \\
815 \\
630\end{array}$ & $\begin{array}{l}74.5 \\
74.7 \\
42.0\end{array}$ & PKCa & $\begin{array}{l}\text { HHAH } \\
\text { BMB } \\
\text { HLH }\end{array}$ & $\begin{array}{r}928 \\
1045 \\
783\end{array}$ & $\begin{array}{l}96.3 \\
99.5 \\
61.3\end{array}$ \\
\hline & MHIB & 912 & 111.3 & & MHIH & 772 & 79.8 \\
\hline & MMH & 1210 & 138.6 & & MMH & 930 & 100.7 \\
\hline & MLH & 957 & 90.7 & & MLH & 730 & 56.8 \\
\hline & Tath & 201 & 13.0 & & THAl & 226 & $22 \cdot 7$ \\
\hline & TYH & 206 & 14.4 & & IMH & 256 & 27.4 \\
\hline & LIF & 174 & 11 & & LIH & 249 & 25.9 \\
\hline & HiEW & 874 & 96.3 & & Hith & 988 & 109.1 \\
\hline & HMM & 587 & 61.9 & & BMM & 776 & $81: 8$ \\
\hline & HTM & 128 & 7.8 & & HLM & 355 & 27.2 \\
\hline & Mald & 1150 & 157.5 & & MAlin & 946 & 127.6 \\
\hline & $\mathrm{MOM}$ & 1017 & 121.5 & & MMM & 773 & 90.8 \\
\hline & MIM & 499 & 39.8 & & MLM & 302 & 23.2 \\
\hline & Then & 180 & 14.3 & & Len' & 269 & 31.5 \\
\hline & IXM & 170 & 14.6 & & IMN & 225 & 25.4 \\
\hline & IIM & 172 & 14.8 & & LIM & 142 & 12.0 \\
\hline
\end{tabular}

the date designated by $N$ are examined first. Then to determine in what manner, if any, $P$ modified the general offects of $\mathrm{N}$, the $\mathrm{NP}$ group is considered. By examining the NPCa group it is possible to determine whether or not the relationships of $\mathrm{N}$ and $\mathrm{P}$ were different at the two Ca levels.

The data for the dry weight and the total length of shoots from Table 2 are also presented in Graphs 1 and 2 , which are composed of a series of subgraphs corresponding to the primary treatments and their interactions with the exception of the higher interactions, NPCa, NKCa, and PKCa.

The effects of N: The average effects of $N$ are apparont in subgraph N, Graphs 1 and 2. Growth (dry weight and total length of shoots) was at a maximum when $N$ was medium; it was least when $N$ was low and intermediate when $N$ was high (see also Figs. 1,8 and 9 ). The effects of $N$ were comparatively the same regardless of the supplies of $P, K$, or $\mathrm{Ca}$ (Graphs 1 and 2 , NP, NK, bars $1: 4: 7,2: 5: 8,3: 6: 9$; NCa, bars $1: 2: 3,4: 5: 6)$; that $1 \mathrm{~s}$, regardless of $\mathrm{P}, \mathrm{K}$, or $\mathrm{C8}$, growth was always at a maximum when $N$ was medium.

The intermediate amount of growth with high $\mathrm{N}$ indicates 


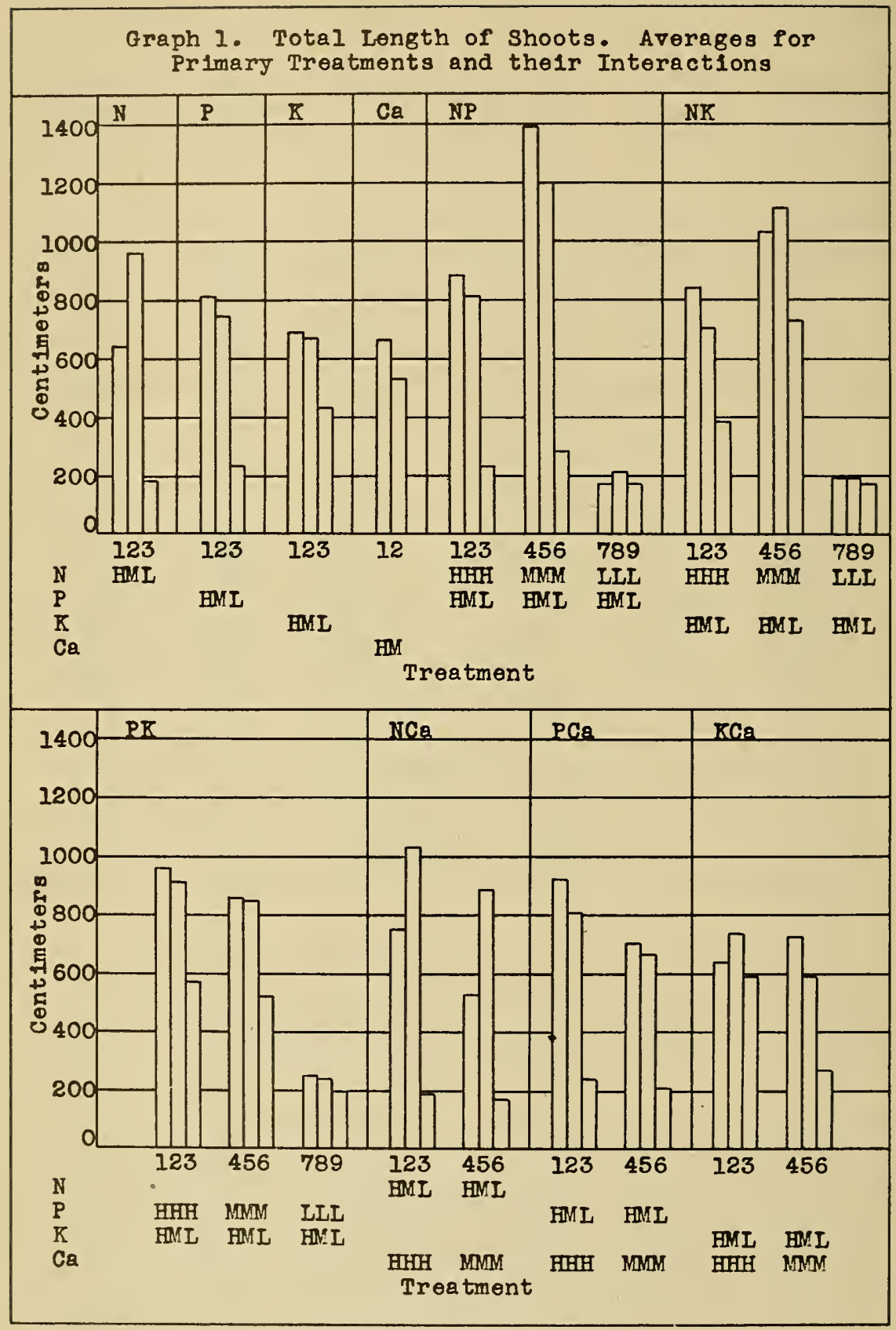




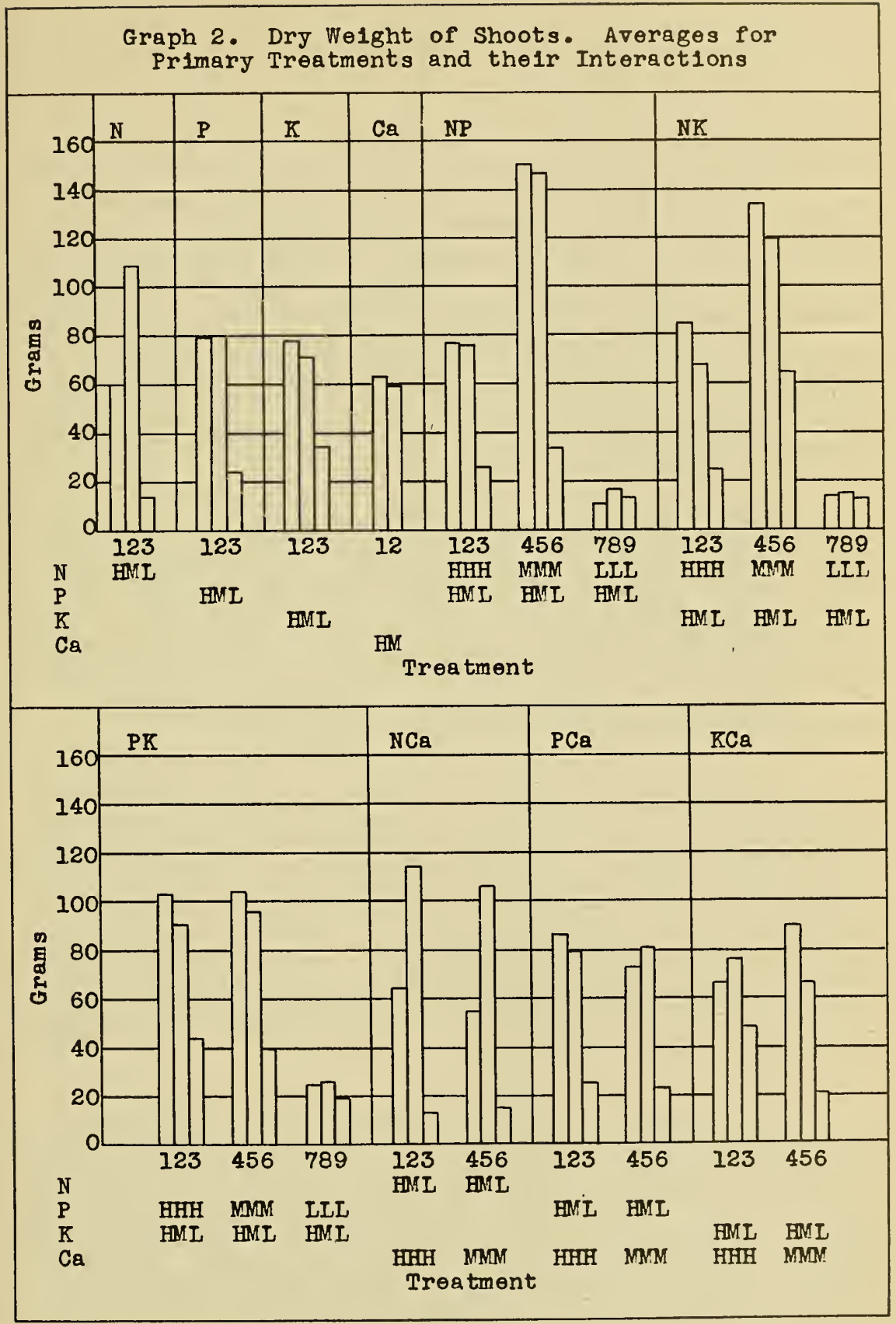


that that level of $\mathrm{N}$ was excessive. Two other factors, however, may also have contributed to this result. First, the concentration of magnesium was higher, and second, the total concentration of the solutions was greater in the high than in the medium-N series. If these factors had been of primary importance in limiting the growth of the high-N trees, it seems likely that they also should have altered the effects of variations in the supplies of other elements, so that the growth within the high and the medium-N series as affected by other elements would also have differed markedly. However, the effects of other elements on the growth w1thin the two series were fundamentally similar. Therefore it seems likely that any limiting effects of the magnesium supply or of the total concentration of the solutions were of a secondary nature and, if anything, merely intensified the limiting effect of the high $\mathrm{N}$.

Nitrogen evidently was the most important of the elements as a determinant of growth. The others became important only as they influenced growth within the limits of the $\mathrm{N}$ supply. As a result, the intensity of balance in the nutrient-element supplies was dependent first on $N$. The solutions with the highest intensity of balance obviously were among those of the medium-N series, since maximum growth resulted under conditions of medium-N.

The Effects of $K$ and $C a$ : $K$ and $C a$ were so markedly interdependent in their effects on growth that they must be considered together. Consequently their effects are shown best by the $\mathrm{KCa}, \mathrm{NKCa}$, and $\mathrm{PKCa}$ interactions in which both elements are included as variables. Examination of the averages for those interactions shows that from the standpoint of maximum growth, two combinations of $K$ and $C a$ were of nearly equal effectiveness. Those combinations were $\mathrm{high}-\mathrm{K}-$ medium-Ca and medium-K-high-Ca (Graphs 1 and $2, \mathrm{KCa}$, $\mathrm{HM}$, and $\mathrm{MH}$; Table $2, \mathrm{NKCa}, \mathrm{PKCa})$.

A more detailed consideration of these relationships can be approached in two ways: first, as to the effects of an increasing $K$ supply when $C a$ was at a given level, and second as to the effects of an increasing $C a$ supply when $K$ was at a given level. Thus, using the first approach, when $\mathrm{Ca}$ was medium, an increase in the $\mathrm{K}$ supply from medium to high resulted in an increased growth, but when $\mathrm{Ca}$ was high, It resulted in a decreased growth (Graphs 1 and 2, Table 2, $\mathrm{KCa}$ ). On the other hand, an increase in $\mathrm{K}$ from low to medium resulted in an increased growth at both levels of $\mathrm{Ca}$; 
however, the increase was comparatively greater at medium than at high Ca. Evidently, any increase in $\mathrm{K}$ was most effective in promoting growth when $\mathrm{Ca}$ was medium.

The intensity of the effects of increasing $K$ appear to have been influenced also by the $\mathrm{N}$ supply ( $\mathrm{Table} 2, \mathrm{NKCa}_{2}$ ). Increase in growth with increasing $K$ was comparatively greater at high-N-medium-Ca then at medium-N-medium-Ca. Apparently, under the conditions of medium $\mathrm{Ca}$, the high level of $K$ was more favorable, relatively, to growth at high than at medium $\mathrm{N}$. Under conditions of high $\mathrm{Ca}$, also, the high level of $\mathrm{K}$ was comparatively more favorable to growth at high $N$. This effect is indicated by the fact that the depression in growth which resulted with high $K$ at medium-Nhigh-Ca was not shown at high-N-high-Ca; under the latter conditions, therefore, high $K$ was less detrimental (comparatively beneficial) since it did not decrease growth as at medium-N-high-Ca. It is possible, of $\operatorname{course,~that~} K$ with either level of Ca was comparatively more favorable to growth at high $N$ because it reduced or offset any deleterious effects of the higher Mg supply which accompanied high $N$; perhaps, if the $\mathrm{Mg}$ supply had been the same with high and medium $\mathrm{N}$, there would have been no apparent difference in the intensity of the effects of increasing $K$. At low $N$ the effects of $\mathrm{K}$ were minimized, since growth was so limited by the $\mathrm{N}$ deficiency; maximum growth within the limits of low $\mathrm{N}$ usually resulted, however, when $\mathrm{K}$ was medium.

The relations of $\mathrm{K}$ and $\mathrm{Ca}$ will now be considered from the other point of view, that of the effects of increasing $C a$ when $K$ was at a given level. When $K$ was low, growth increased markedly with an increase in the $\mathrm{Ca}$ supply (Graphs 1 and 2 , Table 2, $\mathrm{KCa}$ ). A similar though less pronounced increase in growth with increasing $\mathrm{Ca}$ resulted when $\mathrm{K}$ was medium. When $\mathrm{K}$ was high, however, growth decreased with increasing $\mathrm{Ca}$.

As with the effects of increasing $K$, the intensity of the effects of $\mathrm{Ca}$ also appear to have been affected by the $\mathrm{N}$ supply (Table 2, NKCa). The increase in growth which resulted with increasing $\mathrm{Ca}$ at both low and medium $\mathrm{K}$ levels was more pronounced when $N$ was high than when $N$ was medium. The decrease in growth with increasing $\mathrm{Ca}$ at high $\mathrm{K}$ was relatively less when $N$ was high so that comparatively, high $\mathrm{Ca}$ was less detrimental (relatively more beneficial) to growth at high-N-high-K than at medium-N-high-K. Thus, at all three levels of $\mathrm{K}$, high $\mathrm{Ca}$ tended to be more favorable, rela- 
tively, to growth when $N$ was high than when $N$ was medium. It is possible, however, that the intensity of the $\mathrm{Ca}$ erfects was modifled not so much by the high $N$ level itself as by the higher Mg supply which accompanied high N. At low $\mathrm{N}$ the effects of $\mathrm{Ca}$ were minlmized by the marked limiting effect of the $N$ deficiency.

The effects of both $\mathrm{K}$ and $\mathrm{Ca}$ and their interrelations were not altered appreclably by the level of the $P$ supply ( Table 2, PKCa).

As determinants of growth, $\mathrm{K}$ and $\mathrm{Ca}$ apparently were next to $N$ in importance. The growth which resulted within the limits of any level of $\mathrm{N}$ was determined by the relationship between $\mathrm{K}$ and $\mathrm{Ca}$. The highest intensities of balance with respect to those two elements occurred with high-Kmedium-Ca and medium- $K-h i g h-C a$, the combinations which resulted in maximum growth. The lowest intensities of balance with respect to $K$ resulted when $K$ was low; however, the intensity of balance at low- $\mathrm{K}-\mathrm{high}-\mathrm{Ca}$ was greater than at low$\mathrm{K}$-medium-Ca.

The Effects of $P$ : The growth of the trees receiving solutions deficient in $P$ was much less than that of trees supplied with higher levels of that element (Graphs 1 and 2 , Table 2, P). There was no significant difference in growtb between the trees recelving medium and high P. Apparently, the medium $P$ supply was sufficient with respect to maximum growth.

The effects of $P$ were not altered appreciably by $N, K$, or $\mathrm{Ca}$ (Graphs 1 and 2, Table 2, NP, PK, PCa, NPCa, PKCa). It is perhaps worthy to note, however, that when both $K$ and Ca were high there was an indication that growth was greater at high than at medium $\mathrm{P}$ ( Table 2, PKCa, HHH:MHH); the difference is not great enough, however, to be more than indicative of a possible trend. It will be shown later that the quality of growth at the two higher $P$ levels differed even though the quantity was practically the same.

As a determinant of growth, $P$ was apparently the least important of the four elements used as variables. The lowest intensities of balance with respect to the $P$ supply resulted when $P$ was low. On the other hand, the highest intensities with respect to that element resulted when its supply was elther medium or high. No real distinction between medium and high $\mathrm{P}$ as to their influence on the intensity of balance 
is possible, since there vas no significant difference in growth at those two levels of P. Practically, therefore, medium and high $P$ could be interchanged without altering appreciably the intensity of balance with respect to growth.

Balance with respect to $N, P, K$, and Ca: Because of the K-Ca effects, there were two combinations of $N, P, K$, and $\mathrm{Ca}$ which were practically equal as to intensity of balance. Within the limits of medium $N$, these combinations were: mediura $+\mathrm{N}-$ medium-P-high- $\mathrm{K}-$ medium-Ca and medium-N-medium-P-medium-K-high-Ca. These combinations represent the nutrient-element supplies with the highest intensities of balance among all the solutions used. Two other combinations which had a somewhat lower intensity of balance in comparison to the first two were: medium- $N$-medium-P-medium- $\mathrm{K}-$ medium-Ca and medium-N-medium-P-high-K-high-Ca. The differences between these four combinations are indicated by the averages in Table 2, NKCa. Although these averages do not indicate any effects of $P$, they can be used for comparing the effects of the complete nutrient-element combinations because growth was determined primarily by $\mathrm{N}, \mathrm{K}$, and $\mathrm{Ca}$, and, comparatively at least, the effects of those elements were not altered significantly by $P$.

Similar combinations of $P, K$, and $\mathrm{Ca}$ with high $\mathrm{N}$ represent the solutions with the highest intensities of balance within the high $N$ series. They all were, however, of a comparatively lower intensity of balance than those of the medium $N$ series. Within the limits of high $N$, the combination high-N-medium-P-high-K-medium-Ca had the highest intensity of balance. High-N-medium-P-medium-K-high-Ca and high-Nmedium-P-high-K-high-Ca were practically the same in their effects on growth. High-N-medium-P-medium-K-medium-Ca had a definitely lower intensity of balance than the other three combinations ( Table 2, NKCa).

It should be noted that since high $\mathrm{P}$ did not result in growth significantly different from that at medium $P$, the high $P$ values could be slibstituted for medium $P$ in the above combinations (both those at medium and at high $N$ ) to produce nutrient-element supplies practically equal to them as to the intensity of balance, at least in so far as growth is concerned.

Of all the combinations used, the solutions with the 
lowest intensities of balance were those in which the supplies of either $N, P$, or $K$ were low. Growth under these conditions was so markedly limited by the deficient element that the potentialities of the supplies of the other elements could in no way be realized.

From the standpoint of maximum growth it is obvious that there were a number of the nutrient-element supplies which were quite high as to their intensities of balance, even though they varied widely as to their relative and $a b-$ solute composition. Only when the supply of one or more of the elements was markedly limiting, as in the case of the low levels of $N, P$, or $K$, or the high level of $N$, were the intensities of balance greatly reduced.

Other Considerations Related to Growth: The relationships between the elements with respect to maximum growth may also be considered from the viewpoint that one of their number was deficient when that maximum was not attained. As long as growth was improved by an increase in the supply of a given element, that element must have been deficient relative to the supplies of the others and the growth which potentially they could support. Thus, when $\mathrm{Ca}$ was medium (at either medium or high $N$ ), $K$ must have been deficient, since growth increased when $K$ was raised to the high level. Similarly, when $\mathrm{K}$ was low or medium, $\mathrm{Ca}$ also could be considered as deficient, since on increase in the $\mathrm{Ca}$ supply improved growth. When Ca was high, however, $K$ was not deficient, since the increase in $K$ from medium to high did not improve growth; and similarly, when $\mathrm{K}$ was high, $\mathrm{Ca}$ was not deficient, since an increase in $\mathrm{Ca}$ to the high level did not improve growth.

Apparently there was a variation as to the intensity or degree of a deflciency. When the supply of an element was extremely low as at low $N$, low $P$, or low $K$, the intensity of the deficiency was comparatively high, since growth was markedly limited. However, the intensity of the $K$ deficiency, for example, was comparatively less when $K$ was medium (at medium $\mathrm{Ca}$ ) than when $\mathrm{K}$ was low. In this instance, although growth was not markedly impaired at modium $K$, it atill was not at a maximum, so that comparatively $K$ was deflclent even at the medium level.

It is possible, within rough limits at least, to make a distinction between the deficiencies of different intensi- 
tles. Thus, deffciencies of the highest intensity which result in sharply curtailed growth may be classed as acute. Such deficiencles are the type which are most easily recognized and which usually are implied by the term "deficlency." In addition to reduced growth, the appearence of the follage or shoots is characterized by certain symptoms typical of the deflciency. In contrast, the deficiencies of lower intensity, which comparatively may be classed as mild, are characterized only by a growth which is reduced in comparison with that which potentlally could be supported by the supplies of the elements which are not deficlent. Thus, for example, the deficlency of $K$ at the low level could be classed as acute, whereas that at medium $K$ (and medium $\mathrm{Ca}$ ) would be mild. The line of demarcation between an acute and a mild deflciency, of course, is probably not sharp but $18 \mathrm{rep}-$ resented by a range in the concentration or avallability in the supply of the deficient element.

At the other extreme from a deficiency is the excess of an element. The high $\mathrm{N}$ is an example. In such an instance the supply of an element is so great that growth is reduced as a result. Under such conditions the maximum growth which the supplies of the other elements might support can not be attained unless the element in excess is reduced.

Theoretically, at least, the milder sort of excess is likely which is the complement of a mild deficiency. In such instance the growth is reduced as a result not only of the element in excess but also of an element which comparatively is mildly deficient. Improved growth would be expected either by reducing the element in excess or by increasing the element which 1 s deflclent. The extent to which growth would be improved by elther means would depend on the degree to which one element was excessive or the other deficlent. In all likelihood a larger increase in growth would result from the correction of a mild deficiency than from the reduction in the supply of an element in mild excess. 


\section{COMPOSITION OF THE TREES}

\section{Methods}

The leaf, shoot, and trunk samples were ground in a Wiley Mill in preparation for analysis. Aliquots of the ground samples were reground in a hand-operated mill before the analyses for nitrogen. The root samples were not anelyzed.

The total, the water-soluble, and the water-insoluble nitrogen were determined, using the Kjeldahl method as modified to include nitrates. In order to leach out the soluble nitrogen, a sample was placed in a cotton thimble in a glass Gooch-crucible holder. The top edges of the cotton were pushed down to cover the sample, which was then leached with $200 \mathrm{ml}$ of distilled water. A I gm sample was used for the leaves and a 1-3 gm sample for the shoots and trunks. Dreliminary trials showed that this procedure was satisfactory for removing the water-soluble nitrogen. Determinations were made on both the leachate and the leached sample. Total nitrogen was determined on an unleached sample.

By adding the figures for the soluble $N$ as determined in the leachate and the insoluble $N$ as determined on the residue, a figure for total $N$ was also determined. Iikewlse, additional values for soluble and insoluble $\mathrm{N}$ were calculated by subtraction of the one or the other from the total $N$ as determined on an unleached sample. In general, the calculated and the determined values checked closely. These values were averaged according to the following formulae, which give weight to the values as actually determined:

\section{If $T, I$, and $S$ repre-}

sent total, insoluble, and soluble $\mathrm{N}$, respective-

ly, as actually determined, and $T^{\prime}, I^{\prime}$, and $S^{\prime}$

represent the corresponding calculated values,

then,

$$
\begin{aligned}
& \text { Av. T equals ( } \left.2 T \text { plus } T^{\prime}\right) / 3 \text {, } \\
& \text { Av. I equals ( } \left.2 I \text { plus } I^{\prime}\right) / 3 \text {, and } \\
& \text { Av. S equals ( } \left.2 S \text { plus } S^{\prime}\right) / 3 \text {. }
\end{aligned}
$$

Determinations of $\mathrm{P}, \mathrm{K}, \mathrm{Ca}$, and $\mathrm{Mg}$ were made according to procedures in use in the solls laboratory of the Department of Agronorgy and Genetics at West Virginia University. Phosphorus and magnesium were determined colorimetrically as the phosphate, calcium titrimetrically as the oxalate, and potassium as the cobaltinitrite. 
The results of the analyses, expressed as a percentage of the dry welght, are presented for the individual trees in Appendix Tables 3 to 8. From these data the N, P, K, Ca, and $\mathrm{Mg}$ per gram of dry weight in the shoots, trunks, and leaves were calculated in terms of their microgram-hydrogenequivalents. For each part of each tree the equivalents were sumed and the percentage of each element in that sum was calculated. This is essentially the procedure used by Thomas (17) in his calculations of the NPK-unit in follar diagnosis. In the present paper the calculation has been modified in that the equivalents are expressed on the elemental basis, not as the oxides. Also, the equivalents units include all of the elements being considered, rather than only three of them at a time. The equivalents are based on the amount of each element equivalent to one hydrogen or its equivalent in compounds such as $\mathrm{HNO}_{3}, \mathrm{H}_{3} \mathrm{PO}_{4}, \mathrm{KNO}_{3}, \mathrm{Ca}\left(\mathrm{NO}_{3}\right)_{2}$, and $\mathrm{Mg}\left(\mathrm{NO}_{3}\right)_{2}$. An explanation of the calculation follows:

For any element $Y$,

The milligram-H-equivalents of $Y$ per gram of dry weight equals (percent $Y \times 1000) /(H-e q u i v a l e n t$ weight) equals percent $Y \times$ Factor.

The microgram-H-equivalents of $Y$ per gram of dry weight equals percent $Y \times$ Factor $\times 1000$.

The Factors for the elements considered are:

$\begin{array}{cccc}\text { Element } & \begin{array}{c}\text { Atomic } \\ \text { Welght }\end{array} & \begin{array}{c}\text { Hydrogen } \\ \text { Equivalent }\end{array} & \begin{array}{c}\text { Factor } \\ (1000 / \text { H.E. })\end{array} \\ \mathrm{N} & 14.01 & 14.01 & 71.38 \\ \mathrm{P} & 31.02 & 10.34 & 96.71 \\ \mathrm{~K} & 39.10 & 39.10 & 25.58 \\ \mathrm{Ca} & 40.08 & 20.04 & 49.90 \\ \mathrm{Mg} & 24.32 & 12.16 & 82.24\end{array}$

The percentage of insoluble $N$ in the shoots of one tree was 0.469 . Therefore 1 ts microgram-II-equivalent per gram of dry weight equals $0.00469 \times 71.38 \times 1000$ equals 334.8.

By similar calculations, the microgram-H-equivalents for the other elements were: soluble $N, 259.1 ; P$, $272.7 ; \mathrm{K}, 172.4 ; \mathrm{Ca}, 161.2 ; \mathrm{Ng}, 97.0$. The total $\mathrm{N}$ equals soluble plus insoluble iv equals 593.9.

The sum of the microgram-H-equivalents ( $N$ plus $P$ plus $K$ plus $\mathrm{Ca}$ plus $\mathrm{NC}$ ) equals 593.9 plus 272.7 plus 172.4 plus 161.2 plus 97.0 equals 1297.2 .

The percentage of each element in the total was: total N, 45.78; insoluble $\mathrm{N}, 25.81$; soluble $\mathrm{N}, 19.97$; $\mathrm{P}$, 
$21.02 ; \mathrm{K}, 13.29 ; \mathrm{Ca}, 12.43 ; \mathrm{Mg}, 7.48$.

The sum of the percentages for $\mathrm{N}, \mathrm{P}, \mathrm{K}, \mathrm{Ca}$, and $\mathrm{Mg}$, that is 100 , constitutes the equivalents unit.

In discussing these data the percentages of a given element in the microgram-H-equivalents unit will be referred to as either the amount or the percentage of that element in the equivalents unit, or simply, in the unit.

The data for the amount of the elements in the units were averaged according to the primary treatments and their interactions; these arerages are presented in the text in Tables 3, 4, and 5 for the shoots, trunks, and leaves, respectively. The data for the primary treatments and their interactions, with the exception of $\mathrm{NPCa}, \mathrm{NKCa}$, and $\mathrm{PKCa}$, are also presented in Graphs 3,4 , and 5 .

\section{The Amount of the Elements in the Tops}

The amount of an element in the equivalents units in the tops was determined primarily by the supply of that element. This is indicated by the fact that in the leaves, shoots, and trunks the $\mathrm{P}, \mathrm{K}$, and $\mathrm{Ca}$ increased as the respective supplies of those elements increased (Graphs 3 to 5 , subgraphs $P, K, C a)$. Also, the total $N$ in the shoots and trunks increased as the supply of $N$ increased (Graphs 3,4, $N)$. In the leaves, however, it increased only with the increase in $\mathrm{N}$ from low to medium (Graph $5, \mathrm{~N}$ ).

In all three parts of the trees, insoluble $N$ was at a maximum when the $\mathrm{N}$ supply was medium. The soluble $\mathrm{N}$, however, increased as the $\mathrm{N}$ supply increased. Roughly 90 percent of the total $\mathrm{N}$ in the leaves was insoluble in contrast to about 50 percent in the shoots and trunks. Consequently, variations in the insoluble $N$ were reflected in similar variations in total $\mathrm{N}$ in the leaves, but not in the shoots and trunks. This accounts for the fallure of total $N$ to increase in the leaves with the increase to the high $N$ supply.

Usually the leaves, shoots, and trunks differed as to the amounts of the elements within them (Tables 3 to 5 ), probably as a result of natural differences in their structure and functions. The amount of total $N$ wes about the same in the units for all three parts of the trees. The soluble $N$, however, was much smaller and the insoluble $N$ larger in the leaves then in the shoots and trunks. The level of 
Tablo 3a. The $N, P, K, C e$ and $M g$ in the Equivalents Units in the Shoots. Averages for Primary Treatmenta and their Interactions

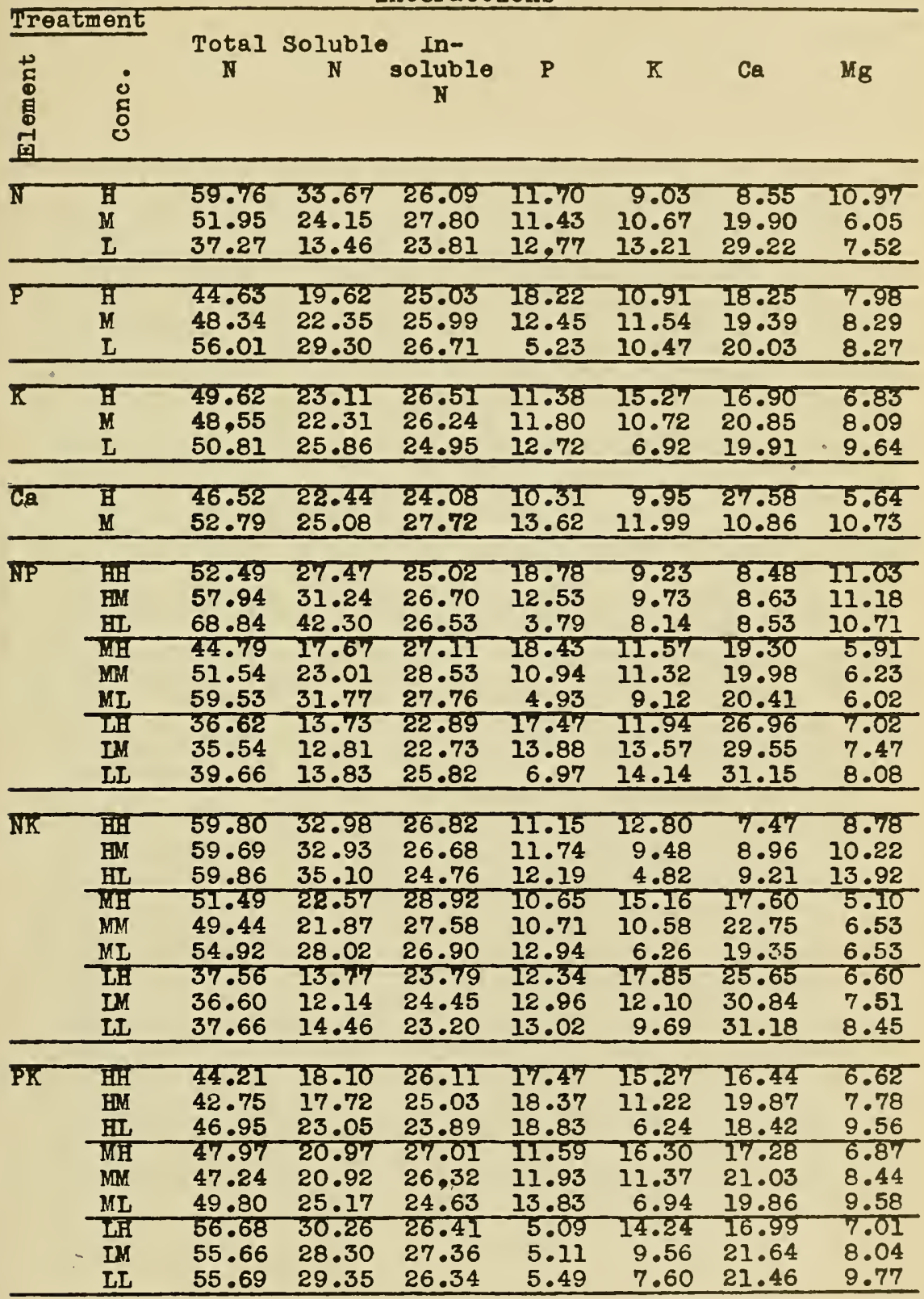


Table 3b. The $N, P, K, C a$ and $M g$ in the Equivalents Units in the Shoots. Averages for Primary Treatments and their Interactions

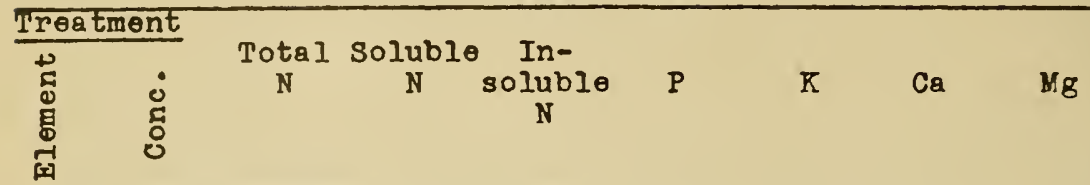

\begin{tabular}{|c|c|c|c|c|c|c|c|c|}
\hline $\mathrm{NCQ}$ & $\begin{array}{l}\mathrm{HH} \\
\mathrm{MH} \\
\mathrm{LH} \\
\mathrm{HH} \\
\mathrm{MM} \\
\mathrm{IM} \\
\end{array}$ & $\begin{array}{l}59.61 \\
48.81 \\
31.15 \\
59.90 \\
55.10 \\
43.39 \\
\end{array}$ & $\begin{array}{l}34.54 \\
22.40 \\
10.37 \\
32.79 \\
25.90 \\
16.54 \\
\end{array}$ & $\begin{array}{l}25.06 \\
26.40 \\
20.78 \\
27.11 \\
29.20 \\
26.85 \\
\end{array}$ & $\begin{array}{r}12.19 \\
9.67 \\
9.07 \\
11.21 \\
13.19 \\
16.47 \\
\end{array}$ & $\begin{array}{r}8.21 \\
9.24 \\
12.41 \\
9.86 \\
12.09 \\
14.02 \\
\end{array}$ & $\begin{array}{r}12.89 \\
28.17 \\
41.68 \\
4.20 \\
11.63 \\
16.76 \\
\end{array}$ & $\begin{array}{r}7.11 \\
4.11 \\
5.69 \\
14.84 \\
7.99 \\
9.36 \\
\end{array}$ \\
\hline$\overline{P C Q}$ & $\begin{array}{l}\mathrm{HH} \\
\mathrm{MH} \\
\mathrm{LH} \\
\mathrm{HM} \\
\mathrm{MN} \\
\mathrm{LM} \\
\end{array}$ & $\begin{array}{l}42.37 \\
45.61 \\
51.59 \\
46.89 \\
51.07 \\
60.43 \\
\end{array}$ & $\begin{array}{l}17.92 \\
21.69 \\
27.71 \\
21.32 \\
23.01 \\
30.90 \\
\end{array}$ & $\begin{array}{l}24.44 \\
23.92 \\
23.88 \\
25.51 \\
28.06 \\
29.53 \\
\end{array}$ & $\begin{array}{r}15.68 \\
10.92 \\
4.33 \\
20.76 \\
13.97 \\
6.13 \\
\end{array}$ & $\begin{array}{r}10.14 \\
10.27 \\
9.45 \\
11.68 \\
12.80 \\
11.48 \\
\end{array}$ & $\begin{array}{l}26.09 \\
27.50 \\
29.15 \\
10.40 \\
11.27 \\
10.91 \\
\end{array}$ & $\begin{array}{r}5.72 \\
5.70 \\
5.49 \\
10.26 \\
10.88 \\
11.05 \\
\end{array}$ \\
\hline$\overline{\mathrm{KC} \Omega}$ & $\begin{array}{l}\mathrm{HH} \\
\mathrm{MH} \\
\mathrm{LH} \\
\mathrm{HM} \\
\mathrm{MM} \\
\mathrm{IM}\end{array}$ & $\begin{array}{l}46.58 \\
44.21 \\
48.78 \\
52.66 \\
52.88 \\
52.84 \\
\end{array}$ & $\begin{array}{l}22.49 \\
19.73 \\
25.10 \\
23.72 \\
24.90 \\
26.62 \\
\end{array}$ & $\begin{array}{l}24.04 \\
24.49 \\
23.68 \\
28.94 \\
27.99 \\
26.23 \\
\end{array}$ & $\begin{array}{r}9.86 \\
10.23 \\
10.85 \\
12.91 \\
13.37 \\
14.59 \\
\end{array}$ & $\begin{array}{r}13.41 \\
10.07 \\
6.39 \\
17.14 \\
11.37 \\
7.46 \\
\end{array}$ & $\begin{array}{r}24.85 \\
29.59 \\
28.31 \\
8.96 \\
12.10 \\
11.52 \\
\end{array}$ & $\begin{array}{r}5.33 \\
5.90 \\
5.69 \\
8.34 \\
10.28 \\
13.58 \\
\end{array}$ \\
\hline NPCa & $\begin{array}{l}\text { HHH } \\
\text { HMH } \\
\text { HLH } \\
\text { MHH } \\
\text { MMH } \\
\text { MLH } \\
\text { LFH } \\
\text { LMH } \\
\text { LIH } \\
\end{array}$ & $\begin{array}{l}51.13 \\
57.27 \\
70.44 \\
43.11 \\
49.60 \\
53.71 \\
32.89 \\
29.95 \\
30.62 \\
\end{array}$ & $\begin{array}{r}25.52 \\
32.07 \\
46.06 \\
16.65 \\
22.55 \\
28.02 \\
11.60 \\
10.40 \\
9.05 \\
\end{array}$ & $\begin{array}{l}25.60 \\
25.21 \\
24.38 \\
26.47 \\
27.05 \\
25.70 \\
21.28 \\
19.49 \\
21.57 \\
\end{array}$ & $\begin{array}{r}19.26 \\
13.82 \\
3.48 \\
16.13 \\
8.62 \\
4.28 \\
11.66 \\
10.34 \\
5.22 \\
\end{array}$ & $\begin{array}{r}8.73 \\
8.70 \\
7.20 \\
10.26 \\
9.25 \\
8.22 \\
11.43 \\
12.87 \\
12.93 \\
\end{array}$ & $\begin{array}{l}13.49 \\
12.78 \\
12.39 \\
26.35 \\
28.02 \\
30.14 \\
38.43 \\
41.70 \\
44.92 \\
\end{array}$ & $\begin{array}{l}7.39 \\
7.43 \\
6.50 \\
4.16 \\
4.53 \\
3.66 \\
5.60 \\
5.15 \\
6.32 \\
\end{array}$ \\
\hline & $\begin{array}{l}\text { HEIM } \\
\text { HMM } \\
\text { HIM } \\
\text { MEMM } \\
\text { MMM } \\
\text { MIM } \\
\text { LEHM } \\
\text { LMM } \\
\text { LIM }\end{array}$ & $\begin{array}{l}53.86 \\
58.61 \\
67.24 \\
46.46 \\
53.48 \\
65.35 \\
40.36 \\
41.12 \\
48.70\end{array}$ & $\begin{array}{l}29.40 \\
30.42 \\
38.55 \\
18.70 \\
23.46 \\
35.53 \\
15.86 \\
15.16 \\
18.62\end{array}$ & $\begin{array}{l}24.45 \\
28.19 \\
28.69 \\
27.76 \\
30.02 \\
29.82 \\
24.50 \\
25.96 \\
30.08\end{array}$ & $\begin{array}{r}18.28 \\
11.24 \\
4.09 \\
20.73 \\
13.27 \\
5.57 \\
23.28 \\
17.42 \\
8.72 \\
\end{array}$ & $\begin{array}{r}9.74 \\
10.76 \\
9.08 \\
12.88 \\
13.39 \\
10.02 \\
12.44 \\
14.27 \\
15.34 \\
\end{array}$ & $\begin{array}{r}3.46 \\
4.47 \\
4.67 \\
12.26 \\
11.94 \\
10.68 \\
15.48 \\
17.41 \\
17.39 \\
\end{array}$ & $\begin{array}{r}14.67 \\
14.93 \\
14.93 \\
7.61 \\
7.93 \\
8.38 \\
8.45 \\
9.79 \\
9.85 \\
\end{array}$ \\
\hline
\end{tabular}


Table 3c. The N, P, K, $\mathrm{Ca}$ and $\mathrm{Ng}$ in the Equivalents Units in the Shoots. Averages for Primary Treatments and their Interactions

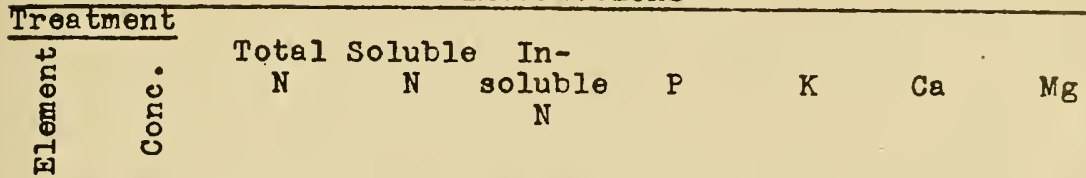

\begin{tabular}{|c|c|c|c|c|c|c|c|c|}
\hline \multirow[t]{2}{*}{ NKCQ } & $\begin{array}{l}\mathrm{KHH} \\
\mathrm{HMH} \\
\mathrm{HLH} \\
\mathrm{MHH} \\
\mathrm{MMH} \\
\mathrm{MLH} \\
\mathrm{LHH} \\
\mathrm{LNH} \\
\mathrm{LIH} \\
\end{array}$ & $\begin{array}{l}57.82 \\
58.03 \\
62.99 \\
50.50 \\
45.08 \\
50.85 \\
31.42 \\
29.54 \\
32.51 \\
\end{array}$ & $\begin{array}{r}32.48 \\
31.92 \\
39.25 \\
23.73 \\
19.10 \\
24.39 \\
11.29 \\
8.18 \\
11.65 \\
\end{array}$ & $\begin{array}{l}25.34 \\
26.11 \\
23.74 \\
26.74 \\
25.99 \\
26.46 \\
20.15 \\
21.36 \\
20.85 \\
\end{array}$ & $\begin{array}{r}11.67 \\
11.93 \\
12.95 \\
9.19 \\
9.05 \\
10.79 \\
8.70 \\
9.72 \\
8.80 \\
\end{array}$ & $\begin{array}{r}11.55 \\
9.03 \\
4.04 \\
12.37 \\
9.67 \\
5.69 \\
16.28 \\
11.51 \\
9.43 \\
\end{array}$ & $\begin{array}{l}11.56 \\
13.43 \\
13.69 \\
24.38 \\
31.88 \\
28.25 \\
38.59 \\
43.48 \\
42.98 \\
\end{array}$ & $\begin{array}{l}7.39 \\
7.59 \\
6.34 \\
3.57 \\
4.34 \\
4.44 \\
5.01 \\
5.76 \\
6.28 \\
\end{array}$ \\
\hline & $\begin{array}{l}\text { HHM } \\
\text { HMM } \\
\text { HIM } \\
\text { MHIN } \\
\text { MMM } \\
\text { MIM } \\
\text { LHW } \\
\text { LMM: } \\
\text { IIM! }\end{array}$ & $\begin{array}{l}61.78 \\
61.19 \\
56.73 \\
52.48 \\
53.81 \\
59.00 \\
43.71 \\
43.66 \\
42.81 \\
\end{array}$ & $\begin{array}{l}33.48 \\
33.94 \\
30.95 \\
21.41 \\
24.64 \\
31.65 \\
16.26 \\
16.11 \\
17.26 \\
\end{array}$ & $\begin{array}{l}28.30 \\
27.25 \\
25.78 \\
31.07 \\
29.17 \\
27.35 \\
27.45 \\
27.54 \\
25.55 \\
\end{array}$ & $\begin{array}{l}10.63 \\
11.56 \\
11.43 \\
12.11 \\
12.36 \\
15.10 \\
15.98 \\
16.20 \\
17.23 \\
\end{array}$ & $\begin{array}{r}14.05 \\
9.93 \\
5.59 \\
17.95 \\
11.49 \\
6.84 \\
19.43 \\
12.68 \\
9.95 \\
\end{array}$ & $\begin{array}{l}3.31 \\
4.49 \\
4.74 \\
10.82 \\
13.62 \\
10.45 \\
12.10 \\
18.20 \\
19.38\end{array}$ & $\begin{array}{r}10.18 \\
12.84 \\
21.51 \\
6.64 \\
8.72 \\
8.62 \\
8.19 \\
9.27 \\
10.63 \\
\end{array}$ \\
\hline \multirow[t]{2}{*}{ PKCa } & $\begin{array}{l}\mathrm{HHH} \\
\mathrm{HMH} \\
\mathrm{HLH} \\
\mathrm{MHH} \\
\mathrm{MMH} \\
\mathrm{MLH} \\
\mathrm{LHH} \\
\mathrm{IMH} \\
\mathrm{LLH} \\
\end{array}$ & $\begin{array}{l}42.58 \\
38.60 \\
45.95 \\
44.81 \\
42.60 \\
49.41 \\
52.34 \\
51.45 \\
50.97 \\
\end{array}$ & $\begin{array}{l}17.66 \\
14.03 \\
22.09 \\
19.93 \\
18.25 \\
26.89 \\
29.90 \\
26.91 \\
26.32 \\
\end{array}$ & $\begin{array}{l}24.91 \\
24.57 \\
23.86 \\
24.88 \\
24.34 \\
22.52 \\
22.44 \\
24.55 \\
24.66 \\
\end{array}$ & $\begin{array}{l}14.99 \\
15.50 \\
16.56 \\
10.36 \\
10.84 \\
11.58 \\
4.22 \\
4.35 \\
4.41 \\
\end{array}$ & $\begin{array}{r}13.61 \\
11.25 \\
5.57 \\
14.02 \\
10.91 \\
5.88 \\
12.58 \\
8.05 \\
7.71 \\
\end{array}$ & $\begin{array}{l}23.55 \\
28.96 \\
25.76 \\
25.18 \\
29.31 \\
28.01 \\
25.79 \\
30.50 \\
31.15 \\
\end{array}$ & $\begin{array}{l}5.27 \\
5.70 \\
6.18 \\
5.64 \\
6.35 \\
5.13 \\
5.07 \\
5.65 \\
5.76 \\
\end{array}$ \\
\hline & $\begin{array}{l}\text { HHM } \\
\text { HMMN } \\
\text { HLM } \\
\text { MHIM } \\
\text { MMM } \\
\text { N IM } \\
\text { LHMN } \\
\text { LMM } \\
\text { LIM }\end{array}$ & $\begin{array}{l}45.83 \\
46.90 \\
47.94 \\
51.13 \\
51.89 \\
50.19 \\
61.01 \\
59.87 \\
60.41\end{array}$ & $\begin{array}{l}18.53 \\
21.41 \\
24.02 \\
22.00 \\
23.59 \\
23.45 \\
30.62 \\
29.69 \\
32.39\end{array}$ & $\begin{array}{l}27.30 \\
25.49 \\
23.92 \\
22.13 \\
28.30 \\
26.74 \\
30.39 \\
30.18 \\
28.02\end{array}$ & $\begin{array}{r}19.94 \\
21.24 \\
21.11 \\
12.83 \\
13.02 \\
16.08 \\
5.96 \\
5.86 \\
6.57\end{array}$ & $\begin{array}{r}16.94 \\
11.20 \\
6.90 \\
18.58 \\
11.83 \\
8.01 \\
15.91 \\
11.06 \\
7.48\end{array}$ & $\begin{array}{r}9.33 \\
10.79 \\
11.09 \\
9.37 \\
12.74 \\
11.70 \\
8.19 \\
12.78 \\
11.77\end{array}$ & $\begin{array}{r}7.96 \\
9.87 \\
12.95 \\
8.10 \\
10.53 \\
14.03 \\
8.95 \\
10.43 \\
13.78 \\
\end{array}$ \\
\hline
\end{tabular}


Table 4a. The N, $P, K, C a$ and $M g$ in the Equivalents Units in the Trunks. Averages for Primary Treatments and their Interactions

\begin{tabular}{|c|c|c|c|c|c|c|c|c|}
\hline & 100 & & Solub]e & & & & & \\
\hline 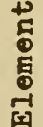 & $\begin{array}{l}\dot{0} \\
0 \\
0 \\
0\end{array}$ & $\mathrm{~N}$ & $\mathbf{N}$ & soluble & $\mathbf{P}$ & $\mathrm{K}$ & $\mathrm{Ca}$ & $\mathrm{Mg}$ \\
\hline
\end{tabular}

\begin{tabular}{|c|c|c|c|c|c|c|c|c|}
\hline$N$ & $\begin{array}{l}\mathrm{H} \\
\mathrm{M} \\
\mathrm{L}\end{array}$ & $\begin{array}{l}53.86 \\
47.32 \\
37.89 \\
\end{array}$ & $\begin{array}{r}26.46 \\
17.80 \\
8.86 \\
\end{array}$ & $\begin{array}{l}27.40 \\
29.52 \\
29.03 \\
\end{array}$ & $\begin{array}{l}14.31 \\
13.34 \\
15.89 \\
\end{array}$ & $\begin{array}{r}9.23 \\
11.29 \\
13.56 \\
\end{array}$ & $\begin{array}{l}13.81 \\
21.03 \\
24.37 \\
\end{array}$ & $\begin{array}{l}8.80 \\
7.02 \\
8.30 \\
\end{array}$ \\
\hline$\overline{\mathrm{P}}$ & $\begin{array}{l}\mathrm{H} \\
\mathrm{M} \\
\mathrm{L}\end{array}$ & $\begin{array}{l}42.11 \\
45.60 \\
51.35\end{array}$ & $\begin{array}{l}15.25 \\
17.30 \\
20.56\end{array}$ & $\begin{array}{l}26.86 \\
28.30 \\
30.80 \\
\end{array}$ & $\begin{array}{r}19.34 \\
15.00 \\
9.20 \\
\end{array}$ & $\begin{array}{l}11.18 \\
11.63 \\
11.26 \\
\end{array}$ & $\begin{array}{l}19.38 \\
19.52 \\
20.32 \\
\end{array}$ & $\begin{array}{l}7.99 \\
8.25 \\
7.87 \\
\end{array}$ \\
\hline $\bar{K}$ & $\begin{array}{l}\mathrm{H} \\
\mathrm{M} \\
\mathrm{I}\end{array}$ & $\begin{array}{l}47.59 \\
46.11 \\
45.38\end{array}$ & $\begin{array}{l}18.82 \\
17.54 \\
16.76\end{array}$ & $\begin{array}{l}28.75 \\
28.58 \\
28.62\end{array}$ & $\begin{array}{l}13.35 \\
14.69 \\
15.50\end{array}$ & $\begin{array}{r}14.35 \\
11.27 \\
8.45\end{array}$ & $\begin{array}{l}17.52 \\
19.83 \\
21.86\end{array}$ & $\begin{array}{l}7.22 \\
8.09 \\
8.81\end{array}$ \\
\hline
\end{tabular}

\begin{tabular}{lllllllll}
\hline $\mathrm{Ca}$ & $\mathrm{H}$ & 44.99 & 17.48 & 27.51 & 13.72 & 10.99 & 23.33 & 6.96 \\
& $\mathrm{M}$ & 47.72 & 17.94 & 29.79 & 15.30 & 11.72 & 16.14 & 9.11 \\
\hline
\end{tabular}

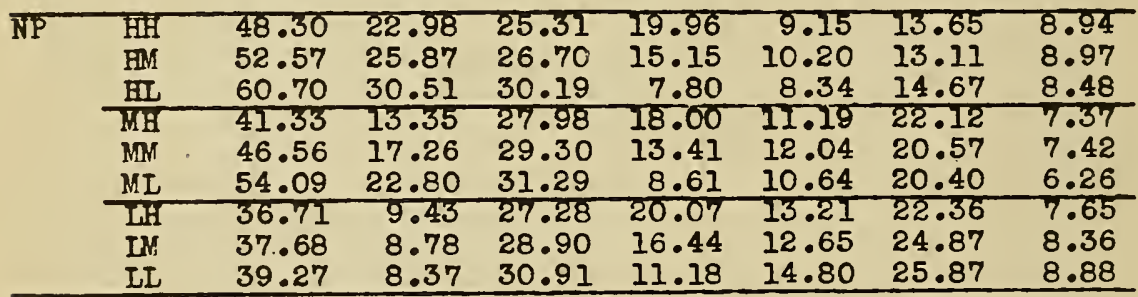

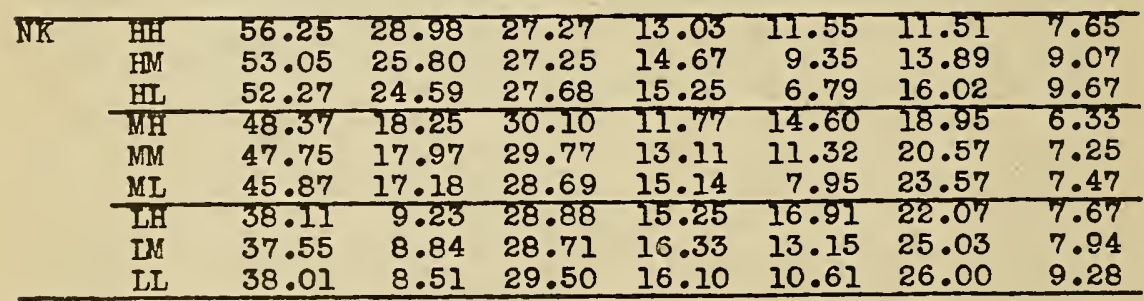

\begin{tabular}{lrrrrrrrr} 
PK HH & 42.95 & 15.12 & 27.23 & 17.75 & 14.41 & 11.87 & 1.02 \\
HM & 41.07 & 14.15 & 26.92 & 20.18 & 11.27 & 19.12 & 8.36 \\
HL & 42.32 & 15.89 & 26.43 & 20.10 & 7.87 & 21.13 & 8.58 \\
\hline$M H$ & 45.91 & 17.29 & 28.62 & 13.95 & 15.43 & 17.10 & 7.61 \\
$M M$ & 46.35 & 18.26 & 28.10 & 14.62 & 11.80 & 19.25 & 7.97 \\
$M L$ & 44.54 & 16.36 & 28.18 & 16.43 & 7.66 & 22.20 & 9.17 \\
\hline LH & 53.85 & 23.44 & 30.41 & 8.34 & 13.22 & 17.51 & 7.02 \\
IM & 50.92 & 20.21 & 30.72 & 9.28 & 10.74 & 21.12 & 7.93 \\
LL & 49.29 & 18.02 & 31.26 & 9.97 & 9.83 & 22.25 & 8.67 \\
\hline
\end{tabular}


Table 4b. The N, P, K, Ca and Mg in the Equivalents Units In the Trunks. Averages for Primary Treatments and their Interactions

\begin{tabular}{|c|c|c|c|c|c|c|c|c|}
\hline 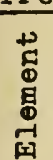 & $\begin{array}{l}\dot{0} \\
0 \\
0\end{array}$ & $\operatorname{TotaI}_{\mathrm{N}}$ & $\underset{N}{\text { Soluble }}$ & $\underset{N}{\operatorname{In}-}$ & $P$ & $\mathrm{~K}$ & $\mathrm{Ca}$ & $\mathrm{Mg}$ \\
\hline
\end{tabular}

\begin{tabular}{|c|c|c|c|c|c|c|c|c|}
\hline$\overline{\mathrm{NCa}}$ & $\begin{array}{l}\mathrm{HH} \\
\mathrm{MH} \\
\mathrm{LH} \\
\mathrm{HM} \\
\mathrm{MM} \\
\mathrm{LM}\end{array}$ & $\begin{array}{l}53.27 \\
46.03 \\
35.67 \\
54.45 \\
48.61 \\
40.11\end{array}$ & $\begin{array}{r}27.73 \\
17.23 \\
7.48 \\
25.18 \\
18.38 \\
10.24\end{array}$ & $\begin{array}{l}25.54 \\
28.81 \\
28.20 \\
29.26 \\
30.24 \\
29.86\end{array}$ & $\begin{array}{l}14.68 \\
11.86 \\
14.62 \\
13.93 \\
14.81 \\
17.17\end{array}$ & $\begin{array}{r}8.44 \\
10.83 \\
13.71 \\
10.02 \\
11.75 \\
13.40\end{array}$ & $\begin{array}{l}16.47 \\
25.26 \\
28.27 \\
11.14 \\
16.80 \\
20.47 \\
\end{array}$ & $\begin{array}{r}7.13 \\
6.01 \\
7.73 \\
10.46 \\
8.02 \\
8.86 \\
\end{array}$ \\
\hline PCa & $\begin{array}{l}\text { HH } \\
M H \\
I H \\
M M \\
M M\end{array}$ & $\begin{array}{l}40.81 \\
44.43 \\
49.74 \\
43.42 \\
46.78 \\
52.97\end{array}$ & $\begin{array}{l}14.56 \\
17.54 \\
20.34 \\
15.95 \\
17.07 \\
20.78\end{array}$ & $\begin{array}{l}26.25 \\
26.89 \\
29.40 \\
27.46 \\
29.71 \\
32.19\end{array}$ & $\begin{array}{r}18.31 \\
14.23 \\
8.63 \\
20.37 \\
15.77 \\
9.77\end{array}$ & $\begin{array}{l}11.14 \\
11.12 \\
10.73 \\
11.23 \\
12.14 \\
11.80\end{array}$ & $\begin{array}{l}22.80 \\
23.18 \\
24.01 \\
15.95 \\
15.85 \\
16.61\end{array}$ & $\begin{array}{l}6.94 \\
7.04 \\
6.90 \\
9.03 \\
9.46 \\
8.85\end{array}$ \\
\hline
\end{tabular}

\begin{tabular}{lrrrrrrrr}
\hline KCa & HH & 45.42 & 17.97 & 27.44 & 13.27 & 13.13 & 20.90 & 6.69 \\
& $M H$ & 44.26 & 16.66 & 27.60 & 13.81 & 11.15 & 23.87 & 6.90 \\
& IH & 45.30 & 17.80 & 27.50 & 14.09 & 8.10 & 25.22 & 7.29 \\
\hline HM & 49.73 & 19.67 & 30.06 & 13.43 & 14.98 & 14.13 & 7.75 \\
$M M$ & 47.97 & 18.42 & 29.55 & 15.57 & 11.39 & 15.79 & 9.28 \\
& IM & 45.47 & 15.72 & 29.75 & 16.91 & 8.80 & 18.49 & 10.32 \\
\hline
\end{tabular}

\begin{tabular}{lrrrrrrr} 
NPCa HIHH & 46.58 & 22.57 & 24.01 & 20.29 & 8.53 & 16.92 & 7.68 \\
HMH & 51.95 & 27.76 & 24.19 & 16.02 & 9.57 & 15.55 & 6.92 \\
HIH & 61.29 & 32.86 & 28.42 & 7.75 & 7.22 & 16.95 & 6.80 \\
\hline MHH & 40.51 & 12.71 & 27.80 & 16.53 & 11.16 & 25.76 & 6.05 \\
MMH & 45.84 & 17.45 & 28.39 & 11.45 & 10.82 & 25.39 & 6.50 \\
MLH & 51.76 & 21.52 & 30.24 & 7.62 & 10.52 & 24.62 & 5.50 \\
\hline LHH & 35.35 & 8.39 & 26.96 & 18.12 & 13.72 & 25.72 & 7.09 \\
IMH & 35.50 & 7.41 & 28.09 & 15.24 & 12.96 & 28.60 & 7.71 \\
LLH & 36.17 & 6.63 & 29.54 & 10.51 & 14.46 & 30.48 & 8.39 \\
\hline & & & & & & & \\
\hline HHM & 50.02 & 23.41 & 26.61 & 19.64 & 9.18 & 10.38 & 10.19 \\
HMM & 53.19 & 23.98 & 29.22 & 14.28 & 10.83 & 10.67 & 11.03 \\
HMM & 60.12 & 28.17 & 31.96 & 7.86 & 9.47 & 12.39 & 10.16 \\
\hline MHM & 42.15 & 13.99 & 28.16 & 19.47 & 11.22 & 18.47 & 8.70 \\
MMM & 47.28 & 17.07 & 30.21 & 15.38 & 13.25 & 15.75 & 8.35 \\
MLM & 56.42 & 24.08 & 32.34 & 9.60 & 10.77 & 16.19 & 7.02 \\
\hline LHM & 38.08 & 10.47 & 27.61 & 22.02 & 12.70 & 19.00 & 8.21 \\
IMM & 39.86 & 10.16 & 29.70 & 17.64 & 12.35 & 21.14 & 9.01 \\
LIM & 42.38 & 10.10 & 32.28 & 11.84 & 15.15 & 21.26 & 9.37 \\
\hline
\end{tabular}


Table 4c. The $N, P, K, C a$ and $M g$ in the Equivalents Units in the Trunks. Averages for Primary Treatments and their Interactions

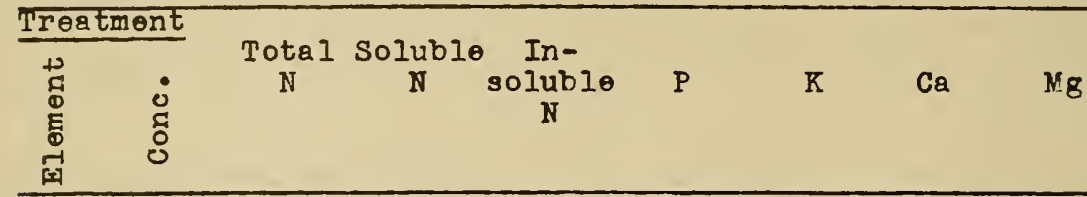

\begin{tabular}{|c|c|c|c|c|c|c|c|c|}
\hline NKCa & $\begin{array}{l}\text { HHH } \\
\text { HMH } \\
\text { HLH } \\
\text { MHHH } \\
\text { MMH } \\
\text { MLH } \\
\text { LHH } \\
\text { IMH } \\
\text { LLH }\end{array}$ & $\begin{array}{l}52.81 \\
51.94 \\
55.06 \\
47.74 \\
45.80 \\
44.57 \\
35.70 \\
35.04 \\
36.28 \\
\end{array}$ & $\begin{array}{l}27.03 \\
26.23 \\
29.93 \\
18.90 \\
16.46 \\
16.32 \\
7.99 \\
7.28 \\
7.16 \\
\end{array}$ & $\begin{array}{l}25.78 \\
25.70 \\
25.14 \\
28.84 \\
29.34 \\
28.24 \\
27.71 \\
27.76 \\
29.12 \\
\end{array}$ & $\begin{array}{l}14.24 \\
15.07 \\
14.74 \\
11.44 \\
11.39 \\
12.77 \\
14.13 \\
14.98 \\
14.75 \\
\end{array}$ & $\begin{array}{r}11.23 \\
8.55 \\
5.53 \\
13.57 \\
11.09 \\
7.85 \\
16.39 \\
13.82 \\
10.92 \\
\end{array}$ & $\begin{array}{l}14.55 \\
17.05 \\
17.82 \\
21.84 \\
25.55 \\
28.38 \\
26.30 \\
29.03 \\
29.47 \\
\end{array}$ & $\begin{array}{l}7.17 \\
7.39 \\
6.84 \\
5.42 \\
6.17 \\
6.44 \\
7.47 \\
7.13 \\
8.59 \\
\end{array}$ \\
\hline & 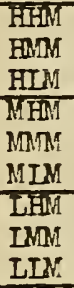 & $\begin{array}{l}59.70 \\
54.17 \\
49.48 \\
48.98 \\
49.70 \\
47.17 \\
40.51 \\
40.06 \\
39.75\end{array}$ & $\begin{array}{r}30.93 \\
25.37 \\
19.25 \\
17.61 \\
19.49 \\
18.04 \\
10.46 \\
10.40 \\
9.87 \\
\end{array}$ & $\begin{array}{l}28.76 \\
28.80 \\
30.23 \\
31.31 \\
30.21 \\
29.13 \\
30.06 \\
29.65 \\
29.88 \\
\end{array}$ & $\begin{array}{r}11.83 \\
-14.20 \\
15.76 \\
12.10 \\
14.83 \\
17.52 \\
16.37 \\
17.68 \\
17.45\end{array}$ & $\begin{array}{r}11.88 \\
10.14 \\
8.06 \\
15.63 \\
11.56 \\
8.06 \\
11.43 \\
12.48 \\
10.30 \\
\end{array}$ & $\begin{array}{r}8.48 \\
10.74 \\
14.21 \\
16.06 \\
15.60 \\
18.75 \\
17.84 \\
21.04 \\
22.52 \\
\end{array}$ & $\begin{array}{r}8.13 \\
10.76 \\
12.49 \\
7.24 \\
8.32 \\
8.50 \\
7.87 \\
8.76 \\
9.97 \\
\end{array}$ \\
\hline
\end{tabular}

\begin{tabular}{lrrrrrrrr}
\hline PKCa & HHH & 40.89 & 14.41 & 26.48 & 17.65 & 14.27 & 20.76 & 6.44 \\
HMH & 39.77 & 12.84 & 26.92 & 18.68 & 11.54 & 23.04 & 6.98 \\
HLH & 41.78 & 16.42 & 25.35 & 18.61 & 7.60 & 24.61 & 7.41 \\
\hline MHH & 43.93 & 17.25 & 26.68 & 13.29 & 14.57 & 20.87 & 6.75 \\
MMH & 44.08 & 16.94 & 27.14 & 14.21 & 11.39 & 23.21 & 7.12 \\
MLH & 45.28 & 18.43 & 26.85 & 14.61 & 7.39 & 25.47 & 7.26 \\
\hline IHH & 51.43 & 22.27 & 29.16 & 8.27 & 12.36 & 21.06 & 6.88 \\
IMH & 48.93 & 20.19 & 28.74 & 8.56 & 10.53 & 25.38 & 6.61 \\
ILH & 48.85 & 18.55 & 30.30 & 9.04 & 9.31 & 25.60 & 7.21 \\
\hline & & & & & & & \\
\hline HHM & 45.02 & 17.04 & 27.98 & 17.85 & 14.56 & 14.98 & 7.61 \\
HMM & 42.37 & 15.46 & 26.91 & 21.68 & 11.01 & 15.21 & 9.74 \\
HIM & 42.86 & 15.36 & 27.50 & 21.59 & 8.13 & 17.66 & 9.75 \\
\hline MHM & 47.90 & 17.34 & 30.56 & 14.02 & 16.29 & 13.33 & 8.47 \\
MMM & 48.63 & 19.58 & 29.05 & 15.03 & 12.21 & 15.30 & 8.83 \\
$M L M$ & 43.81 & 14.29 & 29.52 & 18.24 & 7.93 & 18.93 & 11.09 \\
\hline LHM & 56.27 & 24.62 & 31.65 & 8.42 & 14.08 & 14.07 & 7.16 \\
IMM & 52.92 & 20.23 & 32.69 & 9.99 & 10.96 & 16.87 & 9.26 \\
IIM & 49.73 & 17.50 & 32.23 & 10.90 & 10.35 & 18.89 & 10.13 \\
\hline
\end{tabular}


Table 5a. The $N, P, K, C a$ and $M g$ in the Equivalents Units in the Leaves. Averages for Primary Treatments and their Interactions

\begin{tabular}{|c|c|c|c|c|c|c|c|}
\hline Tr & ent & & & & & & \\
\hline 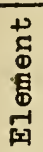 & $\begin{array}{l}\dot{0} \\
\text { : } \\
0\end{array}$ & $\underset{N}{\text { Total }}$ & $\underset{N}{\text { Soluble }}$ & $\operatorname{soluble}_{\mathrm{N}}^{\text {In- }}$ & $P$ & $\mathrm{~K}$ & $\mathrm{Ca}$ \\
\hline
\end{tabular}

\begin{tabular}{|c|c|c|c|c|c|c|c|c|}
\hline $\mathbf{N}$ & $\begin{array}{l}\mathrm{H} \\
\mathrm{M} \\
\mathrm{L}\end{array}$ & $\begin{array}{r}52.95 \\
53.49 \\
37.54 \\
\end{array}$ & $\begin{array}{l}6.24 \\
4.95 \\
3.06 \\
\end{array}$ & $\begin{array}{l}46.11 \\
48.55 \\
34.49 \\
\end{array}$ & $\begin{array}{l}5.23 \\
6.07 \\
9.16 \\
\end{array}$ & $\begin{array}{l}11.19 \\
14.61 \\
18.58 \\
\end{array}$ & $\begin{array}{l}11.36 \\
15.45 \\
21.56 \\
\end{array}$ & $\begin{array}{l}19.27 \\
10.37 \\
13.16 \\
\end{array}$ \\
\hline$P$ & $\begin{array}{c}\mathrm{H} \\
\mathrm{M} \\
\mathrm{L} \\
\end{array}$ & $\begin{array}{l}47.45 \\
48.43 \\
48.10 \\
\end{array}$ & $\begin{array}{l}4.68 \\
4.81 \\
4.76 \\
\end{array}$ & $\begin{array}{l}42.18 \\
43.62 \\
43.34 \\
\end{array}$ & $\begin{array}{r}10.67 \\
6.66 \\
3.12 \\
\end{array}$ & $\begin{array}{l}14.19 \\
14.65 \\
15.55 \\
\end{array}$ & $\begin{array}{l}14.92 \\
15.81 \\
17.64 \\
\end{array}$ & $\begin{array}{l}12.74 \\
14.44 \\
15.60 \\
\end{array}$ \\
\hline$\Lambda$ & $\begin{array}{l}\mathrm{H} \\
\mathrm{M} \\
\mathrm{L}\end{array}$ & $\begin{array}{l}47.63 \\
48.51 \\
47.84\end{array}$ & $\begin{array}{l}4.60 \\
4.72 \\
4.93\end{array}$ & $\begin{array}{l}43.03 \\
43.80 \\
42.92\end{array}$ & $\begin{array}{l}7.01 \\
6.16 \\
7.28\end{array}$ & $\begin{array}{r}22.12 \\
14.36 \\
7.90\end{array}$ & $\begin{array}{l}12.48 \\
16.98 \\
18.91\end{array}$ & $\begin{array}{l}10.76 \\
13.98 \\
18.06\end{array}$ \\
\hline
\end{tabular}

$\begin{array}{llllllll}\text { Ca H } & 47.78 & 4.94 & 42.84 & 6.18 & 14.14 & 20.13 & 11.17\end{array}$

\begin{tabular}{|c|c|c|c|c|c|c|c|c|}
\hline$\sqrt{\mathrm{P}}$ & $\begin{array}{l}\text { HH } \\
\mathrm{HM} \\
\mathrm{HL} \\
\mathrm{MH} \\
\mathrm{MM} \\
\mathrm{ML} \\
\mathrm{LH} \\
\mathrm{LM} \\
\mathrm{LI}\end{array}$ & $\begin{array}{l}53.29 \\
52.89 \\
52.66 \\
52.65 \\
55.78 \\
52.05 \\
36.42 \\
36.63 \\
39.59 \\
\end{array}$ & $\begin{array}{l}6.02 \\
5.72 \\
6.99 \\
4.82 \\
5.67 \\
4.35 \\
3.20 \\
3.04 \\
2.94 \\
\end{array}$ & $\begin{array}{l}44.28 \\
47.17 \\
45.67 \\
47.83 \\
50.11 \\
47.70 \\
33.22 \\
33.58 \\
36.65 \\
\end{array}$ & $\begin{array}{r}8.04 \\
5.09 \\
2.55 \\
10.11 \\
5.10 \\
3.01 \\
13.81 \\
9.79 \\
3.81 \\
\end{array}$ & $\begin{array}{l}11.26 \\
11.44 \\
10.86 \\
13.99 \\
14.40 \\
15.46 \\
17.32 \\
18.11 \\
20.31 \\
\end{array}$ & $\begin{array}{l}10.28 \\
10.79 \\
13.01 \\
14.20 \\
14.32 \\
17.83 \\
20.28 \\
22.32 \\
22.07 \\
\end{array}$ & $\begin{array}{r}17.12 \\
19.78 \\
20.92 \\
9.01 \\
10.40 \\
11.65 \\
12.11 \\
13.16 \\
14.22 \\
\end{array}$ \\
\hline $\mathrm{NK}$ & $\begin{array}{l}\text { HIH } \\
\mathrm{HM} \\
\mathrm{HL} \\
\mathrm{MH} \\
\mathrm{MM} \\
\mathrm{ML} \\
\mathrm{LH} \\
\mathrm{LM} \\
\mathrm{LL}\end{array}$ & $\begin{array}{l}54.08 \\
54.44 \\
50.32 \\
53.52 \\
52.79 \\
54.17 \\
35.28 \\
38.32 \\
39.04 \\
\end{array}$ & $\begin{array}{l}6.23 \\
6.60 \\
5.90 \\
4.44 \\
4.76 \\
5.62 \\
3.10 \\
2.80 \\
3.28 \\
\end{array}$ & $\begin{array}{l}47.85 \\
47.84 \\
44.43 \\
49.06 \\
48.03 \\
48.55 \\
32.18 \\
35.52 \\
35.76 \\
\end{array}$ & $\begin{array}{r}4.94 \\
5.23 \\
5.52 \\
4.87 \\
5.35 \\
7.99 \\
11.23 \\
7.90 \\
8.34 \\
\end{array}$ & $\begin{array}{r}17.72 \\
11.46 \\
4.39 \\
22.95 \\
14.65 \\
6.24 \\
25.69 \\
16.98 \\
13.08 \\
\end{array}$ & $\begin{array}{r}9.30 \\
11.08 \\
13.71 \\
11.03 \\
16.75 \\
18.57 \\
11.11 \\
23.11 \\
24.45 \\
\end{array}$ & $\begin{array}{r}13.96 \\
17.81 \\
26.06 \\
1.64 \\
10.46 \\
13.03 \\
10.69 \\
13.69 \\
15.11 \\
\end{array}$ \\
\hline$\overline{\mathrm{PK}}$ & $\begin{array}{l}\text { HH } \\
\mathrm{HM} \\
\mathrm{HL} \\
\mathrm{MH} \\
\mathrm{MM} \\
\mathrm{MI} \\
\mathrm{LH} \\
\mathrm{LM} \\
\mathrm{LL}\end{array}$ & $\begin{array}{l}46.74 \\
47.88 \\
47.74 \\
47.51 \\
48.54 \\
49.24 \\
48.64 \\
49.12 \\
46.55\end{array}$ & $\begin{array}{l}4.34 \\
4.14 \\
5.55 \\
4.66 \\
4.44 \\
5.34 \\
4.80 \\
5.58 \\
3.90\end{array}$ & $\begin{array}{l}42.39 \\
43.75 \\
42.20 \\
42.85 \\
44.11 \\
43.90 \\
43.84 \\
43.54 \\
42.64\end{array}$ & $\begin{array}{r}10.93 \\
9.33 \\
11.77 \\
1.12 \\
6.06 \\
6.80 \\
2.99 \\
3.09 \\
3.29\end{array}$ & $\begin{array}{r}21.24 \\
14.46 \\
6.84 \\
22.36 \\
14.39 \\
7.21 \\
22.16 \\
14.22 \\
9.67\end{array}$ & $\begin{array}{l}11.61 \\
15.94 \\
17.21 \\
12.38 \\
16.60 \\
18.46 \\
13.45 \\
18.41 \\
21.05\end{array}$ & $\begin{array}{r}9.49 \\
12.38 \\
16.44 \\
10.63 \\
14.41 \\
18.29 \\
12.17 \\
15.16 \\
19.46\end{array}$ \\
\hline
\end{tabular}


Tablo 5b. The N, $P, K, C a$ and $M g$ in the Equivalents Units in the Leaves. Averages for Primary Treatments and their Interactions

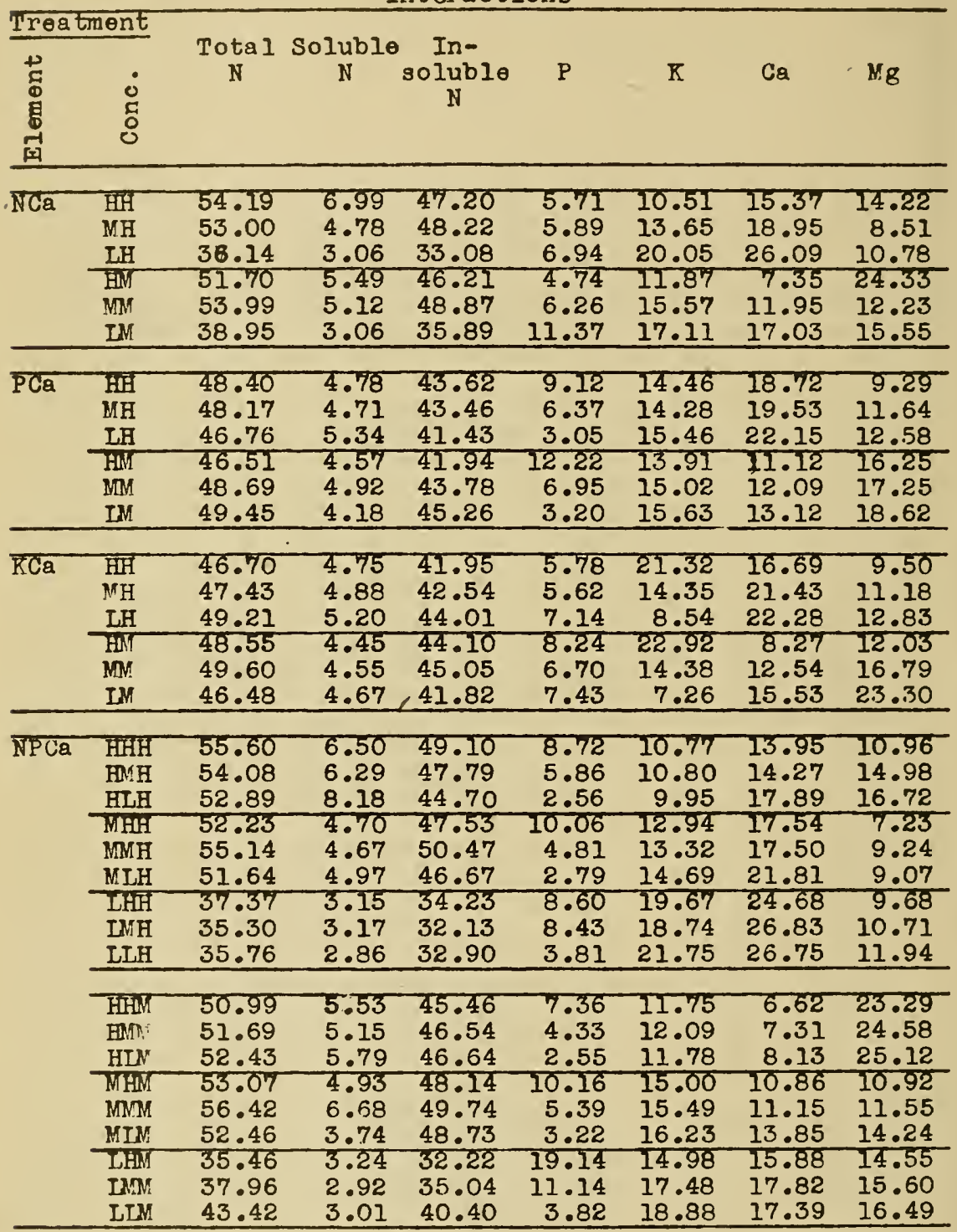


Table 5c. The $\mathrm{N}, \mathrm{P}, \mathrm{K}, \mathrm{Ca}$ and $\mathrm{Mg}$ in the Equivalents Units in the Leaves. Averages for Primary Treatments and their Interactions

\begin{tabular}{|c|c|c|c|c|c|c|c|c|}
\hline 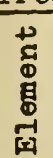 & $\begin{array}{l}\dot{0} \\
\text { ¿ } \\
0\end{array}$ & $\underset{N}{\text { Tota } I}$ & Soluble & $\underset{\mathrm{N}}{\mathrm{In}-}$ & P & $\mathrm{K}$ & $\mathrm{Ca}$ & $\mathrm{Mg}$ \\
\hline
\end{tabular}

\begin{tabular}{|c|c|c|c|c|c|c|c|c|}
\hline \multirow[t]{2}{*}{ NKCa } & $\begin{array}{l}\text { HiHH } \\
\text { HMH } \\
\text { HLH } \\
\text { MEHH } \\
\text { MMH } \\
\text { MLH } \\
\text { LHH } \\
\text { LMH } \\
\text { LLH }\end{array}$ & $\begin{array}{l}52.46 \\
54.07 \\
56.04 \\
53.49 \\
51.61 \\
53.90 \\
34.16 \\
36.60 \\
37.67 \\
\end{array}$ & $\begin{array}{l}6.30 \\
7.05 \\
7.63 \\
4.44 \\
4.83 \\
5.04 \\
3.49 \\
2.77 \\
2.92 \\
\end{array}$ & $\begin{array}{l}46.17 \\
47.01 \\
48.42 \\
49.02 \\
46.78 \\
48.87 \\
30.67 \\
33.83 \\
34.75 \\
\end{array}$ & $\begin{array}{l}4.94 \\
5.53 \\
6.67 \\
4.61 \\
5.16 \\
7.90 \\
7.81 \\
6.18 \\
6.84 \\
\end{array}$ & $\begin{array}{r}16.64 \\
10.94 \\
3.94 \\
21.34 \\
13.82 \\
5.80 \\
25.98 \\
18.29 \\
15.89 \\
\end{array}$ & $\begin{array}{l}13.66 \\
15.51 \\
16.95 \\
13.87 \\
20.82 \\
22.16 \\
22.55 \\
27.87 \\
27.75 \\
\end{array}$ & $\begin{array}{r}12.29 \\
13.97 \\
16.40 \\
6.69 \\
8.59 \\
10.25 \\
9.50 \\
10.97 \\
11.85 \\
\end{array}$ \\
\hline & $\begin{array}{l}\text { HHM } \\
\text { HNM } \\
\text { HLM } \\
\text { MHIN } \\
\text { MMM } \\
\text { MLM } \\
\text { LHM } \\
\text { LMM } \\
\text { LIM }\end{array}$ & $\begin{array}{l}55.70 \\
54.81 \\
44.60 \\
53.56 \\
53.96 \\
54.45 \\
36.40 \\
40.04 \\
40.40\end{array}$ & $\begin{array}{l}6.17 \\
6.14 \\
4.17 \\
4.47 \\
4.68 \\
6.21 \\
2.42 \\
2.83 \\
3.63\end{array}$ & $\begin{array}{l}49.53 \\
48.67 \\
40.44 \\
49.09 \\
49.28 \\
48.24 \\
33.68 \\
37.21 \\
36.77\end{array}$ & $\begin{array}{r}4.94 \\
4.92 \\
4.37 \\
5.14 \\
5.55 \\
8.08 \\
14.65 \\
9.62 \\
9.83\end{array}$ & $\begin{array}{r}18.80 \\
11.97 \\
4.85 \\
24.55 \\
15.49 \\
6.68 \\
25.40 \\
15.68 \\
10.26\end{array}$ & $\begin{array}{r}4.93 \\
6.66 \\
10.47 \\
8.19 \\
12.69 \\
14.99 \\
11.68 \\
18.26 \\
21.15\end{array}$ & $\begin{array}{r}15.62 \\
21.64 \\
35.72 \\
8.58 \\
12.32 \\
15.81 \\
11.88 \\
16.41 \\
18.36\end{array}$ \\
\hline \multirow[t]{2}{*}{ PKCa } & $\begin{array}{l}\text { HHH } \\
\text { HM!H } \\
\text { HLH } \\
\text { MHH } \\
\text { MMH } \\
\text { MLH } \\
\text { LHH } \\
\text { LMH } \\
\text { LLH } \\
\end{array}$ & $\begin{array}{l}47.82 \\
46.92 \\
50.47 \\
46.56 \\
47.69 \\
50.27 \\
45.14 \\
47.67 \\
46.88 \\
\end{array}$ & $\begin{array}{l}4.52 \\
3.80 \\
6.03 \\
4.19 \\
4.30 \\
5.05 \\
4.95 \\
6.56 \\
4.50 \\
\end{array}$ & $\begin{array}{l}43.30 \\
43.12 \\
44.43 \\
41.71 \\
43.40 \\
45.22 \\
40.79 \\
41.11 \\
42.38 \\
\end{array}$ & $\begin{array}{r}7.19 \\
8.35 \\
11.23 \\
6.87 \\
5.45 \\
6.78 \\
2.70 \\
3.06 \\
3.40 \\
\end{array}$ & $\begin{array}{r}21.04 \\
14.90 \\
7.45 \\
21.22 \\
14.02 \\
7.62 \\
21.70 \\
14.12 \\
10.57 \\
\end{array}$ & $\begin{array}{l}15.43 \\
20.57 \\
20.17 \\
16.12 \\
20.69 \\
21.79 \\
18.53 \\
23.03 \\
24.88 \\
\end{array}$ & $\begin{array}{r}7.92 \\
9.27 \\
10.68 \\
9.24 \\
12.15 \\
13.54 \\
11.33 \\
12.12 \\
14.28 \\
\end{array}$ \\
\hline & $\begin{array}{l}\text { HWM } \\
\text { HMM } \\
\text { HIM } \\
\text { MHM } \\
\text { MMM } \\
\text { MLM } \\
\text { LHIY } \\
\text { IMM } \\
\text { LIM }\end{array}$ & $\begin{array}{l}45.66 \\
48.85 \\
45.02 \\
48.47 \\
49.39 \\
48.22 \\
51.53 \\
50.57 \\
46.21\end{array}$ & $\begin{array}{l}4.17 \\
4.47 \\
5.06 \\
4.53 \\
4.58 \\
5.64 \\
4.65 \\
4.59 \\
3.30\end{array}$ & $\begin{array}{l}41.49 \\
44.37 \\
39.96 \\
43.93 \\
44.82 \\
42.58 \\
46.88 \\
45.97 \\
42.91\end{array}$ & $\begin{array}{r}14.07 \\
10.30 \\
12.30 \\
7.38 \\
6.67 \\
6.81 \\
3.29 \\
3.13 \\
3.18\end{array}$ & $\begin{array}{r}21.44 \\
14.06 \\
6.24 \\
23.50 \\
14.75 \\
6.80 \\
23.81 \\
14.33 \\
8.75\end{array}$ & $\begin{array}{r}7.79 \\
11.31 \\
14.26 \\
8.64 \\
12.52 \\
15.12 \\
8.31 \\
13.78 \\
17.22\end{array}$ & $\begin{array}{l}11.05 \\
15.50 \\
22.20 \\
12.02 \\
16.67 \\
23.05 \\
13.01 \\
18.20 \\
24.64\end{array}$ \\
\hline
\end{tabular}




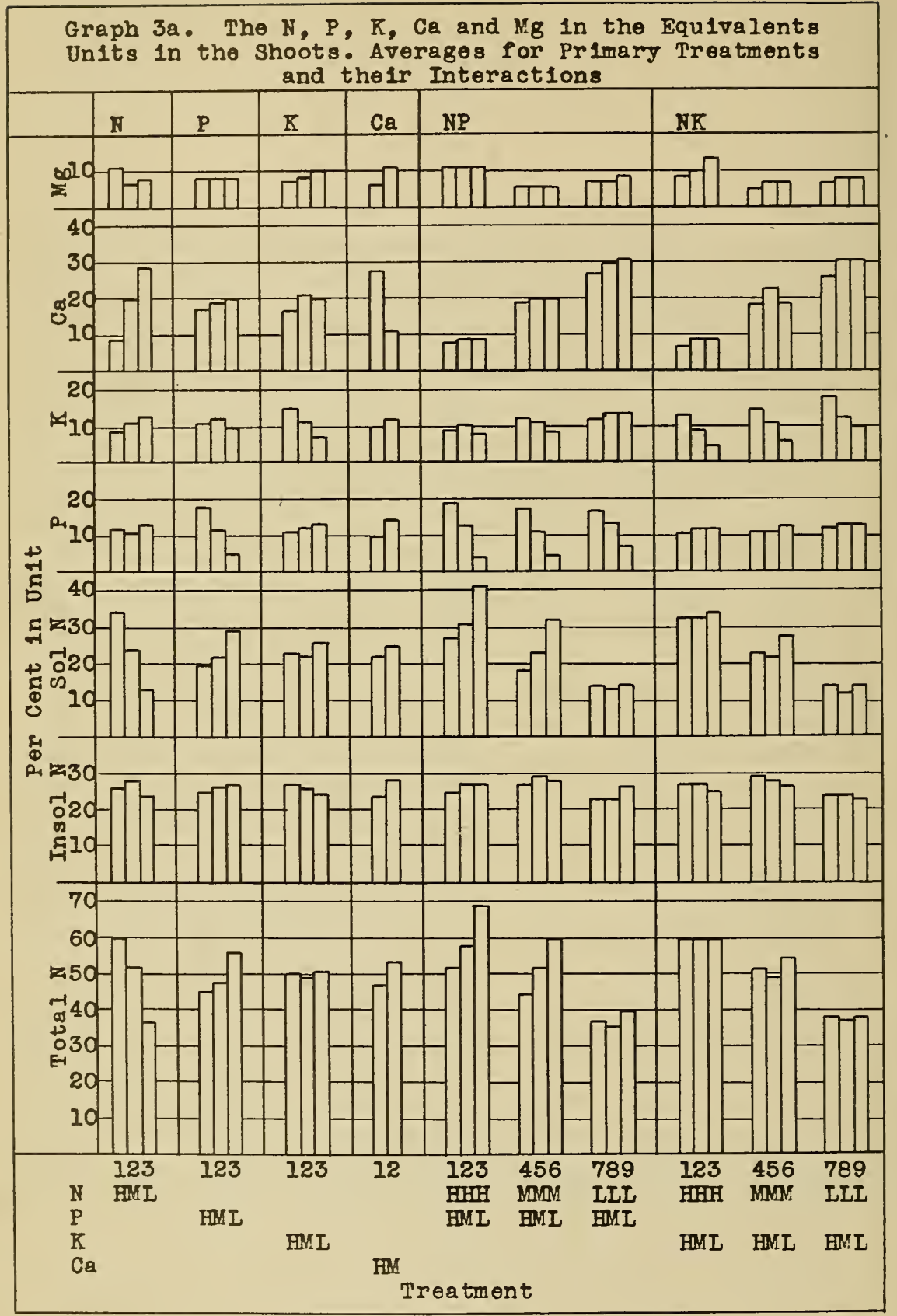




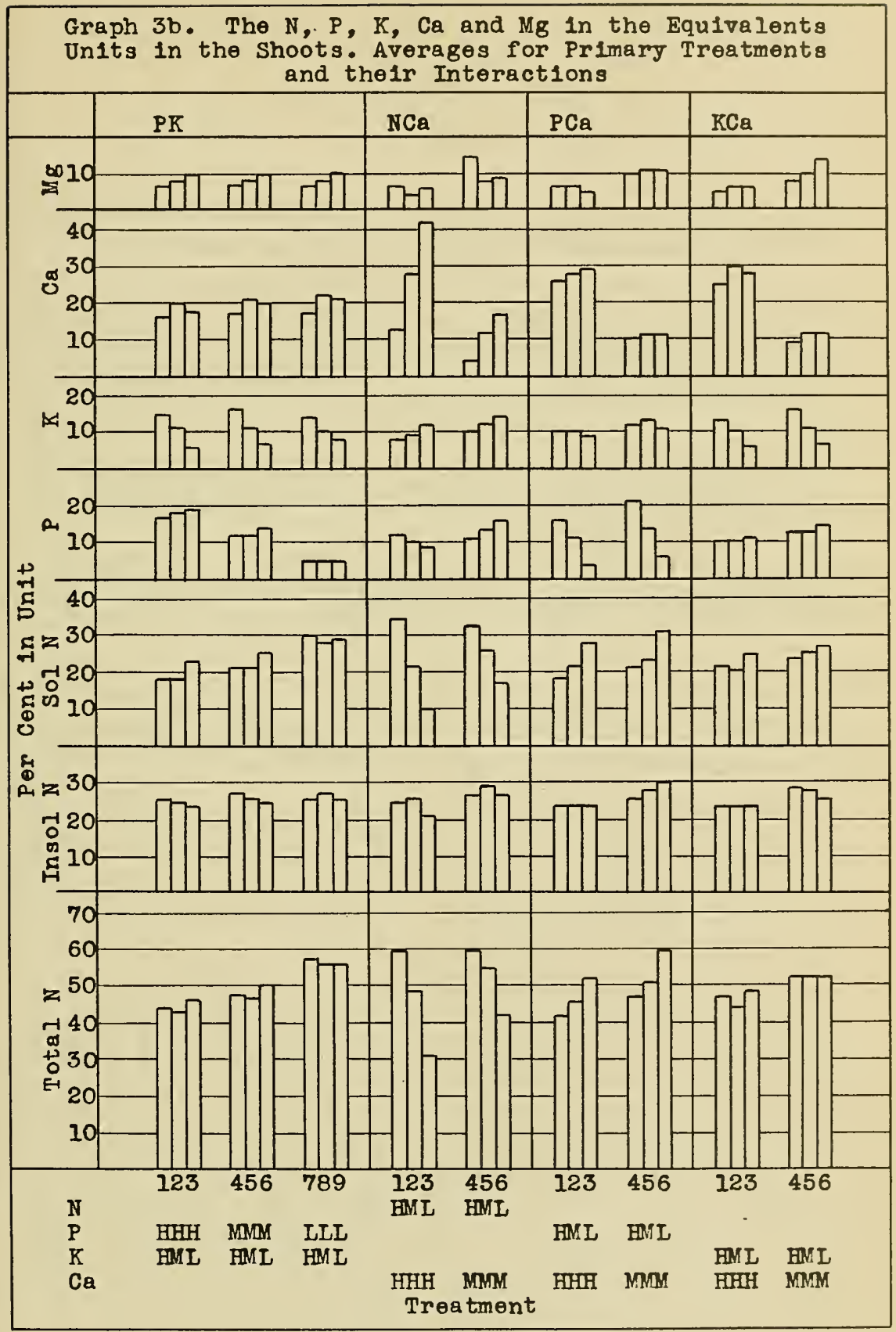




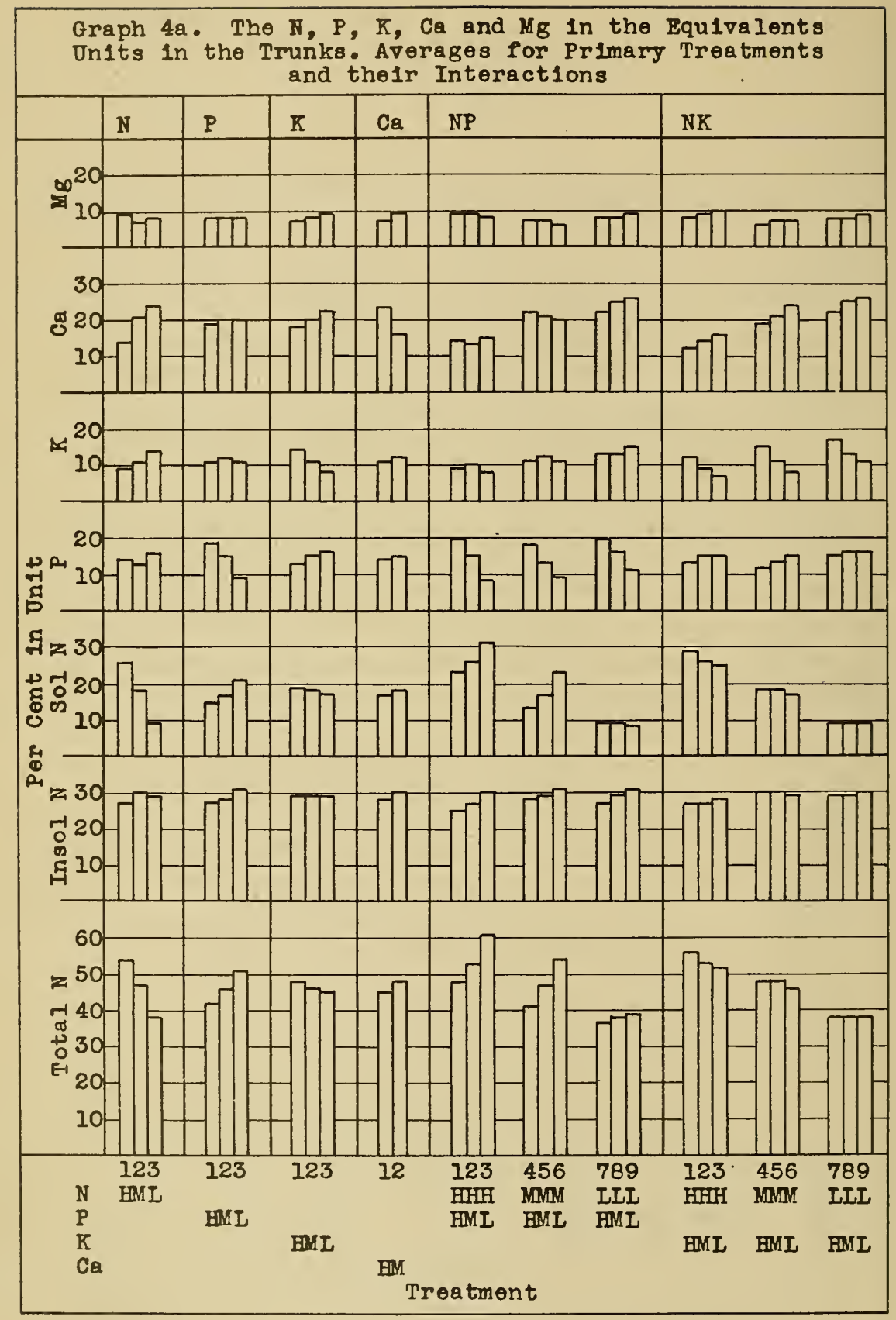


Graph 4b. The N, P, K, Ca and $\mathrm{Mg}$ in the Equivalents

Units in the Trunks. Averages for Primary Treatments and their Interactions

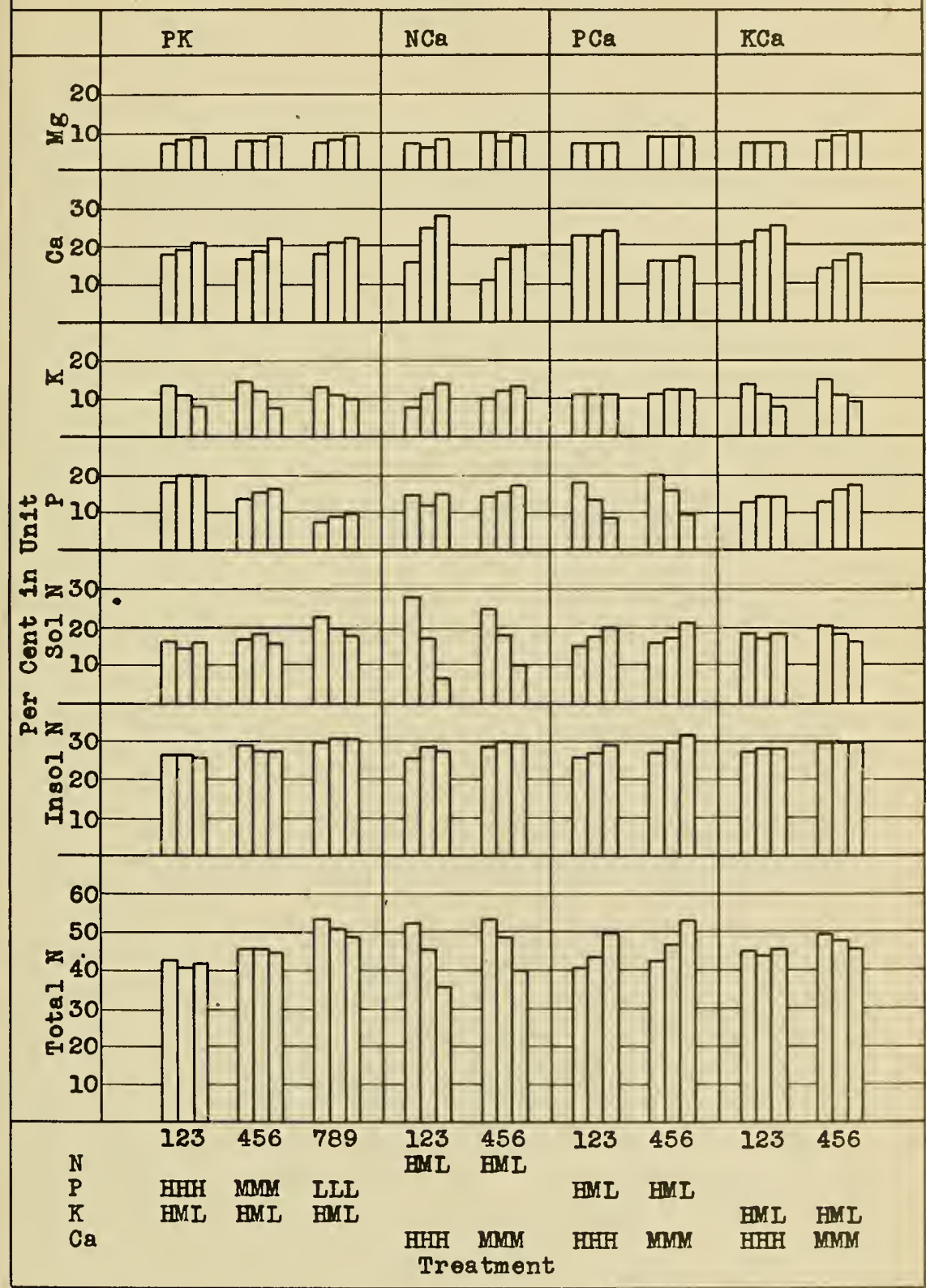


Graph 5a. The N, $\mathrm{P}, \mathrm{K}, \mathrm{Ca}$ and $\mathrm{Mg}$ in the Equivalents Units in the Leaves. Averages for Primary Treatments and their Interactions

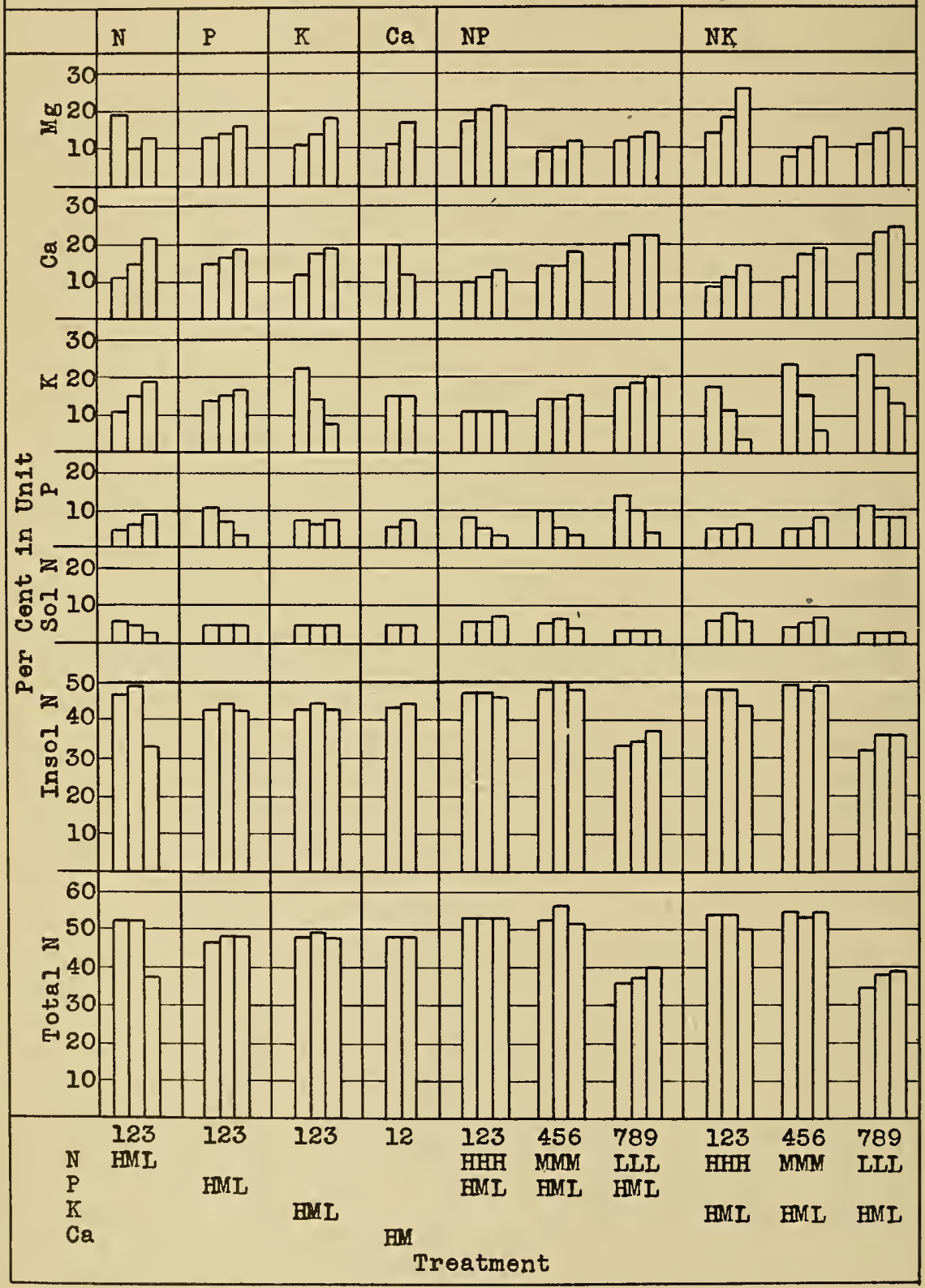


Graph 5b. The $\mathrm{N}, \mathrm{P}, \mathrm{K}, \mathrm{Ca}$ and $\mathrm{Mg}$ in the Equivalents Un1ts in the Leaves. Averages for Primary Treatments and their Interactions

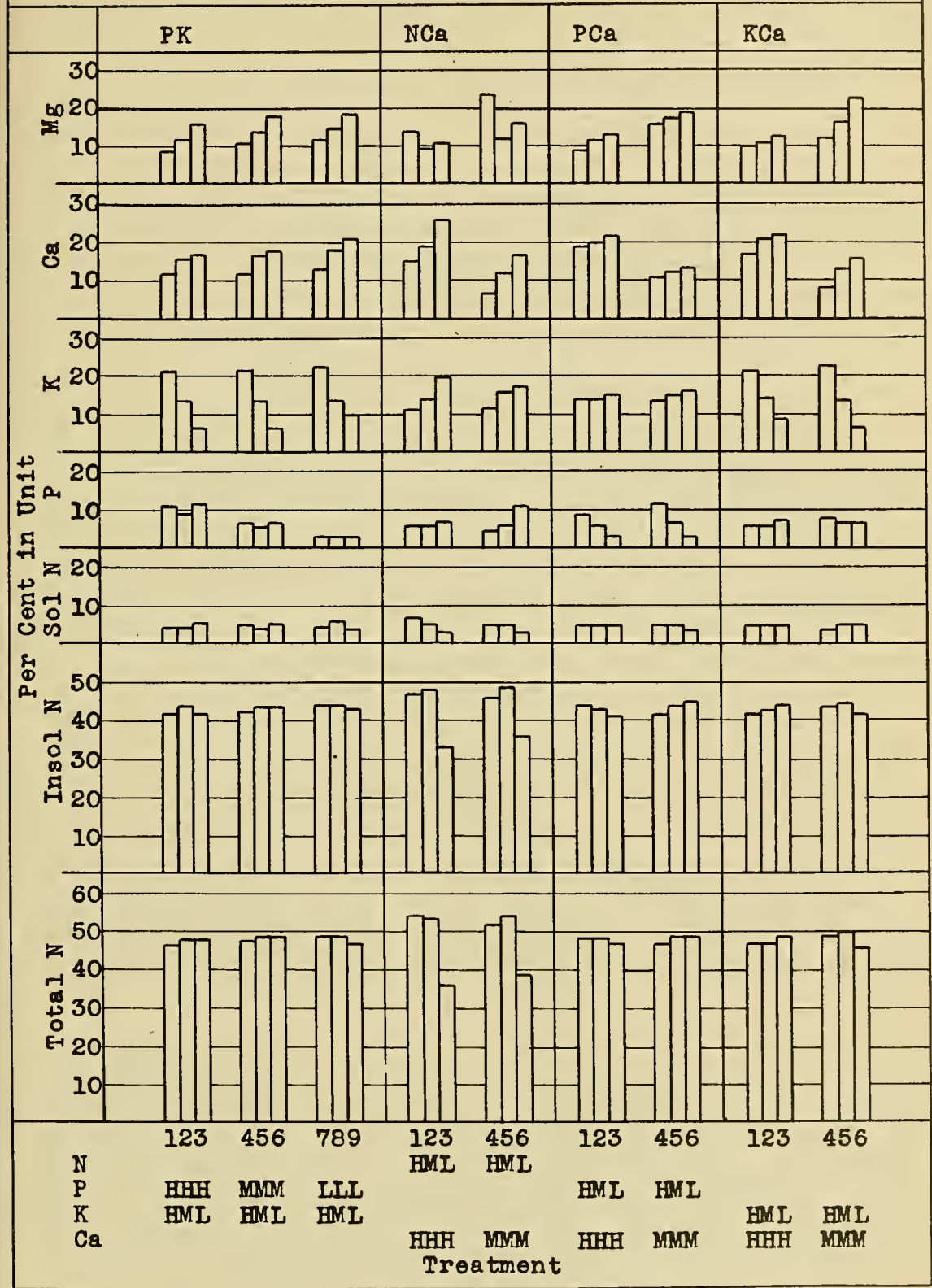


$P$ in the leaves was also lower than it was in the shoots and trunks; the amount of $P$ in the trunks was slightly higher than in the shoots. Both $K$ and Mg were higher in the leaves. With respect to the amount of $\mathrm{Ca}$, differences between the parts of the trees were dependent in part on the supplies of the elements. Thus Ca was usually higher in the trunks than in the leaves and shoots when the supply of Ca was medium, but greater in the shoots than in the trunks and leaves when Ca was high (Tables 3 to $5, \mathrm{Ca}$ ). Also, it usually was greatest in the trunks and least in the shoots when the $N$ supply was high, greatest in the trunks and least in the leaves when $\mathrm{N}$ was medium, and greatest in the shoots and least in the leaves when $\mathrm{N}$ was low (Tables 3 to $5, N$ ).

\section{The Relations between Elements}

The fundamental nature of the relations between the elements is indicated by the effects of an increase in the $\mathrm{N}$ supply on the composition of the shoots. As the supply of $N$ increased, the amounts of both $K$ and $C a$ in the equivalents units for the shoots decreased (Graph $3, N$ ). The $P$, on the other hand, did not always decrease (Graph $3, N$ ). In fact, when the $P$ supply was high, the amount of $P$ in the shoots tended to increase as the $N$ supply increased (Graph 3, NP, Bars $1: 4: 7)$. And when $P$ was medium, it decreased as $N$ increased from low to medium but increased when $N$ was raised from medium to high (Graph 3, NP, bars $2: 5: 8$ ). When $P$ was low, however, it decreased regularly with increasing $N$ (Graph 3 , NP, bars $3: 6: 9)$. In addition, when $\mathrm{Ca}$ was high, the $\mathrm{P}$ in the units tended to increase as $\mathrm{N}$ increased, whereas when Ca was medium, it decreased (Graph 3, NCa). The Mg in the shoats decreased only with the increase in the $\mathrm{N}$ supply from low to medium; the larger Mg supply which accompanied high $N$ naturally resulted in an increased accumlation of Mg in the shoots when $N$ increased to the high level (Graph 3, N).

The fact that an increase in the supply of $\mathrm{N}$ tended to decrease the amounts of $\mathrm{P}, \mathrm{K}, \mathrm{Ca}$, and $\mathrm{Mg}$ suggests that fundamentally $N$ was antagonistic to their accumlation in the shoots This antagonism or repressive effect of $\mathrm{N}$ for $\mathrm{K}, \mathrm{Ca}$, and $\mathrm{Mg}$ was clearly indicated. Even for $P$, an inverse relation between its accumiation in the shoots and the supply of $N$ was sufficiently evident under some conditions to indicate the fundamental nature of the repressive tendency. 
On the other hand, the fact that the repressive effect of $N$ on the bases was expressed more regularly or frequently than its effect on $P$ suggests that there was a difference in the effectiveness or strength of the repressive action of $\mathrm{N}$ on different elements. Since it was evident more regularly, the repressive effect of $\mathrm{N}$ on the bases was apparently stronger than its effect on $P$.

The fundamental antagonism which was characteristic of the effects of $N$ was also characteristic for the other elements. It was indicated by the effects of variations in their supply on the composition of the trunks and leaves as well as of the shoots (Graphs 3 to 5, Tables 3 to 5). However, as with $\mathrm{N}$, there were variations in the apparent strength of their repressive effects. These variations for the different elements were evaluated on the basis that the more regularly or frequently an inverse relation was evident between the supply of one element and the amount in the tops of a second, the stronger was the repressive action of the first on the second. A summary of this evaluation, which was made from an examination of Tables 3 to $5, \mathrm{NPCa}, \mathrm{NKCa}$, and $\mathrm{PKCa}$, follows.

An inverse relation was evident with marked frequency for the following comparisions:

between the amount of $N$ in the tops and the $P$ supply,

between the $\mathrm{K}, \mathrm{Ca}$, and $\mathrm{Mg}$ in the tops and the $N$ supply, and

between the $N, P, K$, and $M g$ in the tops and the $\mathrm{Ca}$ supply.

Consequently, the repressive action of the following is considered to have been comparatively strong:

the effect of $P$ on $N$,

the effect of $\mathrm{N}$ on the bases, $\mathrm{K}, \mathrm{Ca}$, and $\mathrm{Mg}$, and the effect of $\mathrm{Ca}$ on $\mathrm{N}, \mathrm{P}, \mathrm{K}$, and $\mathrm{Mg}$.

In contrast to the above, the effect of $N$ on $P$ evidently was only moderately strong. The inverse relation between the amount of $P$ in the units for the tops and the $N$ supply was evident frequently only under the conditions of medium Ca (Tables 3 to 5, NPCa, HHM:MMM:LYM, HMM:MMM:LMM, HIM:MLM: IIM). Since it was not as evident, the repressive action of $\mathrm{N}$ on $\mathrm{P}$ apparently was comparat 1 vely weaker than the reciprocal effect of $P$ on $N$, as noted above. 
Also in marked contrast to its action on $N$, the effect of $P$ on each of the bases was weak. This weakness is indicated by the fact that the $\mathrm{K}, \mathrm{Ca}$, and $\mathrm{Mg}$ in the tope decreased with the increase in the $P$ supply only in a comparatively few instances (Tables 3 to $5, \mathrm{NPCa}, \mathrm{PKCa}$ ).

The repressive action of $K$ on $N$ and on $P$ was also weak (Tables 3 to 5, NKCa, PKCa). On the other hand, the effect of $\mathrm{K}$ on $\mathrm{Ca}$ and on $\mathrm{Mg}$ was comparatively strong (Tables 3 to 5, $\mathrm{NKCa}, \mathrm{PKCa}$ ).

It w1ll be noted that, for any two elements, the repressive action of one on a second usually was stronger than the reciprocal effects of the second on the first. Thus, comparatively,

the repressive effect of $P$ on $N$ was stronger than that of $N$ on $P$,

the repressive effect of $N$ on the bases was stronger than that of the bases on $N$, the repressive effect of $\mathrm{Ca}$ on $\mathrm{P}$ was stronger then that of $\mathrm{P}$ on $\mathrm{Ca}$, and

the repressive effect of $\mathrm{Ca}$ on $\mathrm{K}$ was stronger than that of $\mathrm{K}$ on $\mathrm{Ca}$.

On the other hand, the repressive actions of $P$ on $K$ and of $K$ on $P$ were both comparatively weak, and there was no indication that either was dominant consistently.

Fundamentally, for any element the evaluation of the relative strength of its repressive action is an indication of the degree to which the expression of its normal antagonism was influenced or modified by the effects of other elements. Thus evidence of comparative weakmess in the effects of an element indicates that the expression of its antagonism was dependent on and easily influenced by the concurrent effects of the other elements. Similarly, evidence of comparatively strong action indicates that the effects of other elements were generally at a minimum or easily offset; on the other hand, for such an element the occasional exceptions to an inverse relation between the supply of that element and the amount of a second in the tops represent the particular situations in which its repressive effects were modifled or reduced by the concurrent actions of other elements.

The modifying effect of the elements on the expression 
of the repressive action of one of their number can be illustrated by consideration of the effects of an increasing $N$ supply on the accumulation of $P$ in the shoots (Table 3 , NP $\mathrm{Ca}$. Under the conditions of medium $\mathrm{Ca}$, the repressive effect of $N$ on $P$ evidently was strong enough to overcome any of the concurrent effects of other elements which might have markedly modified an expression of that antagonism. As a result the $P$ in the equivalents units for the shoots decreased regularly as the $N$ supply increased (Table $3, \mathrm{NPCa}$, LHM:MEM:HHM, LMM:MM:EMM, LLM:MLM:HLM).

Under the conditions of high $\mathrm{Ca}$, however, the results were different, the reaction to $N$ varying with the $P$ supply. Thus the amount of $P$ in the units decreased regularly as the $N$ supply increased only when the supply of $P$ was low (Table 3 , NPCa, LLH:MLH:HIH). At the medium $P$ level it decreased when $N$ increased from low to medium but increased when $N$ was raised to the high level ( Table $3, \mathrm{NPCa}, \mathrm{LMH}: M M H: H M H)$. At high $P$ it increased regularly as $N$ increased (Table 3 , NPCa, LHH :MHH:HHH).

Under these various conditions, $\mathrm{Ca}$ was a dominant element because of its high supply. It strongly depressed both $\mathrm{N}$ and $\mathrm{P}$. At low-P-high-Ca the repression of $\mathrm{P}$ by $\mathrm{Ca}$ was at a maximum, since any reciprocal effect of $P$ on Ca was minimized by the low $\mathrm{P}$ supply. Likewise the usually strong repressive action of $P$ on $N$ was at a minimum, whereas that of $N$ on $P$ was comparatively greater, with the result that the $P$ in the shoots decreased as the $N$ supply increased, the depressing effects of $N$ on $P$ being added to those of the high $\mathrm{Ca}$. It will be noted, however that the effectiveness of $\mathrm{N}$ on $\mathrm{P}$ was reduced by the high $\mathrm{Ca}$; comparatively, the decrease in $\mathrm{P}$ at low-P-medium-Ca was greater than that at low-P-high-Ca (Table 3, NPCa, ILM:NLM:HLM, ILH:MLH:HLH).

At medium-P-high-Ca, the repression of $\mathrm{P}$ by $\mathrm{Ca}$ was still comparatively great, though somewhat less than at low-Phigh-Ca, because the reciprocal effect of $\mathrm{P}$ on $\mathrm{Ca}$ naturally was stronger at the medium $P$ level. However, the net effectiveness of $\mathrm{P}$ on both $\mathrm{Ca}$ and $\mathrm{N}$ was not sufficient to offset the effect of the increase in $\mathrm{N}$ from low to medium, so that, as a result, the $P$ in the shoots was lower at medium- N-medium-P-h1gh-Ca than at low-N-medium-P-high-Ca. On the other hand, when $N$ increased to the high level, the net result of the interactions of the elements was altered so that the $P$ in the shoots increased. This effect was probably as mach 
the result of the higher Mg supply accompanying high $N$ as it was of the increase in $\mathrm{N}$ itself. Because of its antagonism to $\mathrm{Ca}$, the higher $\mathrm{Mg}$ reduced the effect of the high $\mathrm{Ca}$ on $\mathrm{P}$ and $\mathrm{N}$. In addition, the high $\mathrm{N}$ itself was antagonistic to $\mathrm{Ca}$, and its effects were probably added to those of $\mathrm{Mg}$. Apparently the mutual antagonism of $\mathrm{N}, \mathrm{Ca}$, and $\mathrm{Mg}$ was such that their action, both individually and collectively, on $P$ was minimized, with the result that conditions for the accumlation of $\mathrm{P}$ were more favorable at high-Nmedium-P-high-Ca than at medium-N-medium-P-high-Ca.

Under conditions of high-P-high-Ca, the high level of $P$ itself was obviously favorable to a comparatively large accumulation of $\mathrm{P}$ in the shoots. In addition, the fundamental antagonism of $\mathrm{P}$ for both $\mathrm{N}$ and $\mathrm{Ca}$ was greater than at lower levels of $P$; therefore, to begin with, the reciprocal effects of $N$ on $P$ and of $C a$ on $P$ were comparatively minimized because of the high P. At the same time, however, the mutual antagonism of $N$ and $C a$ also reduced the repressive effect of each of those elements on $P$. In particular, as the $\mathrm{N}$ supply increased, the increased repression of $\mathrm{Ca}$ was favorable to the accumlation of $P$. Therefore under conditions of high-P-high-Ca the $\mathrm{P}$ in the shoots actually increased as the $N$ supply increased, an effect which was the end result of the interaction of several factors, especially the fundamentally favorable $P$ supply and the antagonism of $\mathrm{N}$ and $\mathrm{Ca}$ (together with $\mathrm{Mg}$ at high $\mathrm{N}$ ).

In addition to being modified by the effects of other elements, the expression of the normal antagonism of an elemont also varied in some instances in the different parts of the trees, so that the strength of the repressive action sometimes appeared to be greater in one part than in another. Apparently the variation in the natural level of accumlation of the elements was sometimes great enough between parts of the trees to modify the expression of the antagonism. This sort of variation is illustrated by the effects of $P$ on the accumulation of $N$ in the shoots and trunks as compared with that in the leaves. In both the shoots and truaks, the repressive effect of $P$ on $N$ was strong, the $a-$ mount of $N$ in those parts decreasing regularly as the $P$ supply increased (Tables 3 and 4, NPCa). In the leaves, however, the effect was comparatively weaker, and under some conditions the $\mathrm{N}$ actually increased as the $\mathrm{P}$ supply increased (e.g., Table 5, NPCa, MLM:MMM). 
The comparative weakness of the effect of $P$ in the leaves evidently was related to a naturally lower level of accumulation of that element and a higher accumulation of the bases, especially $\mathrm{K}$ and $\mathrm{Mg}$. The lower level of accumulation of $P$ weakened the effectiveness of the antagonism of $P$ for $N$. In addition, the potential repressive effect of the bases on $N$ was greater as a consequence of their higher accumulation. However, because the increase of $\mathrm{K}$ and $\mathrm{Mg}$ in the leaves was greater than that of $\mathrm{Ca}$, the intensity of the mutual antagonism between the bases apparently was increased with a resultant decrease in their effectiveness on $N$ and $P$. Consequently, the reciprocal effect of $P$ on the bases was relatively strengthened so that an increase in the $P$ supply resulted in a decrease in one or more of the bases which further reduced the intensity of the repression of $N$ by those bases. The end result of the interaction of these factors therefore was a comparatively weak expression of the repressive effect of $\mathrm{P}$ on $\mathrm{N}$; evidently the favorable effect on $\mathrm{N}$ of the decrease in the bases which resulted with the increase in the supply of $P$ outweighed the unfarorable, direct effect of $P$ on $N$. Consequently, under some conditions the $N$ in the leaves actually increased as the $P$ supply increased. Even for the conditions under which $N$ decreased, the intensity of the repressive effect of $P$ on $N$ was comparatively less than in the shoots and trunks. 


\section{THE REIATION BETHEEN GROWTH AND COMPOSITION}

It is evident from the discussion of the analytical data that at least three factors were operative in determining the composition of the tops of the trees: first, the nature of the part of the tree; second, the supply of the elements individually; and third, the normal antagonism between them. In effect, the first two limited the accumilation of an element within a given portion of a tree. The third, however, accounted for its variations within those limits, so that consequently, the composition of the tops was always dependent in the end on the relationships between the elements supplied to the tree.

Under the discussion of growth it was pointed out that the growth of the shoots also was dependent on the relationships between the elements or on the intensity of the nutrient-element belence. Obviously, therefore, a relation between the composition, growth, and balance is to be expected. The following discussion is concerned with the nature of that relationship.

The Relations at High N: In previous discussion it was concluded on the basis of the growth data alone that the reduced shoot growth in the high $N$ series was the result of excessive $N$ and a consequent lowered intensity of balance in the nutrient-element supply. The effect of the high $N$ on the composition of the shoots in its relation to growth will now be considered. As expressed in the composition, the excess $N$ resulted in a decreased accumilation of both $\mathrm{K}$ and $\mathrm{Ca}$. $\mathrm{Mg}$, however, increased because of the higher supply of $\mathrm{Mg}$ accompanying high $N$. The $P$ in the shoots was affected by the Ca supply as well as by $N$, so that it was higher at high-N-high-Ca than at medium-N-high-Ca but lower at high-N-medium-Ca than at medium-N-medium-Ca. The total $\mathrm{N}$ in the shoots increased. However, this increase was entirely as soluble $\mathrm{N}$, since the insoluble portion decreased (Table 3, $\mathrm{NPCa}, \mathrm{NKCa}$ ).

It is the accumalation of the soluble relative to the insoluble $N$ which apparently was a primary factor in the reduced growth at high $N$. Evidently the alterations noted above in the accumlations of the other elements produced conditions which were less favorable for an adequate synthesis of insoluble (protein) N. These conditions were brought about in the main by the high $\mathrm{N}$ supply itself as a 
result of an increase in the intensity of the antagonism of $\mathrm{N}$ for the other elements, expecially the bases. In addition, the repressive effect of $\mathrm{Mg}$ was intensified at high $\mathrm{N}$ because of the accompanying high Mg supply.

The higher Mg, however, was only secondary to $N$ in the degree to which it influenced the composition and growth of the shoots in the high $\mathrm{N}$ trees. This fact becomes apparent when the trees which received high-N-high-Ca are compared with those at medium-N-medium-Ca (Tables 2 and $3, \mathrm{NCa}$ ). Best growth resulted under the latter conditions. The difference in the nutrient-element supply for these two groups of trees involved $\mathrm{N}, \mathrm{Ca}$, and $\mathrm{Mg}$, all three being higher in the high-N-high-Ca solutions. Nevertheless, only $\mathrm{N}$ was present in an increased amount within the shoots of the trees receiving those solutions; the increase, however, was entirely as soluble $\mathrm{N}$, the insoluble portion decreasing. This increase of the soluble relative to the insoluble $\mathrm{N}$ being indicative of an inefficient synthesis of protein $N$ accounts for the reduced growth of those shoots.

The unfavorable relation of the soluble to the insoluble $\mathbb{N}$ was not, however, a direct consequence of the higher Mg supply accompanying the high $N$, as is indicated by the fact that there was practically no difference in either the Mg or Ca in the shoots at high-N-high-Ca as compared to those at medium-N-medium-Ca. Evidently, the mutual antagonism of $\mathrm{Mg}$ and $\mathrm{Ca}$ was such that, when the supplies of both were increased, ther $\theta$ was little change in their relative accumulation within the shoots. The $K$ in the shoots, on the other hand, decreased. It is likely that it was this decrease in $K_{2}$ with its consequent effect on the relation of $\mathrm{K}$ to $\mathrm{Ca}$ and $\mathrm{Mg}$ which resulted in the unfavorable solubleinsoluble- $N$ relation. The decrease in $K$ was evidently the result primarily of the repressive effect of the high $N$, since the mutual antagonism of $\mathrm{Mg}$ and $\mathrm{Ca}$ would have reduced their individual repressive effect on $\mathrm{K}$. Therefore, the lower intensity of balance in the high- $\mathrm{N}-\mathrm{high}-\mathrm{Ca}$ solutions was primarily the result of the higher $N$ supply. Because the effectiveness of $\mathrm{N}$ in the other himh $\mathrm{N}$ series was potentially the same, it can be concluded that the lower intensity of balance of those solutions also was a consequence of the high $N$. If anything, the accompanying high $\mathrm{Hg}$ supply merely intensified the effects of $N$ and caused wider variations in the relative amounts of the bases in the shoots than might otherwise have resulted. 
The Relations in the Deficiency Series: The reduced growth of the trees in the low-N series is indicative of a low intensity of nutrient-element balance and presumably was the direct effect of the low-N supply. The nature of that effect is shown by a comparison of the composition of the shoots of trees at low and at medium $N(T a b l e ~ 3, N)$. In the first place, the total $N$ in the shoots was greatly reduced at low $N$. This reduction was accounted for primarily by a decrease in the soluble $N$. The concurrent decrease in the insoluble $N$, though relatively smaller, indicates that the synthesis of insoluble (protein) $\mathrm{N}$ was inadequate for best growth. Evidently the supply of $N$ was insufficient to maintain a level of soluble $N$ in the shoots which was favorable to a continued and rapid synthesis of the insoluble forms. In adition to the difference in the $N$ in the shoots, the accumulations of the other elements were usually higher at low than at medium $N$. Such increased accumulations were a natural consequence of a decrease in the intensity of the normal antagonism of $\mathrm{N}$ under the conditions of a low $N$ supply.

The low intensity of balance indicated by the reduced growth when the supply of $P$ was low was a consequence of the effects of the deficiency of that element. The nature of those effects is indicated by the composition of the shoots. The amount of $P$ in the shoots of the low $P$ trees was characteristically low (Table $3, \mathrm{P}$ ). In addition, in contrast to the medium $P$ trees, there was an accumulation of soluble relative to insoluble $\mathrm{N}$, which indicates that conditions were unfavorable for a satisfactory synthesis of protein N. Evidently, the amount of $P$ in the shoots was insufficient to faror that synthesis. Besides any direct effects of the low $P$ on protein synthesis, the concurrent lowered intensity of its normal antagonism naturally resulted in a greater accumalation of N. The amounts of the bases in the shoots were not greatly different than at medium $P$. On the other hand, however, if they are compared to the amounts of $P$ in the shoots, the bases actually were relatively greater at low than at medium $P$. This condition probably intensified the unfarorable effects of the low $P$ supply.

The low intensity of balance indicated by the reduced growth under conditions of low $K$ was a consequence of the effects of the deficiency of that element. The nature of those effects as indicated by the composition of the shoots (Table 3, K) was very similar to that of low $P$ in that an accumulation of soluble relative to insoluble $\mathrm{N}$ was also characteristic. Evidently, the low amount of $K$ in the shoots 
under the conditions of the deficiency was unfavorable to the synthesis of the insoluble forms of $\mathrm{N}$. The effects of the low $\mathrm{K}$ also were probably intensified by the relatively greater accumulations of the other bases and of $P$.

The Mild Deficiency of $\mathrm{K}$ : As presented in the discussion of growth, the intensity of nutrient-element balance under conditions of medium- $\mathrm{K}$-medium-Ca was shown to be lower than under high-K-medium-Ca. The lower growth under the former conditions was considered to be, in part at least, the result of a mlld deficiency of $K$. The nature of the effects of that deficiency is indicated by a comparison of the composition of the shoots under the two sets of conditions (Table 3, KCa).

At medium-K-medium- $\mathrm{Ca}$, the $\mathrm{K}$ in the shoots was lower than at high-K-medium-Ca. The $\mathrm{Ca}$ and $\mathrm{Mg}$ in the shoots, however, were both higher, because the intensity of the repressive effect of $K$ was naturally lower with medium $K$. The ratio of $\mathrm{K}$ to $\mathrm{Ca}$ and $\mathrm{Mg}$ consequently was markedly lower than at high-K-medium-Ca. It was this narrower interbase relationship which apparently conditioned the lower grouth at medium-K-medium-Ca. However, it appears to have been a factor through its effect on the soluble-insoluble-N relation in the shoots. The insoluble $N$ was lower and the soluble $N$ was higher under the conditions of medium-K-medium-Ca. The greater amount of soluble relative to insoluble $\mathrm{N}$ evidently was less favorable to growth than that at high-K-medium-Ca.

Under the conditions of high $\mathrm{Ca}$, medium $\mathrm{K}$ was not mildiy deficient. In fact, the intensity of balance with medium-Khigh-Ca was in general higher than with high-K-high-Ca, and growth tended to be better under the former conditions. Apparently, under the conditions of $\mathrm{high} \mathrm{Ca}$, the increase in $\mathrm{K}$ to the high level did not result in an interbase relationship which was more favorable to growth, even though it did reduce both the $\mathrm{Ca}$ and $\mathrm{Mg}$ in the shoots. In fact, by its antagonism to $\mathrm{Ca}$ it apparently reduced the repressive effect of that element on $\mathrm{N}$ so that the soluble $\mathrm{N}$ in particular was higher at high-K-high-Ca than at medium-K-high-Ca. At the same time, the conditions for the synthesis of the insoluble forms of $\mathrm{N}$ evidently were not improved, with the result that the soluble $\mathrm{N}$ was relatively higher than the insoluble forms. Consequently growth at high-K-high-Ca tended to be lower then at medium-K-high-Ca. 
The Mild Deficiency of Ca: The intensity of the nutrient-element balance under the conditions of medium-K-me. dlum-Ca was also lower than under medium-K-high-Ca. The smaller growth under the former conditions therefore may just as well be considered as partly the result of a mild deficlency of $\mathrm{Ca}$ as the result of the mild deficiency of $\mathrm{K}$ discussed above. The nature of the effects of $\mathrm{Ca}$ is indicated by a comparison of the composition of the shoots under the two sets of conditions, medium-K-medium-Ca and medium- $\mathrm{K}-\mathrm{high}-$ Ca (Table 3, KCa).

Under the first set of conditions, the Ca in the shoots was much lower than at medium-K-high-Ca. Both the $\mathrm{Ng}$ and the $\mathrm{K}$ in the shoots were higher, the Mg being especially so. Consequently the ratio of $\mathrm{Ca}$ to $\mathrm{K}$ and $\mathrm{Mg}$ was markedly lower than at medium-K-high-Ca. It was this narrower interbase relationship which apparently conditioned the lower growth at medium-K-medium-Ca. However, it appears to have been a factor through its effect on the soluble-insoluble-N relation in the shoots. Both the soluble and the insoluble N were higher under the conditions of medium-K-medium-Ca. However, the difference in the soluble $N$ was comparatively the greater, so that the soluble portion was actually higher relative to the insoluble $N$ under those conditions and was less favorable to growth than at medium-K-high-Ca.

Under the conditions of high $K$, the medium $C a$ was not mildy deficient. In fact, the intensity of balance with high-K-medium-Ca was in general higher than with high-K-high$\mathrm{Ca}$, and growth tended to be better under the former conditions. The increase in $\mathrm{Ca}$, under the conditions of high $\mathrm{K}$, resulted in a decrease in the total $N$ in the shoots, because of the strong repressive effect of the high Ca. This decrease was accounted for by reduction in both the soluble and the insoluble $\mathrm{N}$. However, the decrease in the soluble forms was the smaller. Actually therefore there was an increase in the soluble relative to the insoluble $\mathrm{N}$, a condition which was less favorable to growth. This soluble-insoluble-N relation was conditioned by the effect of the high $\mathrm{Ca}$ on the other bases. Both the $K$ and the $\mathrm{Ng}$ in the shoots were lower at high-K-high-Ca than at high-K-medium-Ca as a result of the repressive effect of the higher $\mathrm{Ca}$. However, this reduction in $K$ and $M g$ naturally lowered the intensity of their repressive effect on the $N$ within the shoots, so that conditions were favorable for an increase in the soluble relative to the insoluble $\mathrm{N}$. 
The Effect of $\mathrm{Ca}$ at low $\mathrm{K}$ : When either the medium or high $\mathrm{N}$ was accompanied by low $\mathrm{K}$, an increase in $\mathrm{Ca}$ resulted in an increased growth. Under the conditions of high-N-low$\mathrm{K}$, this increase in $\mathrm{Ca}$ was favorable to growth because it reduced sharply the $\mathrm{Mg}$ accumlation in the shoots ( Table 3, NKCa). If the high Mg supply accompanying high $\mathrm{N}$ had any direct "toxic" effect on growth it would have been most serlous under the conditions of Iow-K-medium-Ca, because the intensity of the repressive effects of both $\mathrm{K}$ and $\mathrm{Ca}$ on $\mathrm{lig}$ was at a minimum under those conditions. Consequently, when the Ca supply was increased and the intensity of 1ts antagonism for Mg was helghtened, the effect of $\mathrm{Mg}$ was reduced, and growth improved.

That this improvement in growth was a direct result of the shift in the Ca-Mg relation in the shoots rather than a consequence of concurrent alterations in the nitrogen economy is indicated by comparison of the nitrogen data under the conditions of high-N-low-K-medium-Ca and high-N-low-Khigh-Ca (Table 3, NKCa). The total $\mathrm{N}$ increased as the $\mathrm{Ca}$ supply increased. This increase was accounted for solely by an increase in the soluble $\mathrm{N}$, the insoluble portion being decreased. Such increase in the soluble relative to the insoluble $\mathrm{N}$ was usually unfavorable to growth. In this instance, however, it evidently was of less importance than the shift in the $\mathrm{Ca}-\mathrm{Mg}$ relation. The situation is especially noteworthy since the increase in the soluble $\mathrm{N}$ undoubtedly was a consequence of the increase in $\mathrm{Ca}$; the higher $\mathrm{Ca}$ by reducing the accumulation of $\mathrm{Mg}$ in the shoots lowered the intensity of the antagonism of that element for $N$ with the result that the $N$ increased. The increase in the $\mathrm{Ca}$ supply under conditions of high-N-low-K was favorable to growth despite the fact that it resulted in a normally unfavorable nitrogen relationship.

Under the conditions of medium $-\mathrm{N}-10 \mathrm{w}-\mathrm{K}$, in contrast to the situation at hlgh $\mathrm{N}$, the increase in $\mathrm{Ca}$ was favorable to growth because of its effect on the soluble-insoluble-N relation ( $T a b l e ~ 3, N K C a$ ). The increase in $\mathrm{Ca}$ under those conditions resulted in a decrease in total $N$. This decrease was accounted for primarily by a decrease in the soluble fraction and resulted in a lower accumulation of soluble relative to insoluble $\mathrm{N}$, a condition which was more favorable to growth. The decrease in the soluble $\mathrm{N}$ was probably a direct result of the antagonism of $\mathrm{Ca}$ for that element. The concurrent 
decrease in the aocumations of $\mathrm{K}, \mathrm{Mg}$, and $\mathrm{P}$ in the shoots evidently was also favorable; presumably their relationship to $\mathrm{N}$ was more satisfactory.

The beneficial effect of an increase in $\mathrm{Ca}$ discussed above is also of especial interest because such a result is contrary to the effects of $\mathrm{Ca}$ as reported by Davidson and Blake (8) and by Shaw $(13,14)$. The former, working with peach trees in sand cultures, reported that the trees rece1ing solutions containing $2 \mathrm{ppm}$ of $K$ made more growth when the accompanying supply of Ca was at a concentration of 180 ppm than when it was $410 \mathrm{ppm}$. Shaw found that fruit plants grew better where both lime and potash had been used than where potash alone had been applied; on the other hand, where potash had not been used, growth was better on an unlimed plot. In other words, where $K$ was deficient, $C a$ additions were detrimentel, but when the $K$ deficiency wes corrected, $\mathrm{Ca}$ became limiting, and growth was improved by liming.

Because the data presented by those investigators is insufficient to make possible an evaluation of the nature of the effects of $\mathrm{Ca}$ under their conditions, the difference between their results and those of this investigation cannot be accounted for precisely. Presumably, hotrever, it is a result of differences in the absolute and relative supplies of other elements in addition to $K$ and $C a$. With such different supplies, the relations between the bases and between the forms of nitrogen within the plants might easily have varied sufficiently to produce the different growth responses.

It will be noted, however, that the improvement in growth with liming after the deficiency of $K$ was corrected as reported by Shaw was simflar to the effect of an increase in $C a$ under the conditions of medium $K$ in this investigation. This indicates that fundamentally the effects of the relations between $\mathrm{K}$ and $\mathrm{Ca}$ in the two investigations were actually similar. Presumably, therefore, the effects were also fundamentally similar under the conditions of $\mathrm{K}$ deficiency but were expressed differently because of variations in other conditioning factors. It seems likely that the divergent results could be readily reconciled if sufficient information, especially as to analytical data, were avallable to evaluate the effects of those other factors.

The Effects of $P$ : In the discussion of growth is was pointed out that the increase in the supply of $P$ from medium 
to high had no significant effect on the growth of the shoots. Consequently, in so far as growth was concerned, the intensity of nutrient-element balance under the conditions of high $P$ was practically the same as that under medium $P$. On the other hand, the composition of the shoots differed under the two conditions (Table 3, P). In the first place, the increase in the supply of $P$ to the high level resulted in a definite increase in the $P$ in the shoots. In addition, the $N$ in the shoots decreased as a result of the strong antagonism of $P$. The $\mathrm{K}, \mathrm{Ca}$, and $\mathrm{Mg}$, however, were not markedly affected, since $P$ was only weakly repressive of the bases. liost of the decrease in $\mathrm{N}$ was accounted for by the soluble forms. As a consequence, as $P$ increased there was usually a decrease in the soluble relative to the insoluble $N$. Under most conditions, such a shift in the soluble-insoluble-N relation would have resulted in increased growth; however, as previously mentioned, that did not occur to any marked degree with the increase in the $P$ supply to the high level.

This result appears to have been a consequence of the difference in the antagonism of $P$ on $N$ and on the bases. This difference was such that, with the increase in the ? supply, there was very little decrease in the bases as compared with a marked decrease in $\mathrm{N}$. Consequently most of the increase in the $P$ in the shoots usually was accounted for by a corresponding decrease in $\mathrm{N}$, the soluble portion especially. As a result, the sum of $P$ and the soluble $N$ was approximately the same under conditions of the medium and high $P$ supplies. Therefore the relation of the P-plus-soluble-N to the insoluble $N$ was also nearly the same. This suggests that, under conditions of high $P$ supply, the additional $P$ in the shoots substituted, at least partly, for soluble $N$ to maintain with insoluble $\mathrm{N}$ a relationship which was no more favorable to growth than that under conditions of medium $P$ supply.

In so far as the composition of the shoots is a criterIon, the increase in the $P$ supply can be considered to have caused changes in the quality of growth, even though it did not result in differences in the amount of growth. Thus the decrease in the total $\mathrm{N}$ and the shift in the soluble-insoluble-N relation with the increasing $P$ supply represent a change in the quality of growth from the standpoint of the altrogen economy. Likewise, the increase in the $\mathrm{P}$ in the shoots relative to $\mathrm{N}$ and to the bases constitutes a difference in quality. Therefore, in so far as the composition of the shoots was concerned, the intensity of the nutrient-element balance can be considered to have raried with the in- 
creased $P$ supply, despite the fact that it wes no different on the basis of growth.

The significance of the quality factor in nutrient-element balance, however, depends on the purpose for which the plants are grown. When the volume or amount of growth produced is of primary importance, quality may be of little direct significance, and balance may be defined solely on the basis of growth. On the other hend, when other functions of the plant are concerned, such as fruiting, the quality of growth may also have to be considered and balance defined or qualified in terms of the composition as well as the amount of growth. Since this investigation is concerned principally with the amount of growth, the implications of the quality factor can only be indicated. It should not be construed that the effect of the $P$ supply on the quality of growth is necessarily significant from the standpoint of other developmental phases of peach trees. The effects of $P$ have been used merely to illustrate the points that variations in the nutrient-element supply may cause differences in the composition of the plants without significant, concurrent changes in the amount of growth and that, under some conditions and for some purposes, balance may need to be defined in terms of the quality as well as the amount of growth.

\section{The Diagnosis of Deficiencies}

There were two features of the trees under the acute aeficiency conditions of either low $N$, low $P$, or low $K$ which were diagnostic. The first was the symptoms which characterized the follage and shoot growth for each of the respective deficiencies. The second was the typically low level of accumlation of the deficient element in the tops of the trees. Both of these features have a practical value in diagnosing the deficiencies. The symptoms have frequently been described and used $(4,7,8,20)$. The analyses of leaves have been found valuable in the diagnosis of $K$ deflciency especially $(3,18,19)$.

However, these features were not diagnostic of the milder deficiencies such as the deficiency of $K$ under the conditions of medium-K-medium-Ca. In that particular instance there were no special symptoms, only the smaller growth as compared with the trees at high-K-medium-Ca. In addition, the analyses for $\mathrm{K}$ did not indicate the deficiency; in fact 
the $K$ in the shoots as expressed in the equivalents units was higher at medium-K-medium-Ca than at medium- $\mathrm{K}-\mathrm{high}-\mathrm{Ca}$, under which conditions $K$ was not mildiy deficient.

The diagnosis of the mild deficiency was made, however, by reference to the tree making maximum growth. For example, maximum growth resulted under conditions of medium-N-high$\mathrm{K}$-medium-Ca. In comparison, growth was smaller under conditions of medium-N-medium-K-medium-Ca. Therefore the smaller growth must have been a consequence of a mild deficiency of $K$, since it was improved by increasing the supply of that element. Obviously a standard of reference, representing maximum growth, is needed in diagnosing a mild deficiency. In addition, the available supplies of the various elements must be known. The deficiency can then be diegnosed by considering the difference in the nutrient-element supplies which can be related to the difference in growth between the standard or reference trees and those making comparatively poorer growth.

A standard of reference is also needed if the plant analyses are to be of value in diagnosing the deficiency. For example, using again the trees at medium-N-high-K-medium-Ca as a standard, the greater amount of soluble relative to insoluble $\hat{N}$ in the shoots of the trees making smaller growth under the conditions of medium-N-medium-K-medium-Ca was indicative of a mild deficiency that was influencing the quality of nitrogen. The comparatively lower $K$, together with the concurrently higher $\mathrm{Ca}$ and $\mathrm{Mg}$, in the shoots at medium$\mathrm{N}$-medium- $\mathrm{K}$-medium-Ca indicates that $\mathrm{K}$ was the deficient element and that better growth under the reference conditions was the consequence of a more favorable interbase relationship which resulted in improvement in the quality of $N$.

It is to be expected that analyses of the tissues would be of most help in diagnosing a mild deficiency, when the differences in the nutrient-element supplies which were available to the deficient and the reference plants respectively involved more than one element. Under such conditions it might be difficult to assign differences in growth to one of the variable elements in particular, unless comparisons of the inter-elemental relationships within the plants could also be made and used to aid in indicating the element most likely to be limiting. 
1. Elberta peach trees were grown in sand culture, using 54 different treatments which included all of the possible combinations of supplies of $N, P$, and $K$ at three concentrations--high, medium, and low--and of $\mathrm{Ca}$ at two--high and medium. The low concentrations were selected as ndeficiency" levels, such concentrations being used only for $\mathrm{N}, \mathrm{P}$, and $\mathrm{K}$ but not for $\mathrm{Ca}$. The medium concentrations were considered adequate for good growth. The high concentrations were selected with the possibility in mind that they might prove to be greatly excessive.

2. The trees were harvested about five months after planting. Growth was measured in terms of the length and the dry weight of shoots. Samples of the leaves, shoots, and trunks were analyzed for $\mathrm{P}, \mathrm{K}, \mathrm{Ca}, \mathrm{Mg}$ and for watersoluble, water-insoluble, and total N. The amounts of these elements in the samples were expressed in terms of an equivalents unit; i.e., as the percentage of esch in the sum of their microgram-hydrogen-equivalents per gram of dry weight.

3. Nutrient-element balance was defined and qualified in terms of the factors limiting growth. Such a procedure provided for a number of balanced nutrient-element supplies whlch were distinguished by the differences in their intensity of balance as determined by the amount of growth produced. The nutrient-element supply with the highest intensity of balance was defined as that one with which resulted the maximum amount of growth possible within the limits of other environmental factors and of the genetic nature of the plant. As any element became limiting, a balanced supply of a comparatively lower intensity was defined as that one which resulted in the maximum growth possible within the limits of the supply of that element.

4. Nitrogen was the most important of the elements as a determinant of growth. Considering the experiment as a whole, maximum growth occurred when the $\mathrm{N}$ supply was medium regardless of the supplies of the other elements. Growth at low $N$ was greatly reduced; that at high $N$ was intermediate. The supplies with the highest intensities of balance included $N$ at the medium level.

5. $\mathrm{K}$ and $\mathrm{Ca}$ were closely related and next to $\mathrm{N}$ in importance in their effects on growth. Within the limits of elther the high or the medium $\mathrm{N}$ supply, there were two com- 
binations of $\mathrm{K}$ and $\mathrm{Ca}$ which were nearly equal with respect to growth. They were high-K-medium-Ca and medium-K-high-Ca. Within the limits of the N supply, the solutions with the hichest intensities of balance included $\mathrm{K}$ and $\mathrm{Ca}$ in one or the other of those two combinations. Growth at low $K$ was less than at medium or high $\mathrm{K}$.

\section{P was the least important of the four elements as} a determinant of growth. There was no significant difference in growth under the medium and the high $P$ conditions. Therefore the intensities of balance of supplies including high $P$ were practically the same as those with the medium level of that element. Growth at low P, however, was greatly reduced.

7. Acute deficiencies resulted under the conditions of a low supply of $\mathrm{N}, \mathrm{P}$, or $\mathrm{K}$. They were characterized by markedly reduced growth and typical deficiency symptoms.

8. Growth was better with high-K-medium-Ca and medium$\mathrm{K}$-high-Ca than with medium-K-medium-Ca. The comparatively poorer growth under the latter conditions was considered the result of in part a mild deficiency of $I^{*}$ and in part a mild deficiency of $\mathrm{Ca}$, since in the one instance growth improved by increasing $K$ and in the other by increasing $\mathrm{Ca}$. The only evidence of the deficiency was the comparatively lower growth; no typical foliage symptoms were evident.

9. Under the conditions of low $K$, growth improved with an increase in the Ca supply.

10. The amount of an element in the microgram-hydrogen-equivalents units for the tops of the trees was determined primarily by the supply of that element.

11. The leaves, shoots, and trunks differed as to the amounts of the elements within them, probably as a result of natural differences in their structure and functions. Soluble $N$ and $P$ were lower in the leaves than in the shoots and trunks, while insoluble $\mathrm{N}, \mathrm{K}$, and $\mathrm{Mg}$ were higher. Differences between the parts of the trees with respect to $\mathrm{Ca}$ varied with the $\mathrm{Ca}$ and the $\mathrm{N}$ supplies.

12. Fundamentally, each element was antagonistic, at least potentially, to the accumlation of each of the others within the tops of the trees. 
13. The apparent strength of the antagonism or repressive effect of the elements varied. A comparatively strong repressive action was indicated for the following:

the effect of $\mathrm{P}$ on $\mathrm{N}$,

the effect of $\mathrm{N}$ on $\mathrm{K}, \mathrm{C} \varepsilon$, and $\mathrm{Mg}$, and

the effect of $\mathrm{Ca}$ on $\mathrm{N}, \mathrm{P}, \mathrm{K}$, and $\mathrm{Mg}$.

The effects of $N$ on $P$ and of $K$ on $C a$ and ME were only moderately strong. The effect of $P$ on each of the bases was weak; that of $K$ on $P$ was also weak.

14. The relative strength of the repressive effect of an element was an indication of the degree to which an expression of its normal antagonism was influenced or modified by the effects of other elements. A comparatively weak action an was indication that the expression of its antagonism was dependent on and easily influenced by the concurrent effects of other elements. A comparatively strong repressive action indicated that the effects of other elements were generally at a minimum or easily offset.

15. The expression of the normal antagonism of an element also varied in some instances in the different parts of the trees so that the strength of the repressive effect sometimes appeared to be greater in one part than in another. Variation in the natural level of accumulations of the elements was sometimes great enough between parts of the trees to modify the expression of the antagonism.

16. Differences in growth (intensities of nutrientelement balance) were dependent on the relation of the soluble to the insoluble $N$ as affected by the other elements in the shoots. An increase in growth usually resulted when the soluble $\mathrm{N}$ decreased relative to the insoluble portion.

17. The reduced growth with the low intensities of balance in the acute deficiency series was related to an inadequate synthesis of insoluble (protein) $N$.

18. The moderately low intensities of balance under conditions of the mild deficiencies of $\mathrm{K}$ and $\mathrm{Ca}$ resulted in somewhat reduced growth as a consequence of an unfevorable soluble-insoluble- $N$ relation which was conditioned by $a$ narrower inter-base relationship in the shoots.

19. Under conditions of high and low $\mathrm{K}$, the beneficial effect of high $\mathrm{Ca}$ was the result of a narrower Ca-Mg relation. ship without a concurrent favorable shift in the relation of 
the soluble to the insoluble $N$. On the other hand, under conditions of medium $N$ and low $K$, the beneficial effects of high $\mathrm{Ca}$ were the result of a decrease in the soluble relative to the insoluble $\mathrm{N}$, a shift which was conditioned by changes in the inter-base relationship.

20. High $P$ did not alter significantly the intensity of balance resulting with medium $P$, because apparently at the higher level the $P$ in the shoots partly substituted for soluble $N$ to maintain with the insoluble portion a relation which was no more favorable to growth than the relation at the medium level. However, even though it did not alter the amount of growth appreciably, the high $P$ level caused variations in the quality of growth as indicated by changes in the composition of the shoots.

21. The diagnosis of acute and mild deficiencies was discussed.

\section{LITTERATURE CITFED}

1. Batjer, L.P., Baynes, W.C., and Regeimbal, L.0. 1940. The Interaction of nitrogen, potassium and phosphorus on the growth of young apple trees in sand culture. Proc. Amer. Soc. Hort. Sci. 37:43.

2. ---- and Degman, E.S. 1940. Effects of various amounts of nitrogen, potassium and phosphorus on the growth and assimilation in young apple trees. Jour. Agr. Res. 60:101-116.

3. --..- and Magness, J.P. 1939. Potassium content of leaves from commercial apple orchards. Proc. Amer. Soc. Hort. Sc1. 36:197-201.

4. Blake, M.A., N1ghtingale, G.T., and Davidson, 0.W. 1937. Nutrition of apple treөs. N. J. Agr. Expt. Sta. Bul. 626.

5. Cullinan, F.P. Oct. 1940. Personal communication.

6. --.--, Scott, D.H., and Waugh, J.G. 1939. The effects of varying amounts of nitrogen, potassium and phosphorus on the growth of young peach trees. Proc. Amer. Soc. Hort. Sc1. 36:61-68.

7. -...- and Waugh, J.G. 1940. Response of peach trees to potassium under field conditions. Proc. Amer. Soc. Hort. Sc1. 37:87-94.

8. Davidson, O.H., and Blake, M.A. 1937. Responses of young peach trees to nutrient deficiencies. Proc. Amer. Soc. Hort. Sci. 34:247-248.

9. --.-- and -.--. 1938. Nutrient deficiency and nutrient balance with the peach. Proc. Amer. Soc. Hort. Sc1. 35:339-346.

10. Taton, F.M. 1942. Toxicity and accumlation of chloride and sulfate salts in plants. Jour. Agr. Res. 64:357-399. 
11. Hayward, H.E., and Long, E.1.. 1942. Vegetative responses of the Elberta peach on Lovell and Shalil rootstocks to h1gh chloride and sulfate solutions. Proc. fmer. Soc. Hort. Sc1. 41:149-155.

12. Reed, H.S., and Haas, A.R.C. 1923. Effect of sodium chlorlde and calcium chloride upon the growth and composition of young orange trees. Cal1f. Agr. Fupt. Sta. Tech. Paper 4.

13. Shaw, J.K. 1924. Some unusual results in fertillzing frult plants. Proc. fmer. Soc. Hort. Sci. for 1924: 281-286.

14. --.-. 1931. Further evidence of a potash-lime deficiency in a sandy loam so11. Proc. Amer. Soc. Hort. Sc1. 27:12-14.

15. Thomas, i. 1932. Composition of current and previous season's branch growth in relation to vegetative and reproductive responses in Pyrus lialus L. Plant Physiol. 7:391 $\$ 45$.

16. -.... 1933. Absorption, utilization and recovery of nitrogen, phosphorus and potassium by apple trees grown in cylinders and subject to differential treatment with nutrient salts. Jour. Agr. Res. 47: $565-581$.

17. - - 1937. Foliar diagnosis: Principles and practice. Plant Physiol. 12:571-599.

18. Tiaugh, J.G., and Cullinan, F.P. 1941. The nitrogen, phosphorus and potassium content of peach leaves as influenced by soil treatments. Proc. Amer. Soc. Hort. Sci. 38:13-16.

19. -..-, - - - and Scott, D.H. 1940. Responses of young peach trees in sand culture to varying amounts of nitrogen, potassium and phosphorus. Proc. Amer. Soc. Hort. Sci. 37:95-96.

20. Veinberger, J.H., and Cullinan, F.P. 1937. Symptoms of some mineral derlclencies in one-year Elberta peech trees. Proc. Amer. Soc. Hort. Sc1. 34:249-254. 
Append1x Table 1. Growth Measuremente for Indifldual Trees. Iength and Dry Welght of Shoots and Dry Weight per Millimeter of Lensth

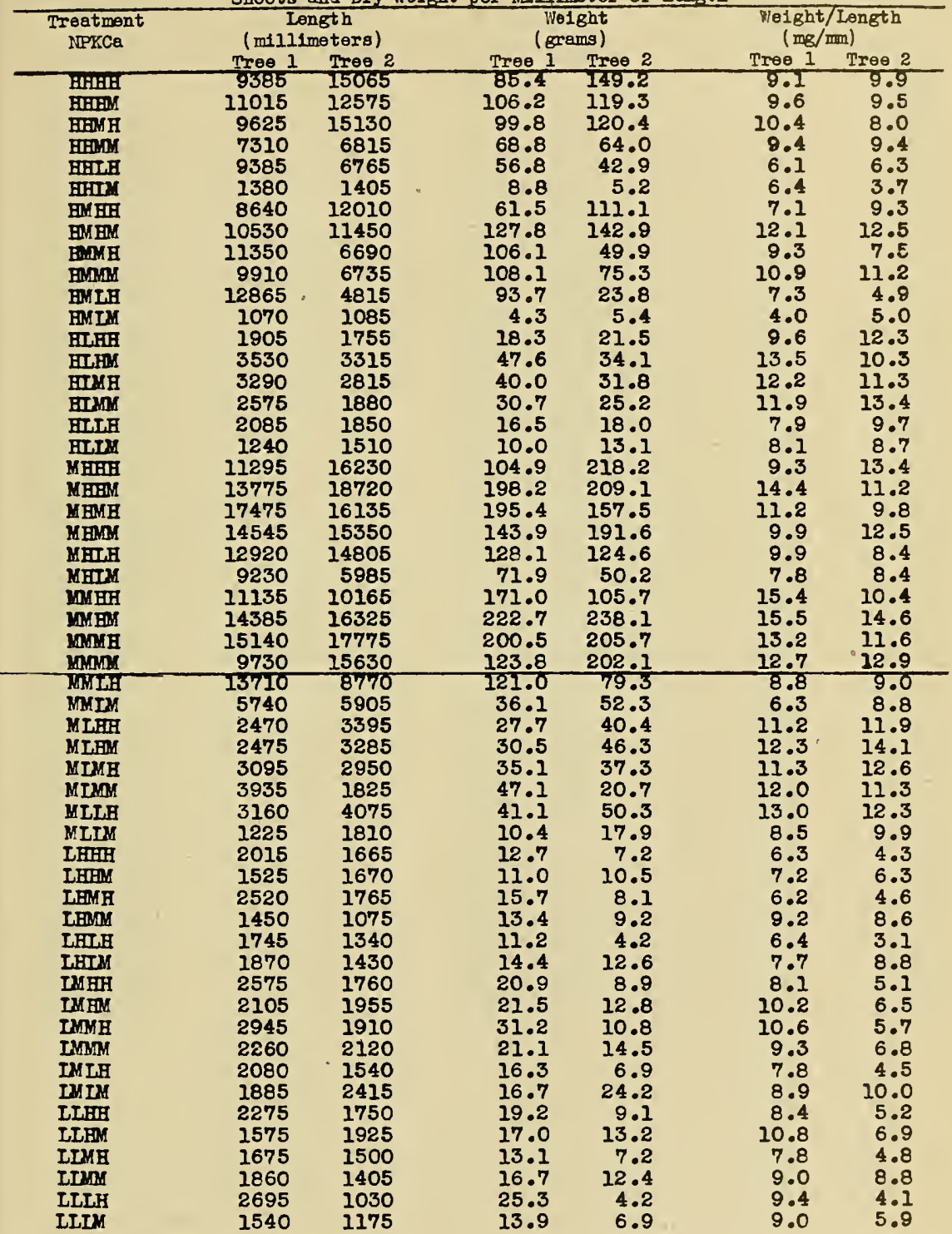


Appond1x Table 2. Growtb Measuremente for Individual Treee. Increase in Diemeter, Dry Weight of Trunke, and Dry Welghte of Fine and Coerse Roote

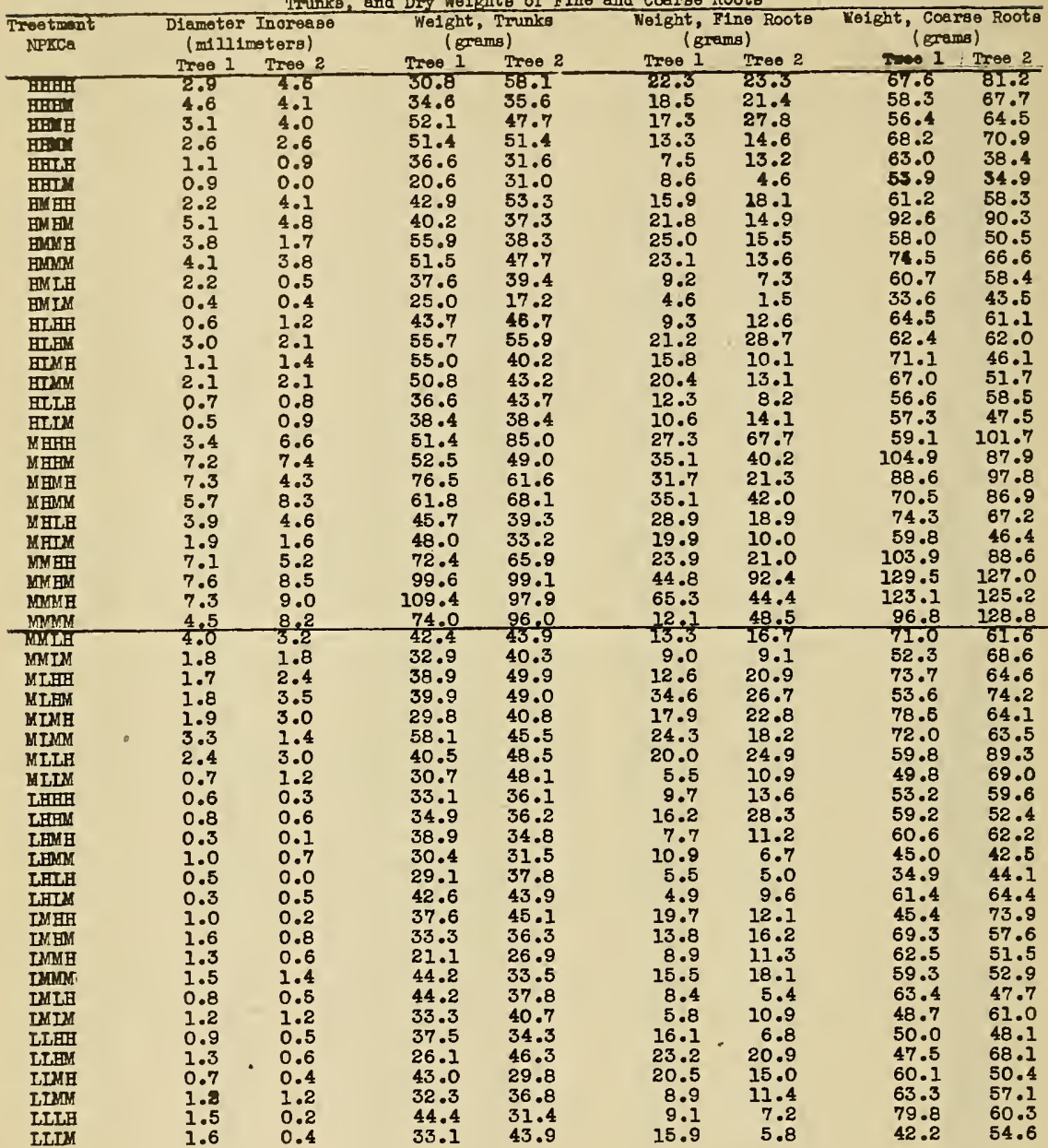


Append1x Table 3. Nitrogen in Shoote as Percentage of Dry Height for Individual Trees

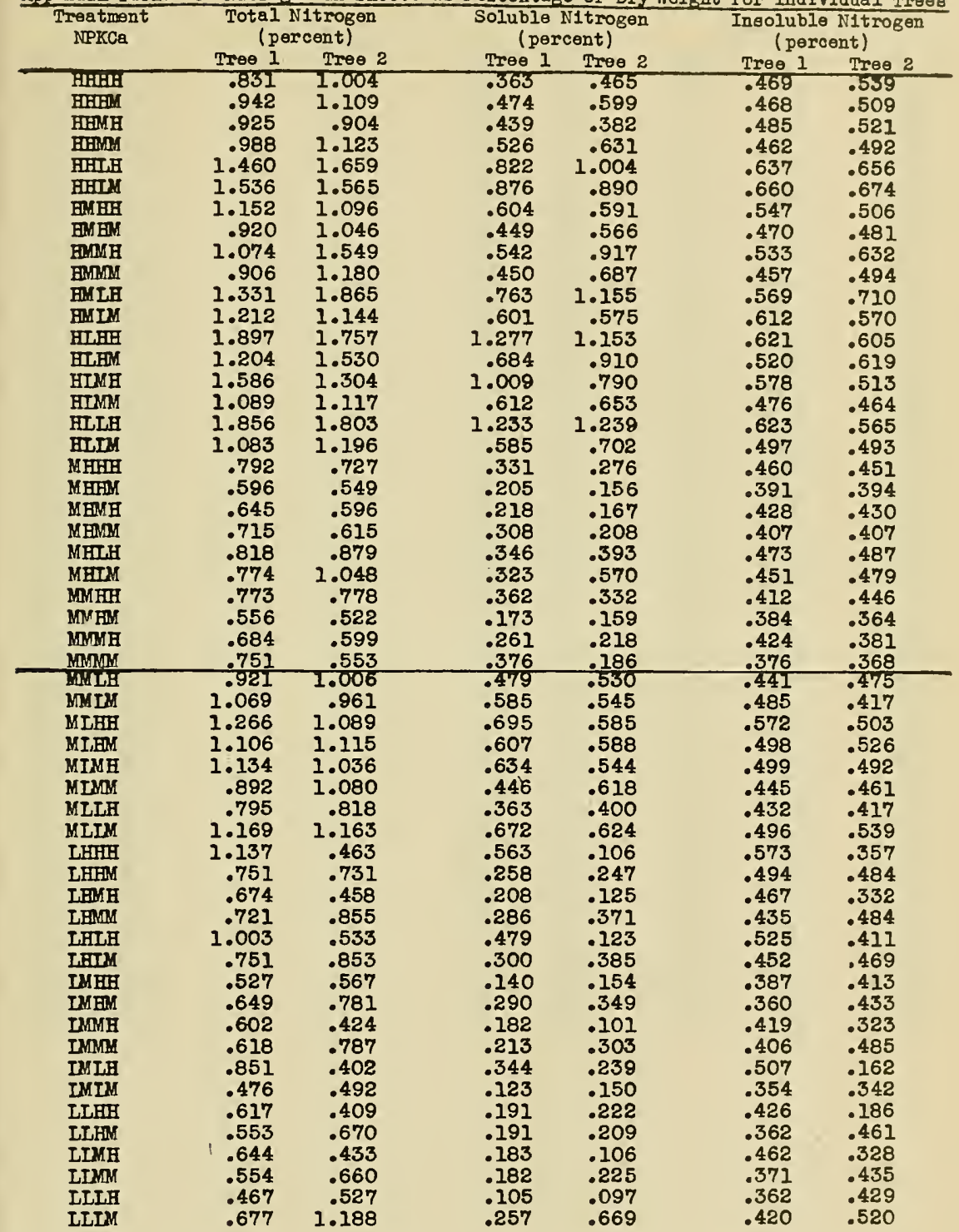


Append1x Tablo 4. $\mathrm{P}, \mathrm{K}$ Ce, and $\mathrm{Yg}$ in Shoote es Percentege of Dry Melght for Indivaluel Treoe

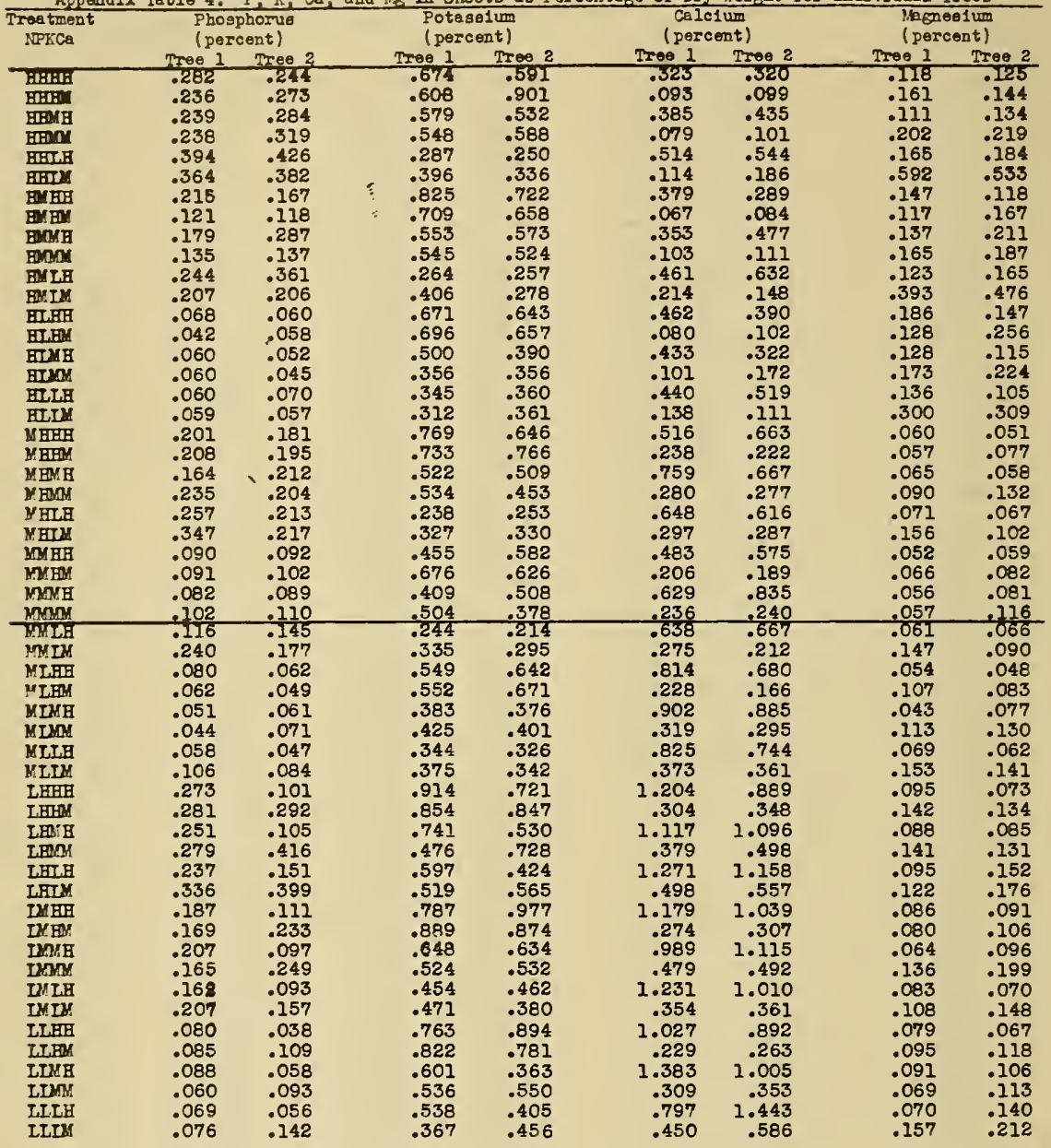


Append1x Table 5. N1trogen 1n Trunks es Percentege of Dxy We1ght for Individuel Trees Treatment Total N1trogen Soluble N1trogen Insoluble N1trogen

\begin{tabular}{|c|c|c|c|c|c|c|}
\hline NPKCa & \multicolumn{2}{|c|}{ (percent) } & \multicolumn{2}{|c|}{ (percent) } & \multicolumn{2}{|c|}{ (percent) } \\
\hline HHAH & .465 & .546 & $\frac{17 e 8}{.198}$ & .258 & $\frac{1 r e \theta}{267}$ & $7 x \theta^{2}$ \\
\hline HसमM & .556 & .665 & .267 & .360 & .289 & .306 \\
\hline HHMH & .511 & .520 & .237 & .235 & .274 & .284 \\
\hline HHLMM & .451 & .453 & .211 & .206 & .241 & .246 \\
\hline $\mathrm{HHTH}$ & .543 & .620 & .283 & .344 & .259 & .275 \\
\hline HHIM & .432 & .376 & .190 & .153 & .242 & .224 \\
\hline सM HН & .578 & .611 & .300 & .319 & .278 & .291 \\
\hline ENM $\mathrm{BM}$ & .499 & .570 & .245 & .301 & .255 & .269 \\
\hline FMMH & .558 & .665 & .267 & .382 & .292 & .284 \\
\hline HMMM & .522 & .615 & .215 & .333 & .307 & .283 \\
\hline EMLH & .626 & .528 & .344 & .298 & .282 & .231 \\
\hline EMIM & .325 & .309 & .107 & .109 & .218 & .200 \\
\hline HLHH & .618 & .631 & .345 & .339 & .273 & .292 \\
\hline HLFM & .632 & .669 & .336 & .354 & .296 & .314 \\
\hline HIUH & .546 & .510 & .290 & .263 & .256 & .246 \\
\hline EIXNM & .514 & .498 & .241 & .229 & .273 & .270 \\
\hline HLL.H & .645 & .569 & .359 & .292 & .285 & .277 \\
\hline HILM & .339 & .462 & .118 & .206 & .221 & .256 \\
\hline МसHН & .413 & .395 & .138 & .126 & .276 & .269 \\
\hline M BHM & .283 & .385 & .073 & .124 & .209 & .261 \\
\hline MEMH & .406 & .311 & .238 & .068 & .268 & .243 \\
\hline MEMM & .385 & .383 & .137 & .124 & .247 & .259 \\
\hline MELLH & .394 & .393 & .128 & .133 & .267 & .261 \\
\hline МभIM & .300 & .392 & .089 & .164 & .212 & .228 \\
\hline MMHH & .424 & .381 & .181 & .128 & .242 & .254 \\
\hline MNEM & .324 & .324 & .085 & .081 & .240 & .242 \\
\hline MMMH & .392 & .397 & .129 & .144 & .263 & .252 \\
\hline MMM & .443 & .375 & .206 & & .237 & .252 \\
\hline MMLH & .412 & .413 & .173 & .170 & .240 & .244 \\
\hline MMLM & .392 & .367 & .159 & .161 & .233 & .207 \\
\hline MLHH & .483 & .545 & .213 & .260 & .270 & .285 \\
\hline MLEM & .559 & .569 & .274 & .267 & .286 & .301 \\
\hline MLWH & .422 & .469 & .184 & .199 & .238 & .271 \\
\hline MILMM & .444 & .446 & .192 & .188 & .253 & .259 \\
\hline MLLH & .375 & .381 & .139 & .126 & .235 & .256 \\
\hline MLIM & .389 & .394 & .140 & .145 & .248 & .248 \\
\hline LHHH & .377 & .182 & .142 & .020 & .236 & .162 \\
\hline IHHM & .336 & .312 & .102 & .078 & .235 & .234 \\
\hline LFME & .274 & .195 & .058 & .031 & .215 & .164 \\
\hline LEMM & .289 & .312 & .074 & .089 & .214 & .222 \\
\hline LHLH & .374 & .191 & .127 & .030 & .248 & .161 \\
\hline LHIM & .272 & .303 & .071 & .088 & .202 & .216 \\
\hline LMEH & .292 & .221 & .072 & .039 & .220 & .182 \\
\hline IXEM & .297 & .342 & .064 & .109 & .234 & .234 \\
\hline IMN!H & .336 & .222 & .099 & .033 & .237 & .188 \\
\hline LMMN & .284 & .393 & .072 & .136 & .212 & .258 \\
\hline IM LH & .282 & .204 & .072 & .024 & .210 & .181 \\
\hline IM IM & .240 & .262 & .043 & .053 & .197 & .208 \\
\hline LLFH & .296 & .197 & .075 & .026 & .221 & .171 \\
\hline LI.FM & .283 & .286 & .068 & .063 & .215 & .223 \\
\hline LLM H & .288 & .195 & .071 & .031 & .216 & .164 \\
\hline IIIMM & .245 & .267 & .047 & .060 & .199 & .208 \\
\hline LLLH & .244 & .209 & .029 & .036 & .214 & .174 \\
\hline LLIM & .275 & .328 & .060 & .108 & .214 & .221 \\
\hline
\end{tabular}




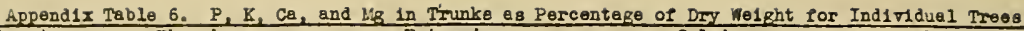

\begin{tabular}{|c|c|c|c|c|c|c|c|c|}
\hline $\begin{array}{l}\text { Troatment } \\
\text { NPECe }\end{array}$ & Phos & $\begin{array}{l}\text { horus } \\
\text { ent) }\end{array}$ & $\begin{array}{l}\text { Potes } \\
\text { (perc }\end{array}$ & Ium & Cal & & lagne & nt) \\
\hline & Tree 1 & Treo 2 & Trae 1 & Treo 2 & Treo 1 & Treo 2 & Tres 1 & Tree 2 \\
\hline HНHAH & .167 & .163 & .398 & .342 & .288 & .237 & .070 & .076 \\
\hline HEHEY & .156 & .133 & .330 & .376 & .136 & .115 & .087 & .063 \\
\hline BHM H & .170 & .181 & .296 & .252 & .295 & .245 & .080 & .075 \\
\hline BEMM & .133 & .165 & .296 & .276 & .124 & .143 & .094 & .101 \\
\hline समाप्स & .160 & .187 & .165 & .171 & .288 & .309 & .083 & .073 \\
\hline HसाN & .119 & .132 & .174 & .166 & .165 & .160 & .089 & .073 \\
\hline EM HER & .137 & .128 & .410 & .452 & .220 & .207 & .070 & .067 \\
\hline BOM HM & .079 & .083 & .339 & .330 & .081 & .113 & .075 & .075 \\
\hline BMOEE & .131 & .156 & .316 & .322 & .215 & .322 & .064 & .089 \\
\hline ВMMM & .107 & .100 & .302 & .308 & .136 & .126 & .090 & .094 \\
\hline EOALH & .124 & .135 & .181 & .165 & .279 & .284 & .060 & .064 \\
\hline FM LM & .086 & .089 & .182 & .154 & .171 & .141 & .082 & .078 \\
\hline ELUEH & .060 & .049 & .249 & .231 & .201 & .213 & .059 & .067 \\
\hline BIIEM & .036 & .049 & .314 & .297 & .100 & .192 & .060 & .062 \\
\hline HIME & .052 & .052 & .174 & .192 & .230 & .254 & .051 & .057 \\
\hline HTMM & .052 & .046 & .213 & .213 & .164 & .164 & .073 & .077 \\
\hline BLIH & .054 & .060 & .160 & .150 & .245 & .239 & .045 & .059 \\
\hline BLIX & .051 & .055 & .153 & .182 & .134 & .144 & .074 & .092 \\
\hline $\mathrm{MHHH}$ & .130 & .099 & .374 & .401 & .300 & .348 & .048 & .037 \\
\hline$\triangle \mathrm{BH}$ & .092 & .089 & .353 & .393 & .275 & .186 & .048 & .059 \\
\hline MEMH & .099 & .115 & .304 & .292 & .341 & .303 & .047 & .054 \\
\hline M BMAM & .143 & .135 & .262 & .253 & .196 & .213 & .075 & .070 \\
\hline YHLY & .132 & .120 & .208 & .190 & .348 & .467 & .061 & .051 \\
\hline YसIX: & .131 & .132 & .148 & .161 & .186 & .267 & .068 & .059 \\
\hline MMYH & .078 & .059 & .323 & .385 & .284 & .264 & .053 & .039 \\
\hline MONBIII & .060 & .080 & .354 & .402 & .151 & .162 & .039 & .060 \\
\hline MMN & .066 & .070 & .262 & .277 & .282 & .350 & .043 & .056 \\
\hline Many & .084 & .083 & .335 & .297 & .193 & .171 & .063 & .054 \\
\hline LIF & .079 & .087 & .148 & .186 & .335 & .414 & .052 & .056 \\
\hline MHIM & .123 & .106 & .161 & .165 & .205 & .179 & .064 & .062 \\
\hline ELHH & .059 & .047 & .292 & .316 & .277 & .258 & .050 & .033 \\
\hline YIEM & .056 & .054 & .277 & .324 & .198 & .146 & .047 & .054 \\
\hline М IMB & .041 & .050 & .222 & .264 & .311 & .328 & .042 & .038 \\
\hline M UM & .040 & .073 & .259 & .207 & .166 & .181 & .050 & .052 \\
\hline MLIH & .046 & .046 & .209 & .217 & .339 & .284 & .040 & .041 \\
\hline YLIM & .062 & .062 & .212 & .211 & .226 & .211 & .046 & .050 \\
\hline LHसH & .114 & .075 & .360 & .313 & .284 & .196 & .047 & .039 \\
\hline I. मासल & .122 & .132 & .354 & .380 & .175 & .230 & .050 & .057 \\
\hline LENH & .120 & .073 & .312 & .228 & .277 & .254 & .046 & .032 \\
\hline IEMM & .123 & .152 & .246 & .297 & .218 & .242 & .060 & .054 \\
\hline IHLH & .122 & .087 & .233 & .204 & .328 & .262 & .046 & .055 \\
\hline LAIY & .124 & .126 & .196 & .240 & .230 & .205 & .057 & .062 \\
\hline IM HH & .091 & .080 & .338 & .314 & .337 & .258 & .044 & .050 \\
\hline IXEX & .091 & .108 & .377 & .372 & .211 & .183 & .048 & .064 \\
\hline IMMH & .105 & .077 & .275 & .298 & .337 & .299 & .050 & .050 \\
\hline Ixan & .091 & .125 & .284 & .275 & .267 & .235 & .048 & .067 \\
\hline IMLH & .073 & .065 & .254 & .120 & .339 & .220 & .049 & .044 \\
\hline IXIM & .087 & .089 & .100 & .190 & .222 & .233 & .053 & .072 \\
\hline IIIHH & .054 & .041 & .302 & .310 & .312 & .234 & .048 & .046 \\
\hline LLAM & .055 & .059 & .379 & .357 & .183 & .186 & .045 & .050 \\
\hline LIMH & .063 & .042 & .240 & .272 & .318 & .271 & .043 & .042 \\
\hline ILMM & .060 & .052 & .238 & .210 & .190 & .187 & .060 & .047 \\
\hline $\begin{array}{l}\text { LILH } \\
\text { ILIM }\end{array}$ & $\begin{array}{l}.058 \\
.056\end{array}$ & $\begin{array}{l}.047 \\
.065\end{array}$ & $\begin{array}{l}.228 \\
.237\end{array}$ & $\begin{array}{l}.212 \\
.165\end{array}$ & $\begin{array}{r}.312 \\
.243\end{array}$ & $\begin{array}{l}.262 \\
.218\end{array}$ & $\begin{array}{l}.045 \\
.057\end{array}$ & $\begin{array}{l}.058 \\
.064\end{array}$ \\
\hline
\end{tabular}


Appendir Table 7. N1trogen in Loaves as Percentege of Dry We1ght for Ind171dual Trees Treotment Total N1trogen (peroent) Soluble ititrogen NPSCa

Biriali:

BIIIH

BHMM

Bसाप

समIL

BM EM

FMM H

Buran

EM IM

HLHII

HIFIM

HIM $\mathrm{E}$

HLIE

HLIM

M EIHM

MHIM

MHIM

MM BM

MMME

MMNDM

MiLth

MIIM

MIHIH

MLEM

MIMH

MIMM

MLIE

MIIM

I.समH

I.HIN

LFMH

LFMM!

IRILH
LHIM

IMEH

IM TIM

IMME

IXMM

IN I.

IMIM

LIHH

LIEM

IIMH

LIXM

IIIH

IIIM Tree 1

3.142
3.511

3.550

3.388

3.942

2.825

3.386

3.234

3.559

3.231

3.918

2.665

3.578

3.675

3.701

3.348

3.832

2.957

3.611

3.176

3.367

3.310

3.440

3.348

3.374

3.214

Tree 2

3.167

3.317

3. 451

3.209

3.778

2.574

3.469

3.318

3.414

3.228

3.861

2.525

3.552

3.728

3.509

3.485

3.584

3.083

3.422

3.113

3.496

3.187

3.562

3.457

3.603

3.197

$3.338 \quad 3.282$

3.287

3.342

3.307

3.357

3.352

3.532

3.307

3.206

2.970

3. 003

2.219

3.148

2.557

3.243

2.723

2.211

2.033

2.716

2.253

3. 118

2. 391

2.464

2.549

2. 366

2. 677

2.678

2.779

3.259

3.334
3.364

3.256

3.275

3.261

3.042

2.976

3.069

1.615

2. 176

1.513

2.872

1.850

2.563

1.773

2.416

1.930

2. 405

1. 448

2.567

1.458

2.432

1.717

2.414

1.904

2.707 (percent) Tree 1 Tree 2

.455

.287

$.651 \quad .545$

$.208 \quad .390$

$.328 \quad .416$

$.285 \quad .402$

$.272 \quad .457$

$.274 \quad .378$

$.588 \quad .461$

$.343 \quad .139$

$.457 \quad .664$

$.357 \quad .520$

$.643 \quad .713$

$.432 \quad .460$

$.416 \quad .448$

$.186 \quad .283$

$.289 \quad .318$

.214 .292

$.239 \quad .256$

$.286 \quad .278$

$.476 \quad .302$

$.459 \quad .293$

$.337 \quad .273$

$.320 \quad .303$

$.268 \quad .297$

$.311 \quad .320$

$.325 \quad .717$

$.183 \quad .314$

$.209 \quad .271$

$.567 \quad .264$

$.332 \quad .157$

$.249 \quad .303$

$.174 \quad .210$

$.320 \quad .155$

$.190 \quad .143$

$.185 \quad .137$

$.167 \quad .266$

$.191 \quad .205$

$.333 \quad .287$

$.210 \quad .267$

$.198 \quad .116$

$.161 \quad .184$

$.146 \quad .205$

$.152 \quad .177$

$.212 \quad .199$

$.197 \quad .137$

$.183 \quad .195$

$.195 \quad .131$

.162 .139

$.142 \quad .196$

.200 .202
Insolible N1trogen (peroent) Tred 1

3.476 - 3.300

$3.226 \quad 2.863$

$3.255 \quad 3.057$

$3.102 \quad 2.805$

$3.291 \quad 3.232$

$2.616 \quad 2.183$

$3.057 \quad 3.052$

2.948 2.915

$3.286 \quad 2.957$

2.957 2.849

$3.329 \quad 3.399$

$2.323 \quad 2.386$

$3.122 \quad 2.888$

$3.317 \quad 3.207$

$3.057 \quad 2.796$

$2.915 \quad 3.024$

3.4153 .136

$2.771 \quad 2.799$

$3.321 \quad 3.104$

$2.961 \quad 2.822$

$3.127 \quad 3.240$

$3.024 \quad 2.908$

$2.964 \quad 3.259$

2.889 3.165

$3.036 \quad 3.329$

$2.893 \quad 2.894$

$3.069 \quad 2.984$

$2.975 \quad 2.938$

$2.982 \quad 2.647$

$3.175 \quad 2.943$

$3.142 \quad 3.005$

$2.964 \quad 2.996$

$2.974 \quad 2.884$

$2.957 \quad 2.673$

$2.797 \quad 2.858$

$2.684 \quad 1.459$

$2.028 \quad 2.032$

$2.962 \quad 1.375$

$2.389 \quad 2.605$

$3.052 \quad 1.646$

$2.390 \quad 2.275$

$2.001 \quad 1.505$

1.8362 .300

2.556 1.746

$2.108 \quad 2.201$

$2.965 \quad 1.272$

$2.179 \quad 2.367$

$2.268 \quad 1.322$

$2.366 \quad 2.237$

$2.170 \quad 1.585$

$2.514 \quad 2.276$

$2.537 \quad 1.707$

$2.578 \quad 2.505$ 
Append1x Table 8. $\mathrm{P}, \mathrm{K}, \mathrm{Ca}$, and Ng in Leaves as Percentage of Dry Weight for Individuel Trees

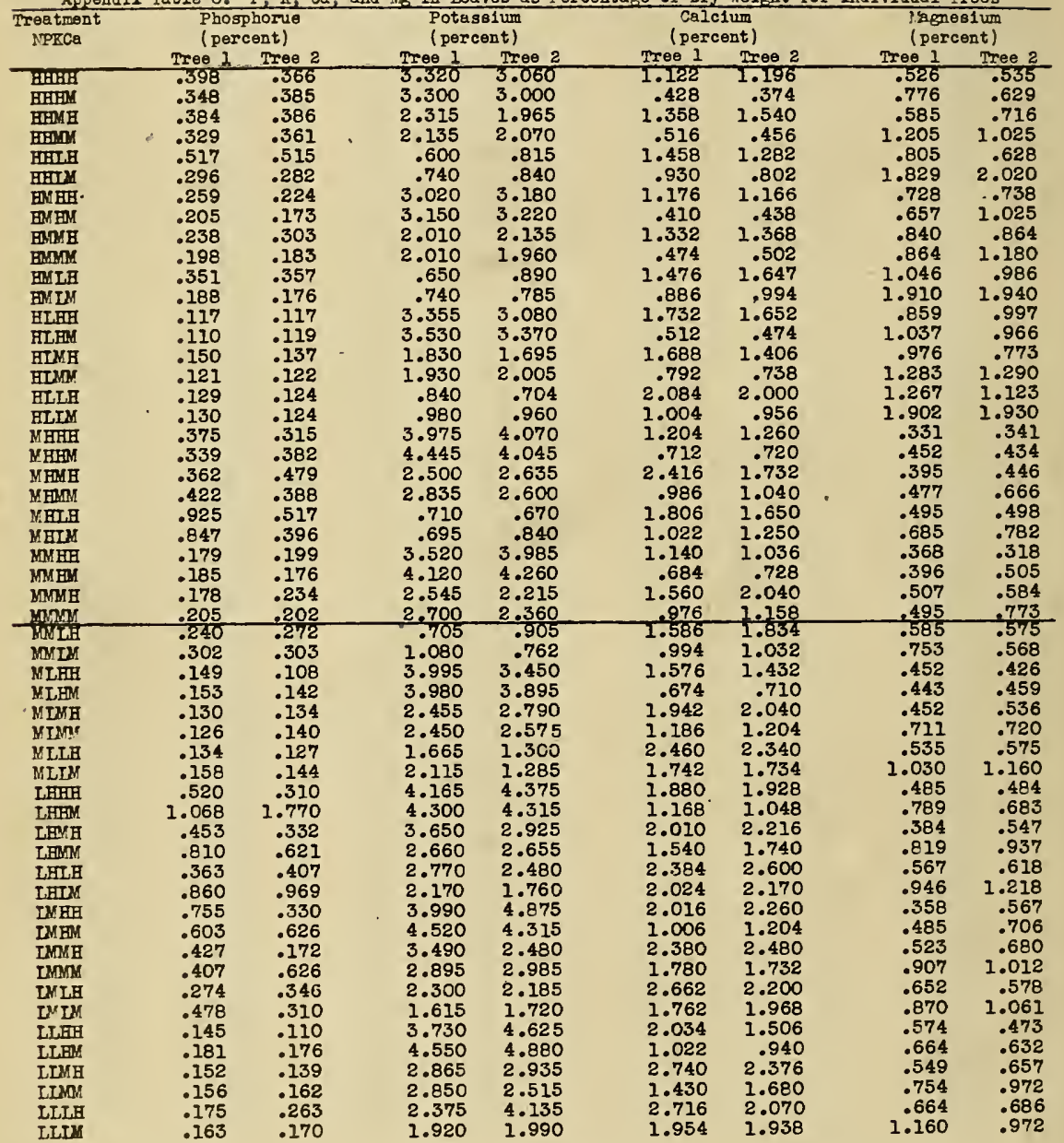




